\title{
WestVirginiaUniversity
}

THE RESEARCH REPOSITORY @ WVU

Graduate Theses, Dissertations, and Problem Reports

2012

\section{Strategies to maximize feed quality and poultry performance}

\author{
Kelley G. S. Wamsley
}

West Virginia University

Follow this and additional works at: https://researchrepository.wvu.edu/etd

\section{Recommended Citation}

Wamsley, Kelley G. S., "Strategies to maximize feed quality and poultry performance" (2012). Graduate Theses, Dissertations, and Problem Reports. 310.

https://researchrepository.wvu.edu/etd/310

This Dissertation is protected by copyright and/or related rights. It has been brought to you by the The Research Repository @ WVU with permission from the rights-holder(s). You are free to use this Dissertation in any way that is permitted by the copyright and related rights legislation that applies to your use. For other uses you must obtain permission from the rights-holder(s) directly, unless additional rights are indicated by a Creative Commons license in the record and/ or on the work itself. This Dissertation has been accepted for inclusion in WVU Graduate Theses, Dissertations, and Problem Reports collection by an authorized administrator of The Research Repository @ WVU.

For more information, please contact researchrepository@mail.wvu.edu. 
STRATEGIES TO MAXIMIZE FEED QUALITY AND POULTRY PERFORMANCE

\author{
by
}

Kelley G. S. Wamsley

Dissertation submitted to the Davis College of Agriculture, Natural Resources and Design

at West Virginia University

in partial fulfillment of the requirements

for the degree of

Doctor of Philosophy

in

Animal and Food Science

Approved by

Joseph S. Moritz, Ph.D., Committee Chairperson

Gary K. Bissonnette, Ph.D.

Hillar Klandorf, Ph.D.

Donald Mclntyre, Ph.D., PAS

Janet C. L. Tou, Ph.D.

Animal and Nutritional Science

Morgantown, West Virginia

2012

Keywords: feed manufacture, feed quality, diet formulation, poultry performance Copyright 2012 K. G. S. Wamsley 


\section{Abstract \\ STRATEGIES TO MAXIMIZE FEED QUALITY AND BIRD PERFORMANCE}

\section{by Kelley Grace Stacey Wamsley}

The majority of the research in this dissertation was conducted specifically to benefit a local turkey integrator, Virginia Poultry Grower's Cooperative, which has turkey growers in both West Virginia and Virginia. All of the research presented in this dissertation is applied in nature and may be directly implemented in the commercial poultry industry to improve production. Many commercial feed mills utilize low mixer-added fat (MAF) to increase ingredient binding opportunities and pellet quality, but this technique may decrease feed nutrient digestibility. In Chapter 2, two experiments were conducted in order to determine the best feed manufacture technique (MTECH) to maximize pellet quality and subsequent true amino acid digestibility (TAAD) of practical turkey diets. Experiment 1 was a 3 Binder (Binder 1, Binder 2, or No Binder) x $2 \mathrm{MTECH}(1 \% \mathrm{MAF}+38.1 \mathrm{~mm}$ die or $3 \% \mathrm{MAF}+44.96 \mathrm{~mm}$ die) factorial design that utilized practical turkey starter diets manufactured at West Virginia University's pilot feed mill. In Experiment 2, diets containing either No Binder of Binder 1 at each MTECH were chosen to test TAAD, using cecectomized roosters. Results from this research established that Binder 1 and 3\% MAF maintained feed quality while improving amino acid digestibility using a rooster model. This led to the development of the experiments conducted in Chapter 3, where the objective was to determine the effect of commercial turkey starter diets varying in amino acid density (AAD) (Normal or High) and MTECH (MTECH1$1 \% \mathrm{MAF}+0.5 \%$ Sand or MTECH2-3\% MAF + 0.5\% Binder) on commercial feed mill manufacture efficiency, D10-40 poult performance and broiler feed retention time. Feed quality was maintained utilizing MTECH2 as compared to feed produced with MTECH1. In addition, MTECH2 also created larger, more uniform crumbles. Chapter 3 results indicated that High AAD diets manufactured with MTECH2 may enhance poult performance due to improved feed quality and associated benefits, increased feed retention time in the gastrointestinal tract, and perhaps improved fat digestibility. Chapter 4 was designed in order to test diet formulation strategies (one of two Yeast Product (YP) inclusion) to improve brooder phase performance (D1-42). Another goal of research conducted in this chapter was to determine feed form advantages during grower/finisher phase production of large toms (D42-118) due to this period of high feed volume consumption. On D42 one of the tested YP improved poult ending weight and feed conversion ratio (FCR). At the end of grow-out, feeding high quality pellets produced toms that were $0.29 \mathrm{~kg} /$ bird heavier with 9 points lower FCR, as compared to toms fed ground pellets. Research in Chapter 5 was conducted with the overall goal of improving brooder phase performance (D1-42) by varying phytase level inclusions (Normal or High) into commercial turkey diets. Recent research has indicated that phytase inclusion may help decrease gut inflammation and subsequent immune response caused by phytate phosphorus $(P)$; therefore, other objectives of research conducted in Chapter 5 were to assess the effect of increasing phytase inclusion on D40 gut inflammation via ileal mRNA expression of Interleukin (IL)$1 \beta$ and IL-6, and D40 total P content of litter. Phytase inclusion levels had no effect on brooder phase poult performance or gut health; however, High Phytase diets fed to poults placed on fresh shavings from D1-40 reduced total $\mathrm{P}$ content of litter by $\sim 11 \%$. For the last chapter of this dissertation (Chapter 6) two experiments were conducted that utilized practical diets and regression analyses to evaluate the utilization of lysine (Experiment 1) and phosphorus (Experiment 2) in corn distiller's dried grains and solubles (DDGS) using a broiler chicken model. This research is warranted because technologies employed to produce this coproduct of corn ethanol production have evolved; thereby potentially changing the availability of its key nutrients. In both Experiments 1 and 2, multiple analyses verified the original nutrient coefficients for digestible lysine $(0.7031 \%)$ and available $\mathrm{P}(0.66 \%)$ suggested for the specific DDGS tested; however, depending on analysis and performance variable, availability may be underestimated by up to 0.07 and 0.02 percentage points, respectively. 


\section{ACKNOWLEDGMENTS}

I would first like to thank my advisor and friend, Dr. Joe Moritz for his guidance, support and honesty in good times and bad, throughout my collegiate career. Words cannot express the impact that he has had on my life to help mold me into the scientist and person that I am today. Next, I would like to thank my committee members Drs. Bissonnette, Klandorf, McIntyre, and Tou. You all have served as invaluable resources and I cannot express my appreciation enough for your time and sincere support throughout this process. I would also like to thank Loyd Whetzel and Rick Wood for their technical support and friendship throughout my research career. In addition, I would like to thank the rest of WVU's graduate students, faculty and staff for always finding time to help me with anything I may need, even if they did not have the time. Because feed manufacture research is extremely labor intensive and often requires unusual work hours, I would like to express my appreciation for past and current members of the Moritz Lab for their friendship, guidance, help and laughs. More specifically, Nancy Buchanan, Amanda Rack, Curran Gehring, Brittany Swiger, Ashley Evans, Kevin Shipe, Angela Lamp, Mark Lemons, and John Boney. Lastly, I would like to thank my family: Larry, Klaye, Meghan and Clayton Lilly; my grandparents: I.D. and Allegra Lilly; and especially my husband, Brock Wamsley, as well as his family. Without the support and love of these people, none of this would have been possible. 
TABLE OF CONTENTS

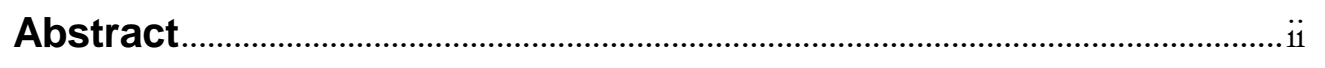

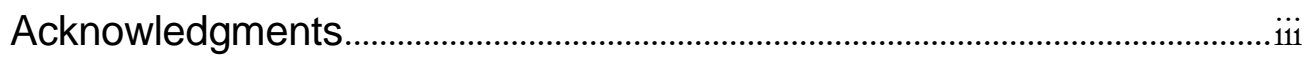

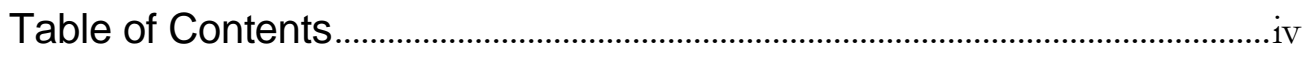

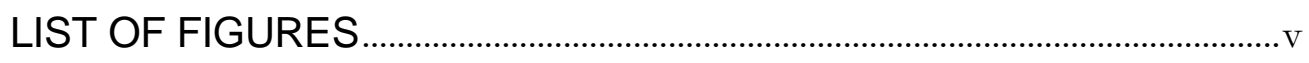

LIST OF TABLES ......................................................................................... v-vi

LIST OF SYMBOLS / NOMENCLATURE................................................... vii-viii

CHAPTER 1: LITERATURE REVIEW ........................................................ 1-14

CHAPTER 2: RESOVLING POOR PELLET QUALITY AND MAINTAINING AMINO ACID DIGESTIBILITY IN COMMERCIAL TURKEY DIET FEED MANUFACTURE .......15-30

CHAPTER 3: ASSESSMENT OF DIET FORMULATION STRATEGIES THAT IMPROVE CRUMBLE QUALITY AND POULT PERFORMANCE..........................................31-48

CHAPTER 4: D1-42 YEAST PRODUCT INCLUSION AND D42-118 FEED FORM EFFECTS ON LARGE TOM PERFORMANCE USING FEED PRODUCED AT A COMMERCIAL FEED MILL 49-67

CHAPTER 5: THE EFFECT OF NORMAL AND HIGH PHYTASE INCLUSION ON D1-42 POULT PERFORMANCE, GUT INFLAMMATION AND PHOSPHORUS CONTENT OF LITTER $.68-84$

CHAPTER 6: THE USE OF PRACTICAL DIETS AND REGRESSION ANALYSES TO DETERMINE UTILIZATION OF LYSINE AND PHOSPHORUS IN CORN DISTILLERS DRIED GRAINS AND SOLUBLES USING COBB 500 MALE BROILERS. .85-117

Appendix: INORGANIC FEED PHOSPHATE EFFECTS ON FEED QUALITY AND MANUFACTUING EFFICIENCY 118-133

Cirriculum Vitae. 134-140 


\section{LIST OF FIGURES}

\section{APPENDIX}

Figure 1. 5X Magnification of Monocalcium Phosphate, Dicalcium Phosphate and Tricalcium

Phosphate 133

\section{LIST OF TABLES}

\section{CHAPTER 2}

Table 1. Starter turkey diet formulation manufacture in Experiment 1 and used for true amino acid digestibility in Experiment 2............................................................................... 27

Table 2. Analyses of lignosulfonate pellet binders ............................................... 28

Table 3. Main effects of manufacture technique (MTECH) and Binder on feed manufacture variables (Experiment 1) 29

Table 4. The effect of manufacture technique (MTECH) and Binder1 inclusion on true amino acid digestibility (Experiment 2) 30

\section{CHAPTER 3}

Table 1. Nutrient profiles of diets utilized in both Experiments 1 and 2

Table 2. The effect of amino acid density (AAD) and manufacturing technique (MTECH) on feed manufacture variable at a commercial feed mill (Experiment 1 descriptive data) 45

Table 3. The effect of amino acid density (AAD) and manufacturing technique (MTECH) on D1-39 performance data of Hybrid Convertor poults (Experiment 1) 46

Table 4. The effect of amino acid density (AAD) and manufacturing technique (MTECH) on D40 breast extraction data from 25 randomly selected Hybrid Convertor poults per pen.. 47

Table 5. Influence of amino acid density (AAD) and manufacture technique (MTECH) on Cobb 500 feed retention time as determined by percentage of acid insoluble ash (AIA) (Experiment 2)

\section{CHAPTER 4}

Table 1. Proximate analysis of diets fed during the brooder phase (D1-42) ...............6 62

Table 2. Proximate analysis of diets fed from D42-118

Table 3. Feed quality description of intact high quality pellets (HQP) diets fed from D42-118

Table 4. Particle size analysis of ground pellet diets fed from D42-118.

Table 5. Effect of Yeast Products on brooder phase performance (D1-42)

Table 6. Yeast Product (YP) Carryover and Feed Form effects on D1-118 tom performance 66

Table 7. Regression analyses to predict the performance of toms fed Ground Pellet (GP) diets based on the same D118 weights as toms fed Intact High Quality Pellets (HQP) diets $(17.41 \mathrm{~kg} / \mathrm{tom}$ and FCR of 1.92) 


\section{LIST OF TABLES (CONTINUED)}

\section{CHAPTER 5}

Table 1. Analyses of dietary phases 1 and 2 ... 82

Table 2. The effect of varying D1-42 phytase inclusion on poult performance and D40 litter analysis

Table 3. Primers used for real-time PCR 83

Table 4. The effect of varying D1-42 phytase inclusion on gut inflammation measurements

\section{CHAPTER 6}

Table 1. Starter period diets formulated to AGRI STATS levels for starter period diets fed from D110 in Experiment 1 105

Table 2.Grower period diets formulated to AGRI STATS levels for grower period diets fed from D1122 in Experiment 1 106

Table 3. Finisher period diets formulated to AGRI STATS levels for finisher period diets fed from D23-42 in Experiment 1 107

Table 4. Outline of dietary treatments manufactured and fed in Experiment 1 from D3-42 108

Table 5. Diets varying in available phosphorus (AP) and distiller's dried grains and solubles (DDGS) fed in Experiment 2 from D3-21 109

Table 6. Analyzed diets fed in Experiment 2 from D3-21.... 110

Table 7. Descriptive feed manufacturing variables for Experiment 1 diets formulated to $100 \% \mathrm{AGRI}$ STATS digestible lysine (Dig Lys)....

Table 8. The effect of varying Digestible Lysine (Dig Lys) and distiller's dried grains and solubles (DDGS) inclusion on D3-42 male broiler performance .... 112

Table 9. Distiller's dried grains and solubles (DDGS) sparing effects for Average Digestible Lysine (Dig Lys) from standard curve quadratic regression (Method 1) 113

Table 10. Distiller's dried grains and solubles (DDGS) sparing effects for Digestible Lysine (Dig Lys) using each DDGS Level's regression analysis (Method 2) 114

Table 11. The effect of varying Available Phosphorus (AP) and distiller's dried grains and solubles (DDGS) inclusion on D3-21 male broiler chick performance 115

Table 12. Distiller's dried grains and solubles (DDGS) sparing effects for Available Phosphorus (AP) from standard curve quadratic regression (Method 1) 116

Table 13. Distiller's dried grains and solubles (DDGS) sparing effects for Available Phosphorus (AP) using each DDGS Level's regression analysis (Method 2).

\section{APPENDIX}

Table 1. Specifications of inorganic feed phosphate products utilized in Experiments 1 and 2

Table 2. Diet formulations and nutrient parameters for Experiments 1 and 2.......... 130

Table 3. Feed manufacture variables associated with standard pelleting of Cobb 500 broiler starter phase diets containing different sources of inorganic feed phosphate (Experiment 1)

Table 4. Feed manufacture variables associated with standard pelleting of Cobb 500 broiler starter phase diets containing different sources of inorganic feed phosphate (Experiment 2) 


\section{LIST OF SYMBOLS / NOMENCLATURE}

\section{CHAPTER 1}

1. Doctor of Philosophy- Ph.D.

2. Virginia Poultry Growers Cooperative - VPGC

3. Virginia - VA

4. West Virginia - WV

5. Pellet Durability Index - PDI

6. Modified Pellet Durability Index - MPDI

7. Standard Deviation- SD

8. Mixer-added fat-MAF

9. Phosphorus- $\mathrm{P}$

10. Corn distiller's dried grains and solubles- DDGS

\section{CHAPTER 2}

1. Feed manufacture technique- MTECH

2. True amino acid digestibility- TAAD

3. MTECH1- $1 \% \mathrm{MAF}+38.1 \mathrm{~mm}$ die

4. MTECH1- $3 \% \mathrm{MAF}+44.96 \mathrm{~mm}$ die

5. Conditioner relative electrical energy usage- CREE

6. Pellet mill relative electrical energy usage- PMREE

\section{CHAPTER 3}

1. Amino acid density- AAD

2. MTECH1- $1 \% \mathrm{MAF}+0.5 \%$ Sand

3. $\mathrm{MTECH} 2-3 \% \mathrm{MAF}+0.5 \%$ Binder

4. Acid insoluble ash- AIA

5. Feed intake- FI

6. Feed conversion ratio- FCR

\section{CHAPTER 4}

1. Yeast Product- YP

2. Intact high quality pellets- HQP

3. Ground pellets- GP

4. Ending weight- EW 
LIST OF SYMBOLS / NOMENCLATURE (CONTINUED)

\section{CHAPTER 5}

1. Interleukin- IL

2. Phytase units- FTU

3. Real time- RT

4. Messenger Ribonucleic Acid- mRNA

5. Non-phytate phosphorus- nPP

6. Ribonucleic Acid- RNA

7. Ethyl Alcohol- ETOH

8. polymerase chain reaction- PCR

9. Deoxyribonucleic acid- DNA

10. Complementary DNA- cDNA

11. Glyceraldehyde-3-phosphate dehydrogenase- GAPDH

12. Calcium- $\mathrm{Ca}$

\section{CHAPTER 6}

1. Digestible lysine- Dig Lys

2. Available phosphorus- AP

3. Average live weight gain- LWG

4. Acid insoluble ash- AIA

5. Carcass characteristics- CC

6. Total sulfur amino acids- TSAA

7. Average hot carcass weight- $\mathrm{CW}$

8. Average hot boneless skinless breast weight- BBW

9. Average hot boneless skinless breast yield- BBY

10. Negative control- NC

11. Positive control- PC

12. Average tibia ash per chick-TA

13. Percent tibia ash per chick- percent TA

\section{APPENDIX}

1. Monocalcium phosphate- MCaP

2. Dicalcium phosphate- DCaP

3. Tricalcium phosphate- TCaP

4. Moncalcium phosphate of a coarse particle size- MCaPC

5. Monocalcium phosphate from manufacture plant A- MCaPA

6. Monocalcium phosphate from manufacture plant A- MCaPB 


\section{CHAPTER 1: LITERATURE REVIEW}

\section{Introduction}

The purpose of this literature review is to give a proper introduction to the research that will be presented in this dissertation to fulfill my Ph.D. Of the papers that will be covered, one has been accepted for publication (Appendix 1), two have been submitted (Chapters 2 and 6) and the other three will be submitted after publication of this dissertation (Chapters 3-5). Literature covered in this review will attempt to provide readers with the background for this research and translate how this research impacts the commercial poultry industry locally in the West Virginia area and in the United States. Specific literature that pertains to this research will be covered in more detail in that particular Chapter/Appendix within the sections entitled "Description of the Problem" and/or "Results and Discussion".

Much of the research in this dissertation has been conducted in collaboration with Virginia Poultry Growers Cooperative (VPGC) (Chapters 2-5). This company was established shortly after the closure of the local processing plant in Hinton, Virginia was announced in April 2004, which would have affected approximately 170 farms and 1800 employees [1]. Select groups of farmers joined together to form the Cooperative and with some support from local businesses, the processing plant and a nearby feed mill was purchased [1]. Turkey growers for VGPC are located in the Shenandoah Valley of Virginia and in West Virginia. Products produced by VPGC include antibiotic-free, 
organic, and conventionally reared large toms that are grown to approximately 18 wks of age, weighing over $18 \mathrm{~kg}(40 \mathrm{lbs})$ [1].

To keep a competitive edge on competition and to produce products of high quality in a cost effective manner, VPGC and West Virginia University joined forces in 2009 for a collaborative research agreement. To help with this collaboration, the West Virginia State Legislature provided $\$ 125,000$ to help completely renovate one of the industry style poultry barns at the Reymann Memorial Farm in Wardensville, West Virginia. This renovation enabled the research facility to hold 1,280 large toms (80 toms/pen; 16 pens) and made it one of the most technologically advanced research facilities in the country. In fact, companies from across the country have toured this facility in hopes of creating something similar. In addition, research that has been conducted at this facility has been presented both nationally and internationally.

The collaborative research agreement that West Virginia University has with VPGC is very rare and benefits are mutually shared. The Cooperative provides West Virginia University with real-world industry challenges and potential strategies to overcome these challenges through research. West Virginia University provides the Cooperative with research experience, facilities, labor, and shared compassion in VPGC succeeding and maintaining profitability. Current or anticipated production challenges for VPGC have always served as the core component of every research study that West Virginia University has designed in collaboration with VPGC. The first few studies were conducted to test various commercially available genetic strains and to help provide the cooperative with diet formulation strategies to reduce phosphorus content of litter. Because feed and feed 
manufacture represent the largest investment required to rear poultry $(\sim 70 \%$ of production costs), studies conducted with VPGC that will be presented in this dissertation involve feed manufacture and/or diet formulation manipulation strategies to improve production. Chapters 2-4 focus on the importance of feed quality to turkey performance and diet formulation strategies to improve feed quality. In addition, Chapters 3-5 focus on implementing specific diet formulation strategies in order to improve brooder phase performance. The brooder phase (typically D1-42) is of interest because it is considered to be one of the most important stages of a turkey's life. Performance from this period is thought to largely impact tom performance at the end of grow-out. This period of time also represents a time of low feed intake; therefore, implementing diet formulation strategies that may add to up-front investments may be worthwhile if preferred performance benefits are realized. Much of the research that West Virginia University has conducted with VPGC has been directly implemented into their production system, speaking to its value and applied nature; undoubtedly helping VPGC keep a competitive edge. In fact, VPGC currently ranks tenth in turkey production for the U.S, slaughtering nearly 245 million pounds of turkey in 2011 [2].

\section{Pellet Quality: Benefits and Strategies to Improve}

The majority of poultry produced in the United States are fed pelleted feed. Feed and feed manufacture represent approximately $70 \%$ of costs required to rear poultry. These costs may be justified if pellet quality is maintained from the feed mill to the feed pan. Benefits of feeding high quality pellets include decreased prehension time and energy by 
the bird, increased intake and consequent weight gain, and decreased ingredient segregation and selective feeding [3-9]. In general, pellet quality in the commercial poultry industry is poor due to feed volume requirements produced by feed mills (often times outdated) that must be run above intended capacity. However, due to ingredient costs reaching record highs, it is imperative that the commercial poultry industry appreciate the benefits of feeding high quality pellets so that special efforts can be made to ensure efficient production.

When poor quality pellets are conveyed through extensive augered systems of modern broiler and turkey barns, ingredient segregation is inevitable and detriments to health and performance are probable. Scheideler [10] found that feed sampled at a commercial feed mill contained an average of $66.6 \%$ pellets and then decreased to an average of $32.9 \%$ from samples obtained from feed pans across several commercial poultry houses. Analyzed nutrients from these samples revealed that pellets contained a higher percentage of protein and ash and a lower percentage of fat when compared to mash samples [10]. Scheideler was the first academic to recognize ingredient segregation in the commercial industry and currently no one has followed this work.

In this dissertation, pellet quality it is to be assumed to be synonymous with feed quality. In Chapter 3 crumble quality will be of interest and should also be assumed to be synonymous with feed quality. Crumbles undergo the same feed manufacture process as pellets, except an additional step is added to reduce the particle size of the pellet to create the crumble. Crumbles are generally fed in the starter phases of poultry production in order to meet bird beak capacity. Benefits of feeding high quality crumbles are the same as the 
aforementioned benefits of feeding high quality pellets. In order to produce high quality crumbles, high quality pellets must first be manufactured. Feed quality will be assessed throughout this dissertation in a variety of ways:

1.Pellet Durability Index (PDI) and Modified Pellet Durability Index (MPDI), using the Pfost tumbling can: This methodology tumbles $500 \mathrm{~g}$ of sifted pellets for $10 \mathrm{~min}$ at $50 \mathrm{rpm}$ [11]. Tumbled samples are then sifted again and weighed to determine percent of surviving pellets [11]. The only difference between PDI and MPDI is that MPDI involves the addition of five 13-mm hex nuts for added pressure on pellets to simulate transportation stress pellets would undergo prior to feeding [11]. This technique was utilized in Chapters 2, 4, 6 and Appendix 1.

2. New Holman Tester: This test uses a sample of $100 \mathrm{~g}$ of pellets and subjects this sample to air flow within a perforated chamber for either 30 or $60 \mathrm{~s}$ [12]. This technique was utilized in Chapters 2, 4, 6 and Appendix 1.

3. Percentage of fines produced: This can be determined two ways: 1) collecting and weighing the amount of feed fines that fall through the cooler, relative to the total amount (weight) of feed produced; or 2) sifting a determined amount (weight) of a feed sample and weighing back the sifted fines. In Chapter 3, feed samples were sifted to determine percent crumbles as a means to assess feed quality. 
4. Bulk density: This measurement describes the weight of an ingredient per unit volume. In general, poor pellet quality increases bulk density. This technique was utilized in Appendix 1.

5. Particle size and standard deviation (SD) of particle size: These measurements utilize a Ro-Tap particle size analyzer; the methodology is described in more detail in the reference $[13,14]$. In Chapters 3 and 4 , particle size and uniformity (of crumbles or ground pellets, respectively) was determined using this methodology.

The pelleting process involves conditions of high moisture, pressure and temperature. Strategies that may be employed to improve pellet quality often require a manipulation of the normal pelleting process. However, some of these strategies may affect nutrient availability, thereby negating benefits associated with feed form. Literature supporting this will be covered in more detail throughout this dissertation. The following strategies were employed either alone or in combination to improve feed quality in several of the papers presented in this dissertation:

1. Slower production rate: The majority of feed mills operate beyond their capacity; often producing feed $24 \mathrm{~h}$ a day, 6-7 days a week to meet feed volume demands. Slower production rate can increase feed retention time within the pellet die; thus, increasing nutrient binding and ultimately pellet quality. Research has demonstrated these benefits $[9,15]$. 
2. Use of a thicker pellet die: The effective thickness of a pellet die can enhance nutrient binding and ultimately pellet quality via increased feed retention time within the pellet die; however, this technique can slow feed throughput $[8,9,16]$. 3. Increased steam conditioning temperature: Mash feed is subjected to saturated steam to condition it and prepare it for the pelleting process. In general, increasing conditioning temperature will increase moisture and heat interactions within the feed, increasing starch gelatinization, protein gelation and denaturation [17]; thus improving pellet quality [16].

4. Diet formulation manipulation: Slight manipulations in diet formulation have the potential to drastically affect feed manufacture variables [7, 15, 18-21]. Papers in this dissertation vary diet formulation via mixer added fat (Chapters 2 and 3), lignosulfonate binder addition (Chapters 2 and 3), or varying inorganic feed phosphate (Appendix 1). Specific research pertaining to these diet formulation manipulation strategies will be discussed in their respective Chapters or Appendix.

One topic that will be mentioned in Chapters 2 and 3 is post-pellet fat application. Post-pellet ingredient application has become common in commercial feed mills due to a variety of reasons: to conserve feed mill floor space, improve exogenous feed enzyme efficacy, and improve pellet quality. Many post-pellet application systems require blending lines to thoroughly coat pellets with the sprayed liquid additives; however, these blend lines can be counterproductive to efforts to improve pellet quality by producing a large amount of pellet fines in the finished feed. In Chapters 2 and 3, mixer-added fat 
(MAF) is varied, but the remainder of the fat is added via post-pellet fat application to create similar total fat compositions of diets.

\section{Feed Manufacture: Precautions and Research Pitfalls}

As mentioned several times already, there is concern that certain feed manufacture techniques may affect nutrient availability. Creswell and Bedford [22] cautioned exposing diets high in corn to high conditioning temperatures (above $85^{\circ} \mathrm{C}$ ) due to maillard reaction, resulting in the binding of lysine with free sugars and/or the retrogradation of starch; and causing detriment to bird performance [22]. In our lab, we have speculated similar effects to elicit negative bird performance effects in modern day broilers [9, 20,23]. Shipe and others $[24,25]$ conducted research using modern day broilers as a model to isolate feed manufacture techniques that may alter lysine availability in attempt to identify possible maillard reaction in corn- and soybean- based diets. This research indicated that pelleting, in general, decreased nutrient availability. Specific nutrients affected could not be determined, but specific methodologies employed found lysine to be unaffected. More specific literature regarding the potential negative pelleting effects on bird performance will be broached in Chapters 2-4.

When reviewing literature regarding feed manufacture and bird performance due to pellet quality, there are some potential concerns. Below is a list of some concerns associated with feed manufacture research and the Chapter(s) and/or Appendix that address(es) them. 
1. Not enough information about feed manufacture techniques employed, therefore not repeatable. (Chapters 2-4; Appendix 1)

2. Many times only small laboratory feed mills utilized and results are not relatable for industry feed manufacture on such a large scale. (Chapters 2-4; Appendix 1)

3. It is difficult to discern whether observed performance results are attributed to feed form effects or nutrient availability. (Chapter 4 and 6)

4. Much of the literature is dated; even iffeed mills have not been updated, some of the ingredients incorporated into diet formulations have changed and bird genotypes have also changed. (Chapters 2-6; Appendix 1)

\section{Diet Formulation Manipulation Strategies to Improve Performance}

Formulation of diets is critical in regards to supplying the bird with all of the nutrients needed to reach maximum potential, while maintaining low cost. As previously mentioned, several of the papers presented in this dissertation focus on manipulating turkey diet formulations in the brooder phase. Strategies employed may require more investment initially; however, because this period ( D1-42) represents a period of relatively low feed intake, costs may be worthwhile if performance benefits are obtained. Strategies employed in this dissertation include variations in:

1. Amino acid density: Amino acids represent a major, but necessary cost in poultry diet formulation. Inclusions must be appropriate to maximize poultry performance, but also profit. Chapter 3 tests the effect of two amino acid densities on feed crumble quality, brooder phase poult performance, and breast weight/yield. Specific literature relating to varying amino acid densities and subsequent bird performance will be discussed in that Chapter. 
2. Yeast Product: Chapter 4, tests the efficacy of two different Yeast Products derived from Saccharomyces cerevisiae on poult performance in the brooder phase. Research pertaining to these products will be discussed in that Chapter.

3. Phytase inclusions level: The majority of commercial poultry diets in the U.S. are corn and soybean meal based, in which approximately $2 / 3$ of the phosphorus $(\mathrm{P})$ content of these ingredients is stored as phytate $\mathrm{P}$ [26]. Phytate $\mathrm{P}$ is mostly unavailable to the bird due to the lack or production of endogenous phytase enzymes [26] and also the relatively short passage time of feed within the GI tract. These factors hinder adequate production of phytase to aid in utilization of this phytate bound P [26]. Exogenous phytase enzymes have been successfully included into commercial poultry diets since the 1970s [27] to help poultry better utilize nutrients (phytate P) in diets and improve bird performance. Phytase enzymes also have the potential to reduce litter $\mathrm{P}$ and improve gut health. For this reason, the experiment in Chapter 5 was designed to determine the effect of varying phytase inclusion level on these variables. Literature pertaining phytase effects on bird performance, gut health and $\mathrm{P}$ excretion will be discussed in that Chapter.

Diet formulations may also be altered to contain coproducts, such as corn distiller's dried grains and solubles (DDGS). In the past, DDGS were considered a byproduct and 
were typically produced by the beverage industry; and sold primarily for use in ruminant animal feeding. In 1990, the Clean Air Act amendment favored the use of a ten percent ethanol blend of gasoline [28, 29]. Since then, energy costs have increased drastically and mandates for increased biofuel use in the Energy Acts of 2005 and 2007 have been established [29]. All of these factors have led to increased production of ethanol and consequently DDGS [29].

The nutrient composition of DDGS is dependent upon the grain and methods used to produce the ethanol and resulting DDGS. Typically, nutrients present in DDGS such as protein, fiber, fat, and minerals increase approximately three-fold to that of corn $[30,31]$. In addition, DDGS have low concentrations of starch because most of the starch in the starting grains is converted to ethanol $[30,31]$. Different technologies are employed to create ethanol from corn; therefore DDGS nutrient profiles may also differ. The DDGS product tested in Chapter 6, is different from other DDGS products because it utilizes a proprietary blend of enzymes to begin the starch fermentation process, while other ethanol producers utilize jet cookers with high heat [32]. Due to these varied technologies employed to produce DDGS, it is important to determine the availability of a specific DDGS product's key nutrients in a variety of ways in order to be certain of its nutrient profile. For this reason, Chapter 6 utilizes a practical and different approach to that previously employed in the literature to verify the availability of lysine and phosphorus in a specific DDGS product using a broiler chicken model. Even though the future of corn ethanol production is uncertain, the price of corn continues to increase; therefore, DDGS may still be a cost effective feed ingredient for use in poultry diets. Research specific to 
DDGS inclusion effects on poultry performance and feed manufacture will be discussed in detail in Chapter 6.

\section{REFERENCES}

1. Virginia Poultry Growers Cooperative. Accessed July 30, 2012. http://www.vapoultrygrowers.com/

2. Thornton, G. 2012. Mid-size US turkey producers continue production growth. WATTAgNet. Accessed Aug 1, 2012. http://www.wattagnet.com/Midsize_US turkey_producers_continue_production_growth.html

3. Jensen, L. S., L. H. Merrill, C. V. Reddy, and J. McGinnis. 1962. Observations on eating patterns and rate of food passage of birds fed pelleted and unpelleted diets. Poult. Sci. 41:1414-1419.

4. Nir, I., Y. Twina, E. Grossman, and Z. Nitsan. 1994. Quantitative effects of pelleting on performance, gastrointestinal tract and behavior of meat-type chickens. Br. Poult. Sci. 35:589-602.

5. Behnke, K. C. 1994. Factors affecting pellet quality. Pages 44-54 in Proc. Maryland Nutr. Conf., College Park, MD. Maryland Feed Ind. Counc. and Univ. Maryland, College Park.

6. Behnke, K. C. 1996. Feed manufacturing technology: Current issues and challenges. Anim. Feed Sci. Technol. 62:49-57.

7. Moritz, J. S., R. S. Beyer, K. J. Wilson, K. R. Cramer, L. J. McKinney, and F. J. Fairchild. 2001. Effect of moisture addition at the mixer to a corn-soybean based diet on broiler performance. J. Appl. Poult. Res. 10:347-353.

8. Cutlip, S.E., J.M. Hott, N.P. Buchanan, A.L. Rack, J.D. Latshaw and J.S. Moritz. 2008. The effect of steam conditioning practices on pellet quality and growing broiler nutritional value. J. Appl. Poult. Res. 17:241-269.

9. Lilly, K. G. S., C. K. Gehring, K. R. Beaman , P. J. Turk, M. Sperow, and J. S. Moritz. 2011. Examining the relationships between pellet quality, broiler performance, and bird sex. J. Appl. Poult. Res. 20:231-239.

10. Scheideler, S. E. 1991. Pelleting is important for broilers. Pages 1-7 in Proc. 18th Annu. Carolina Poult. Nutr. Conf., Charlotte, NC. North Carolina State Univ., Raleigh.

11. American Society of Agricultural Engineers. 1997. ASAE S269.4, Cubes, pellets, and crumbles-Definitions and methods for determining density, durability, and moisture. Standards 1997. Am. Soc. Agric. Eng., St. Joseph, MI. Due to the use of a 3/16 in. x 1.77 in. die, pellets were sifted in a No. 6 American Society for Testing and Materials (ASTM) screen. Five hundred grams of sifted pellets were placed in a dust-tight enclosure and tumbled for $10 \mathrm{~min}$ at $50 \mathrm{rpm}$. The enclosure was of the 
dimensions $12 \times 12$ in., with a $2 \times 9$ in. plate affixed diagonally along one of the 12 $\mathrm{x} 12$ in. sides. The tumbled samples were then sifted again (No. 6 ASTM) and weighed. The pellet durability index was calculated by dividing the weight of pellets after tumbling by the weight of pellets before tumbling, then multiplying by 100. The modified pellet durability index was determined in a similar manner with the exception of adding 5, 13-mm hex nuts to the pretumbled sample to obtain added pellet agitation.

12. New Holman Tester, Tekpro limited, UK.

13. Ro-Tap particle size analyzer model RX-29 type $110 \mathrm{~V} 60 \mathrm{H} 2$, WS Tyler, Mentor, $\mathrm{OH}$. One hundred grams of ground corn for each diet was placed in a dust-tight enclosed series of stacked (No. 4, 6, ...) American Society for Testing and Materials (ASTM) screens affixed to the Ro-Tap particle size analyzer and shaken for $10 \mathrm{~min}$. The screens were then separated and weighed. Particle size was calculated by subtracting the weight of the screen from the final weight of screen and sample after shaking. The mean geometric particle size and log normal geometric standard deviation were calculated as described by McEllhiney [14].

14. McEllhiney, R. R. 1994. Determining and expressing particle size. Pages 545-547 in Feed Manufacture Technology IV. American Feed Industry Association, Inc., Arlington, VA.

15. Buchanan, N. P., K. G. S. Lilly and J. S. Moritz. 2010. The effects of altering diet formulation and manufacturing technique on pellet quality. J. Appl. Poult. Res. 19:112-120.

16. Fairchild, D.A. Nov 13, 2003. Pelleting for profit. National Grain and Feed Association: Feed and Feeding Digest. Vol. 54. N. 6.

17. Gehring, C.K. 2009.Improvement of the physical and nutritional quality of pelleted feed. M.S. Thesis. West Virginia University, Morgantown.

18. Hott, J. M., N. P. Buchanan, S. E. Cutlip, and J. S. Moritz. 2008. The effect of moisture addition with a mold inhibitor on pellet quality, feed manufacture, and broiler performance. J. Appl. Poult. Res. 17:262-271.

19. Loar II, R. E., J. S. Moritz, J. R. Donaldson, and A. Corzo. 2010. Effects of feeding distillers dried grains with solubles to broilers from 0 to 28 days posthatch on broiler performance, feed manufacture efficiency, and selected intestinal characteristics. Poult. Sci. 89:2242-2250.

20. Gehring, C. K., K. G. S. Lilly, L. K. Worley, K. R. Beaman, S. A. Loop, and J. S. Moritz. 2011. Increasing mixer-added fat improves exogenous enzyme efficacy and broiler performance. J. Appl. Poult. Res. 20:75-89.

21. Gehring, C. K., J. Jaczynski, and J. S. Moritz. 2009. Improvement of pellet quality with proteins recovered from whole fish using isoelectric solubilizationprecipitation. J. Appl. Poult. Res. 18:418-431.

22. Creswell, D. and M. Bedford. 2006. High pelleting temperatures reduce broiler performance. Proceedings of the Australian Poultry Science Symposium. 18: 1-6. 
23. Buchanan, N. P., K.G.S. Lilly, and J.S. Moritz. The effects of diet formulation, manufacturing technique, and antibiotic inclusion on broiler performance and intestinal morphology. J. Appl. Poult. Res. 2010 19: 121-131.

24. K. J. Shipe, A. M. Evans, K.G.S. Wamsley, and J. S. Moritz. 2012. Pelleting does not decrease lysine digestibility. E-Suppl. 1. Poult Sci 91:132.

25. K.J. Shipe, A.M. Evans, K.G.S Lilly, L.K. Shires, B.N. Swiger, and J.S.Moritz. 2011. Effects of feed manufacture techniques that vary feed exposure to pellet die heat and pressure on pellet quality and subsequent broiler lysine utilization. ESuppl. 1. Poult. Sci. 90:389.

26. Ravindran, V., W. L. Bryden, and E. T. Kornegay. 1995. Phytates: Occurrence, bioavailability and implications in poultry nutrition. Poult. And Avian Biol. Rev. 6:125-143.

27. Nelson, T. S., T. R. Shieh, R. J. Wodzinski, and J. H. Ware. 1971. Effect of supplemental phytase on utilization of phytate phosphorus by chicks. J. Nutr. 101: 1289-1294.

28. Salim, H. M., Z. A. Kruk, and B. D. Lee. 2010. Nutritive value of corn distillers dried grain with solubles as an ingredient of poultry diets: A review. World's Poult. Sci. J. 66:411-432.

29. Hoffman, L. and A. Baker. 2010. Market Issues and Prospects for U.S. Distillers' Grains: Supply, Use, and Price Relationships. A report from the economic research service/ USDA.

30. Batal, A. B. and N. M. Dale. 2006. True metabolizable energy and amino acid digestibility of distillers dried grains with solubles. J. Appl. Poult. Res. 15: 89-93.

31. Batal, A. and N. Dale. 2003. Mineral composition of distillers dried grains with solubles. J. Appl. Poult. Res. 12:400-403.

32. POET. Accessed Aug 3, 2012. http://www.poet.com/advantage 
CHAPTER 2: Resolving poor pellet quality and maintaining amino acid digestibility in commercial turkey diet feed manufacture

(Submitted for peer-review)

K.G.S. Wamsley ${ }^{*}$ and J.S. Moritz ${ }^{*}, 1$

* Division of Animal and Nutritional Sciences, West Virginia University, Morgantown 26506

Primary Audience: Feed Mill Managers, Nutritionists, Researchers, Production Managers

${ }^{1}$ Corresponding author: Joe.Moritz@mail.wvu.edu 


\section{SUMMARY}

Commercial turkey feed manufacture often requires high throughput and high levels of fat, resulting in poor feed quality. Many mills utilize low mixer-added fat (MAF) to increase ingredient binding opportunities and pellet quality, but this technique may decrease feed nutrient digestibility. Two experiments were conducted in order to determine the best feed manufacture technique (MTECH) to maximize pellet quality and subsequent true amino acid digestibility (TAAD) of practical turkey diets. Experiment 1 was a 3 Binder (Binder 1, Binder 2, or No Binder) x 2 MTECH [1\% MAF + $38.1 \mathrm{~mm}$ die (MTECH1) or 3\% MAF + $44.96 \mathrm{~mm}$ die (MTECH2)] factorial design that utilized practical turkey starter diets manufactured at West Virginia University's pilot feed mill. In Experiment 1, both binders improved pellet quality. Employing MTECH2 decreased pellet quality (minimally, 5\% PDI) and pellet mill relative electrical energy usage ( 15\%). Diets that contained Binder 1, the marginally better binder, and No Binder utilized at each MTECH were chosen to test TAAD using cecectomized roosters in Experiment 2. Binder improved the digestibility of several tested amino acids. A Binder $\mathrm{x}$ MTECH interaction demonstrated that when Binder was removed from diets manufactured utilizing MTECH1, the digestibility of some amino acids decreased, while MTECH2 maintained high amino acid digestibility, regardless of binder.

Keywords: pellet quality, turkey diets, mixer-added fat, true amino acid digestibility, lignosulfonate pellet binders 


\section{DESCRIPTION OF THE PROBLEM}

High throughput and high fat inclusion can be common in commercial turkey feed manufacture and diet formulation, both of which are known to decrease pellet quality [1, 2]. The benefits of maintaining high pellet quality in feeding poultry are well documented [3-8]; however, feed volume requirements are paramount in many integrated poultry operations. Consequently, feed manufacturers strive to economically maintain pellet quality without sacrificing high throughput. One solution to resolve poor pellet quality is the application of low MAF, adding the remainder of the fat via a post-pellet application system. Other possible poor pellet quality solutions include the use of commercially available pellet binders or utilization of feed manufacture techniques that maximize heat transfer and nutrient binding opportunities during the pelleting process, e.g. use of a pellet die with a greater effective thickness. However, detrimental effects of pelleting, particularly linked to heat sensitive nutrients have been documented [9-11]. In fact, recent research has demonstrated that a thick pellet die and decreased MAF can be detrimental to both throughput and nutrient digestibility $[2,8]$. The use of increased MAF has been shown to lubricate the pellet die; enhancing throughput and reducing the amount of energy required by the pellet mill [2]. In addition, high MAF has been shown to reduce detrimental pelleting effects on nutrient digestibility $[2,5,8]$. Thus, a variety of factors must be considered to resolve poor pellet quality and maintain nutrient digestibility in the manufacture of turkey diets. The objectives of Experiment 1 were to use practical turkey diets to assess: 1) the effect of either one of two commercially available lignosulfonate pellet binders or the use of no binder on feed manufacture variables; and 2) the ability of 3\% MAF used in conjunction with a thick pellet die (44.96 
$\mathrm{mm})(\mathrm{MTECH} 2)$ to maintain throughput and produce pellets of similar quality to those produced utilizing 1\% MAF and thinner pellet die $(38.1 \mathrm{~mm})$ (MTECH1). The objective of Experiment 2 was to assess the effect of lignosulfonate binder inclusion and the aforementioned MTECHs on TAAD using Single Comb White Leghorn cecectomized roosters.

\section{MATERIALS AND METHODS}

\section{Experiment 1: Diet preparation and feed manufacture}

This experiment was conducted at West Virginia University's pilot feed mill using a 3 Binder (Binder 1, Binder 2, or No Binder) x 2 MTECH (MTECH1 - 1\% MAF and $38.10 \mathrm{~mm}$ effective pellet die thickness or MTECH 2- 3\% MAF and $44.96 \mathrm{~mm}$ effective pellet die thickness) factorial design. Both Binder 1 [12] and Binder 2 [13] were commercially available lignosulfonate binders and top dressed at an inclusion of $0.05 \%$. Manufacturing technique 1 represented a commercial feed manufacture strategy by utilizing low (1\%) MAF to improve feed quality and a thin $(38.10 \mathrm{~mm})$ pellet die to maintain high throughput; MTECH2 confounds 3\% MAF with a thicker pellet die (44.96 $\mathrm{mm}$ ) because the authors believe that $3 \%$ MAF could enhance throughput and protect heat sensitive nutrients, while the use of a thicker pellet diet could maintain pellet quality. The diet used in Experiments 1 and 2 was formulated to commercial specifications for 26 wk poults, using practical ingredients (Table 1). Analyses of Binder 1 and Binder 2 are shown in Table 2.

Batching was accomplished by creating four, $818.4 \mathrm{~kg}$ batches (without binder, containing $1 \% \mathrm{MAF})$ that were allocated evenly $(545.6 \mathrm{~kg})$ to each of the six aliquots 
representing experimental treatments; and then divided into $136.4 \mathrm{~kg}$ allotments for each experimental unit to be randomly pelleted over a four-day period. Binder and/or $2 \%$ MAF were added prior to pelleting, according to treatment. Each day prior to pelleting and after each pellet die change, $90.7 \mathrm{~kg}$ of feed was used to warm up the pellet die; therefore, the time necessary to raise mash temperature to $82.2^{\circ} \mathrm{C}$ was standardized to two minutes. Each treatment was conditioned using a short-term conditioner $(0.31 \times 1.30 \mathrm{~m}$, $10 \mathrm{~s}$ retention time) [14] with a constant temperature of $82.2^{\circ} \mathrm{C}$ and a steam pressure of $262 \mathrm{kPa}$ determined at a gauge in the steam line just prior to the steam inlet to the conditioner. Conditioned feed was extruded through a $4.76 \times 38.10$ or 4.76 x $44.96 \mathrm{~mm}$ pellet die using a 40-horsepower California pellet mill [15]. The auger controlling the rate at which feed empties into the conditioner was adjusted to achieve approximately the same production rate for all treatments ( 0.9 tonne/hr). After pelleting, each treatment was cooled for 1.25 min on a horizontal belt cooler [16] using forced ambient air.

Post-pellet fat application was simulated by using a vertical-screw mixer [17]. Therefore, each day after pelleting, a $90.7 \mathrm{~kg}$ representative sample of pellets and fines corresponding to each treatment was assembled with the remaining fat (either 5.05 or $7.05 \%$ ) and mixed for two minutes. Next, $22.7 \mathrm{~kg}$ were collected for pellet durability index (PDI), modified pellet durability index (MPDI) [18], pelleted percent fines, and bulk density. Other feed manufacture variables measured included: production rate, conditioner relative electrical energy usage (CREE), and pellet mill relative electrical energy usage (PMREE). 


\section{Experiment 2: True Amino Acid Digestibility}

Binder 1 demonstrated marginally better pellet quality compared to Binder 2 and was chosen for TAAD testing. Therefore the following four treatments manufactured in Experiment 1 were utilized in Experiment 2: Binder 1 + MTECH1, No Binder + MTECH1, Binder $1+$ MTECH2, No Binder + MTECH2. A total of 20 cecectomized Single Comb White Leghorn roosters that were approximately 60 weeks of age were used to estimate TAAD using a modified procedure of Sibbald [19]. Prior to precision feeding, roosters were offered a common diet for three weeks, where feed and water were provided for ad libitum consumption. Next, roosters were placed in an environmentally controlled room containing 20 individual raised wire cages, fasted for $24 \mathrm{~h}$, and then precision fed $30 \mathrm{~g}$ of randomly assigned dietary treatments (4 replications per treatment). Cornstarch was also precision fed to 4 roosters as a nitrogen-free control in order to quantify endogenous amino acid losses for TAAD determination. Total excreta were collected over a $48 \mathrm{~h}$ period, then lyophilized, weighed and ground. Feed and excreta samples were submitted to a commercial laboratory to quantify amino acids and nitrogen content [20-22]. All birds utilized in this experiment were cared for in accordance to West Virginia University Animal Care and Use Committee Guidelines.

\section{Statistical Analysis}

In Experiment 1, diets were manufactured as a randomized complete block design and the day of manufacture was utilized as a blocking criterion, producing four replications per treatment. In Experiment 2, treatments were completely randomized, with four replications per treatment. In both experiments, Binder x MTECH factorial 
analyses were performed to explore main effects and interactions. Multiple comparisons were also performed with all treatment means using Fisher's least significant difference test. All data were statistically analyzed using the GLM procedure of Statistical Analysis System [23]. Alpha was designated as 0.05 , and letter superscripts were used to denote differences among treatment means.

\section{RESULTS AND DISCUSSION}

\section{Experiment 1: Feed Manufacture at WVU Pilot Feed Mill}

Binder and MTECH effects on feed manufacture variables are presented in Table 3. Production rate was not affected by Binder or MTECH ( $\mathrm{P}>0.05)$, likely due to the experimental design of controlling the rate at which feed was conveyed into the conditioner. In addition, Binder and MTECH had no effect on CREE ( $\mathrm{P}>0.05)$.

Lignosulfonate binder inclusion significantly improved pellet quality, as defined as pellet durability index (PDI; $\mathrm{P}=0.0023)$, modified pellet durability index (MPDI; $\mathrm{P}=$ 0.0001), and percent fines $(\mathrm{P}=0.0031)$. Multiple comparison data demonstrated that lignosulfonate pellet binders improved pellet quality and performed similarly when manufactured utilizing MTECH2 (Table 3). However, Binder 1 inclusion into diets manufactured with MTECH1 produced significantly higher MPDI $(\mathrm{P}=0.0001$; Table 3$)$ and numerically improved PDI and fines compared to Binder 2 (Table 3).

Increasing MAF by manufacturing feed with MTECH2 significantly reduced PMREE by $15 \%$ ( $\mathrm{P}=0.0002$; Table 3 ). In addition, pellets produced utilizing MTECH1 produced 8.5 percentage points less fines compared to diets manufactured with MTECH2 $(\mathrm{P}=0.0001$; Table 3$)$. A recent study conducted by Lilly and cohorts [8] demonstrated 
that a 10 percentage point increase of intact pellets translates to a 0.4 point improved feed conversion ratio, 10 gram increase in carcass weight, and a 4 gram increase in breast weight with Cobb 500 broilers. Therefore, pellet quality results due to $\mathrm{MTECH}$ in the current experiment may elicit performance differences upon feeding, but the extent of these differences is unclear.

Manufacturing diets utilizing MTECH1 resulted in a higher bulk density $(\mathrm{P}=$ 0.0006; Table 3). Typically higher pellet quality results in lower bulk density; however these diets had $7 \%$ fat added via post-pellet application (compared to the 5\% fat added via post-pellet application required by diets manufactured with $\mathrm{MTECH} 2$ ). It is possible that that fat distribution and adherence may be affected by percent in-tact pellets, thus influencing bulk density.

There is a lack of peer-reviewed literature that provides statistically analyzed data detailing effects of lignosulfonate pellet binders on feed manufacturing variables. Proposed lignosulfonate mechanisms of action from the literature are equally sparse. However, manufacturers of lignosulfonate binders describe them as possessing both hydrophobic and hydrophilic properties which allow for controlled rheology, i.e. flocculation/agglomeration of particles [24]. Research including the inclusion of lignosulfonate pellet binders in broiler diets have not reported performance benefits beyond those associated with feed form $[25,26]$, but one study reported a binder metabolizable energy value of $2.33 \mathrm{kcal} / \mathrm{kg}$ [27]. Studies that have tested the feeding value of pellet binders with turkeys used calcium and/or sodium bentonite pellet binders and determined that their incorporation into diets increased pellet durability and hardness [28], but also diluted nutrients; despite this, growing turkeys were able to efficiently 
utilize the nutrients in the diet $[5,28]$. Therefore, it was of particular interest to the authors of this research to investigate if these binders could affect amino acid digestibility, especially when associated with variations in manufacturing techniques that have been proposed to alter nutrient conformation and digestion.

\section{Experiment 2: True Amino Acid Digestibility}

True amino acid digestibility data are provided in Table 4. Binder inclusion was found to enhance the digestibility of Phenylalanine, Leucine, Glutamine, Proline, and Tyrosine by 4-7\% (Table 4; $\mathrm{P}<0.05$ ). Binder inclusion also demonstrated trends to improve Isoleucine, Lysine, Arginine, and Valine similarly by 4-7\% $(\mathrm{P}=0.0573, \mathrm{P}=$ 0.0646, $\mathrm{P}=0.0531, \mathrm{P}=0.0543$, respectively). Significant Binder $\mathrm{x}$ MTECH interactions were found for Methionine ( $\mathrm{P}=0.0441$; Table 4) and Histidine $(\mathrm{P}=0.0388$; Table 4), which demonstrated that when Binder was removed from the diet, MTECH1 decreased digestibility. A similar Binder x MTECH interaction trend was also shown for Alanine $(\mathrm{P}=0.0671)$; however, MTECH2 demonstrated high TAAD regardless of Binder.

Research not using complete feeds has suggested that Cystine, Lysine, Arginine, Threonine, and Serine are the most heat sensitive amino acids, while Valine, Leucine, Tyrosine, and Phenylalanine are among the more heat tolerant amino acids when feed ingredients containing increased protein are subjected to varying heat processes [29]. The use of complete feed in the current experiment may explain why the TAAD measurements discussed above did not support this exact pattern; however, these data suggest that the combination of lignosulfonate pellet binder and 3\% MAF may be beneficial. Additionally, unpublished data from our lab that utilized methods to obtain 
continuous measurements of pellet mill amperage and hot pellet temperature [30] has found that diet inclusion of lignosulfonate pellet binder per se reduced pellet mill electrical energy use and hot pellet temperature; providing a potential explanation as to why amino acid digestibility in the current study may have been improved. Also, it is important to note that any TAAD benefit associated with MTECH2 occurred despite the use of a pellet die, with greater effective thickness (38.10 vs. $44.96 \mathrm{~mm}$ ).

Future research should investigate whether or not a commercial feed mill could utilize the manufacturing techniques employed in the current study to obtain similar benefits for feed manufacture efficiency and pellet quality. Additionally, because much of the research investigating the feeding value of pellet binders is dated, it is of particular importance to test their feeding value and their ability to improve nutrient retention [5, 28] using modern day genetics. Lastly, it should be tested if the 4-7\% differences in amino acid digestibility found in this study would translate to improved poult performance and in order to assess a more comprehensive view on the economic return of feeding these high quality pellets that maintain a high amino acid digestibility.

\section{CONCLUSIONS AND APPLICATIONS}

1. Binder inclusion improved pellet quality, i.e. increased PDI, and MPDI and decreased percent fines.

2. The inclusion of 3\% MAF and $44.96 \mathrm{~mm}$ die (MTECH2) caused detriment pellet quality, but reduced PMREE by $15 \%$ without sacrificing throughput. The addition of binder into these diets improved pellet quality while maintaining the reduction in PMREE. 
3. The pelleting process can be detrimental to amino acid digestibility. The current study demonstrates that the incorporation of a lignosulfonate pellet binder and 3\% MAF can improve TAAD.

\section{REFERENCES}

1. Buchanan, N. P., K. G. S. Lilly and J. S. Moritz. 2010. The effects of altering diet formulation and manufacturing technique on pellet quality. J. Appl. Poult. Res. 19:112-120.

2. Gehring, C. K., K. G. S. Lilly, L. K. Worley, K. R. Beaman, S. A. Loop, and J. S. Moritz. 2011. Increasing mixer-added fat improves exogenous enzyme efficacy and broiler performance. J. Appl. Poult. Res. 20:75-89.

3. Jensen, L. S., L. H. Merrill, C. V. Reddy, and J. McGinnis. 1962. Observations on eating patterns and rate of food passage of birds fed pelleted and unpelleted diets. Poult. Sci. 41:1414-1419.

4. Proudfoot, F. G. and H. W. Hulan. 1982. Feed texture effects on the performance of turkey broilers. Poult. Sci. 61:327-330.

5. Salmon, R.E. 1985. Effects of pelleting, added sodium bentonite and fat in a wheatbased diet on performance and carcass characteristics of small white turkeys. Anim. Feed Sci. Technol. 12:223-232.

6. Behnke, K. C. 1996. Feed manufacturing technology: Current issues and challenges. Anim. Feed Sci. Technol. 62:49-57.

7. Hott, J. M., N. P. Buchanan, S. E. Cutlip, and J. S. Moritz. 2008. The effect of moisture addition with a mold inhibitor on pellet quality, feed manufacture, and broiler performance. J. Appl. Poult. Res. 17:262-271.

8. Lilly, K. G. S., C. K. Gehring, K. R. Beaman, P. J. Turk, M. Sperow, and J. S. Moritz. 2011. Examining the relationships between pellet quality, broiler performance, and bird sex. J. Appl. Poult. Res. 20:231-239.

9. Bayley, H. S., J. D. Summers, and S. J. Slinger. 1968. The influence of steam pelleting conditions on the nutritional value of chick diets. Poult. Sci. 47:931-939.

10. Plavnik, I., E. Wax, D. Sklan, and S. Hurwitz. 1997. The response of broiler chickens and turkey poults to steam-pelleted diets supplemented with fat or carbohydrates. Poult. Sci. 76:1006-1013.

11. Pickford, J. R. 1992. Effects of processing on stability of heat stability of heat labile nutrients in animal feeds. In: Garnsworthy, P.C., Haresign, W., Cole, D. J. A. (Eds.), Recent Advances in Animal Nutrition. Redwood Press, Melksham, UK, pp. 177-192. 12. Pell-Tuff, Cra-Vac Industries Inc., Toronto, ON Canada.

13. Ameri-bond 2x, Borregaard LignoTech, Sarpsborg, Norway.

14. $4.25 \mathrm{ft}$ length, $1.02 \mathrm{ft}$ diameter short term CPM conditioner ( 3 steam inlet ports), 429 rpm shaft speed; 21 picks; 10 second feed retention time.

15. Master Model Pellet Mill, California Pellet Mill Company (CPM), Crawfordsville, IN. 
16. Horizontal cooler, Pyramid Processing Equipment LLC, Stilwell, KS.

17. Vertical mixer, Avery Weigh-Tronix, Fairmont, MN

18. American Society of Agricultural Engineers. 1997. ASAE S269.4, Cubes, pellets, and crumbles-Definitions and methods for determining density, durability, and moisture. Standards 1997. Am. Soc. Agric. Eng., St. Joseph, MI. Due to the use of a $3 / 16$ in. $x 1.77$ in. die, pellets were sifted in a No. 6 American Society for Testing and Materials (ASTM) screen. Five hundred grams of sifted pellets were placed in a dust-tight enclosure and tumbled for $10 \mathrm{~min}$ at $50 \mathrm{rpm}$. The enclosure was of the dimensions $12 \times 12$ in., with a $2 \times 9$ in. plate affixed diagonally along one of the $12 \times$ 12 in. sides. The tumbled samples were then sifted again (No. 6 ASTM) and weighed. The pellet durability index was calculated by dividing the weight of pellets after tumbling by the weight of pellets before tumbling, then multiplying by 100 . The modified pellet durability index was determined in a similar manner with the exception of adding 5,13-mm hex nuts to the pretumbled sample to obtain added pellet agitation.

19. Sibbald, I. R. 1976. A bioassay for true metabolizable energy in feedingstuffs. Poult. Sci. 55:303-308. (Feed was withheld for 24 hours, approximately 30 grams of feed were precision fed, and excreta was collected for 48 hours.)

20. Experiment Station Chemical Laboratories, Agricultural Experiment Station, Univ. Missouri, Columbia, MO.

21. AOAC Official Method 982.30E(a,b,c), Chp. 45.3.05, 2006.

22. Kjeldahl, AOAC Official Method 984.13 (A-D), 2006.

23. SAS Institute. 2009. The SAS System for Windows 2009. Release 9.2. SAS Inst. Inc., Cary, NC.

24. Borregaard LignoTech. Functionalities. Accessed April 30, 2012. http://www.lignotech.com/Functionalities.

25. Acar, N., E. T. Moran, W. H, Revington, and S. F. Bilgili. 1991. Effect of improved pellet quality from using a calcium lignosulfonate binder on performance and carcass yield of broilers reared under different marketing schemes. Poult. Sci. 70: 13391344.

26. Proudfoot, F. G., H. W. Hulan, and W. F. DeWitt. 1979. Effects of using 0, 1.0, 1.5, and $2.0 \%$ 'Lignosol FG' as a pellet binder in broiler chick finisher diets. Poult. Sci. $58: 87-89$.

27. Morrison, H. L., P. W. Waldroup, D. E. Greene, and E. L. Stephenson. 1968. Determination of the metabolizable energy and feeding value of a lignin sulfonate pellet binder. Poul. Sci. 47: 592-597.

28. Almquist, H. J., H. L. Christensen and S. Maurer. 1967. The effect of bentonites on nutrient retention by turkeys. Feedstuffs. 30(20):54.

29. Papadopoulos, M.C., 1989. Effect of processing on high-protein feedstuffs: a review. Biol. Wastes. 29:123-138.

30. Corey, A. 2012. West Virginia University. Unpublished data. 
Table 1. Starter turkey diet formulation ${ }^{1}$ manufactured in Experiment 1 and used for true amino acid digestibility in Experiment 2

\begin{tabular}{|c|c|c|c|c|c|c|}
\hline \multicolumn{3}{|c|}{ Ingredient } & \multicolumn{4}{|c|}{ Inclusion (\%) } \\
\hline \multicolumn{2}{|c|}{ Corn } & & \multicolumn{4}{|c|}{30.80} \\
\hline \multicolumn{3}{|c|}{${\text { Soybean } \mathrm{Meal}^{2}}^{2}$} & \multicolumn{4}{|c|}{39.50} \\
\hline \multicolumn{3}{|c|}{ Poultry Meal } & \multicolumn{4}{|c|}{7.50} \\
\hline \multicolumn{2}{|c|}{ Wheat Midds ${ }^{3}$} & \multicolumn{5}{|c|}{10.00} \\
\hline \multicolumn{3}{|c|}{ Animal/Vegetable Blend Fat } & \multicolumn{4}{|c|}{8.05} \\
\hline \multicolumn{3}{|c|}{ Limestone } & \multicolumn{4}{|c|}{1.40} \\
\hline \multicolumn{3}{|c|}{ Monocalcium Phosphate } & \multicolumn{4}{|c|}{0.90} \\
\hline \multicolumn{3}{|c|}{ Defluorinated Phosphate } & \multicolumn{4}{|c|}{0.75} \\
\hline \multicolumn{3}{|c|}{ Salt } & \multicolumn{4}{|c|}{0.155} \\
\hline \multicolumn{3}{|c|}{ D-L Methionine } & \multicolumn{4}{|c|}{0.425} \\
\hline \multicolumn{2}{|c|}{ Lysine } & \multicolumn{5}{|c|}{0.345} \\
\hline \multicolumn{2}{|c|}{ L-Threonine } & \multicolumn{5}{|c|}{0.025} \\
\hline \multicolumn{3}{|c|}{ Poultry Premix ${ }^{4}$} & \multicolumn{4}{|c|}{0.25} \\
\hline \multicolumn{7}{|c|}{ Calculated Nutrients } \\
\hline \multicolumn{2}{|c|}{$\mathrm{ME}(\mathrm{kcal} / \mathrm{kg})$} & \multicolumn{5}{|c|}{3163} \\
\hline \multicolumn{2}{|c|}{ Protein $(\%)$} & \multicolumn{5}{|c|}{27.01} \\
\hline \multicolumn{2}{|c|}{ TSAA $(\%)$} & & & 1.1 & & \\
\hline Lysi & $(\%)$ & & & 1.7 & & \\
\hline & Analyzed $^{5} \mathrm{I}$ & utrients of I & iets Manufac & ured in Exp & ment 1 & \\
\hline $\begin{array}{l}\text { Analyzed } \\
\text { Nutrients }\end{array}$ & $\begin{array}{l}\text { Binder1+ } \\
\text { MTECH1 }\end{array}$ & $\begin{array}{l}\text { Binder } 2+ \\
\text { MTECH1 }\end{array}$ & $\begin{array}{c}\text { No Binder + } \\
\text { MTECH1 }\end{array}$ & $\begin{array}{l}\text { Binder1 + } \\
\text { MTECH2 }\end{array}$ & $\begin{array}{l}\text { Binder } 2+ \\
\text { MTECH2 }\end{array}$ & $\begin{array}{c}\text { No Binder + } \\
\text { MTECH2 }\end{array}$ \\
\hline Protein $^{6}(\%)$ & 26.23 & 26.01 & 26.15 & 26.94 & 27.05 & 27.91 \\
\hline Methionine $^{7}(\%)$ & 0.86 & 0.75 & 0.71 & 0.72 & 0.78 & 0.71 \\
\hline Lysine $^{7}(\%)$ & 1.73 & 1.76 & 1.74 & 1.70 & 1.79 & 1.79 \\
\hline
\end{tabular}

${ }^{1}$ Lignosulfonate binder was top-dressed prior to pelleting at $0.05 \%$ inclusion when required by treatment; Analyses of Binders are provided in Table 2

${ }^{2}$ Crude protein of soybean meal was $47 \%$

${ }^{3}$ Crude protein of wheat midds was $16.8 \%$

${ }^{4}$ Supplied per kilogram of diet: manganese, $0.02 \%$; zinc, $0.02 \%$; iron, $0.01 \%$; copper, $0.0025 \%$; iodine, $0.0003 \%$; selenium, $0.00003 \%$; folic acid, $0.69 \mathrm{mg}$; choline, $386 \mathrm{mg}$; riboflavin, $6.61 \mathrm{mg}$; biotin, $0.03 \mathrm{mg}$; vitamin $\mathrm{B}_{6}, 1.38 \mathrm{mg}$; niacin, $27.56 \mathrm{mg}$; pantothenic acid, $6.61 \mathrm{mg}$; thiamine, $2.20 \mathrm{mg}$; manadione, $0.83 \mathrm{mg}$; vitamin $\mathrm{B}_{12}, 0.01 \mathrm{mg}$; vitamin $\mathrm{E}, 16.53 \mathrm{IU}$; vitamin $\mathrm{D}_{3}, 2,133$ ICU; vitamin A, 7,716 IU.

${ }^{5}$ Diets were analyzed at Experiment Station Chemical Laboratories, Agricultural Experiment Station, Univ. Missouri, Columbia, MO.

${ }^{6}$ Crude Protein was determined by Kjeldahl, AOAC Official Method 984.13 (A-D), 2006; Crude protein was calculated by $6.25 \mathrm{x}$ nitrogen value

${ }^{7}$ Amino acids were analyzed using AOAC Official Method 982.30E(a,b,c), Chp. 45.3.05, 2006. 
Table 2. Analyses of lignosulfonate pellet binders

\begin{tabular}{|c|c|c|c|c|c|}
\hline Binder & $\begin{array}{c}\text { Crude Protein } \\
(\%)\end{array}$ & $\begin{array}{c}\text { Moisture } \\
(\%)\end{array}$ & $\begin{array}{c}\text { Ash }^{3} \\
(\%)\end{array}$ & $\begin{array}{c}\text { Acid Detergent } \\
\text { Fiber }^{4}(\%)\end{array}$ & $\begin{array}{c}\text { Neutral Detergent } \\
\text { Fiber }^{5}(\%)\end{array}$ \\
\hline Binder 1 & 12.4 & 13.8 & 0.97 & 48.0 & 50.0 \\
\hline Binder 2 & 0.34 & 15.5 & 16.5 & 51.1 & 52.2 \\
\hline
\end{tabular}

${ }^{1}$ Crude Protein was determined by Kjeldahl, AOAC Official Method 984.13 (A-D), 2006; Crude protein was calculated by $6.25 \mathrm{x}$ nitrogen value

${ }^{2}$ Moisture was determined using AOAC Official Method 934.01, 2006

${ }^{3}$ Ash was determined using AOAC Official Method 942.05

${ }^{4}$ Acid Detergent Fiber was determined using AOAC Official Method 973.18 (A-D), 2006

${ }^{5}$ Neutral Detergent Fiber was determined using JAOAC 56, 1352-1356, 1976 
Table 3. Main effects of manufacture technique $(\mathrm{MTECH})$ and Binder on feed manufacture variables (Experiment 1)

\begin{tabular}{|c|c|c|c|c|c|c|c|}
\hline $\begin{array}{c}\text { Main effects } \\
\left(\text { Binder }^{1}, \mathrm{MTECH}^{2}\right)\end{array}$ & $\begin{array}{l}\mathrm{PDI}^{3} \\
(\%)\end{array}$ & $\begin{array}{l}\mathrm{MPDI}^{4} \\
(\%)\end{array}$ & $\begin{array}{l}\text { Fines }^{5} \\
(\%)\end{array}$ & $\begin{array}{l}\text { Bulk Density } \\
\text { Pellets } \\
\left(\mathrm{kg} / \mathrm{m}^{3}\right)\end{array}$ & $\begin{array}{l}\text { Production } \\
\text { Rate } \\
\text { (tonne/hr) }\end{array}$ & $\begin{array}{l}\text { Conditioner Relative } \\
\text { Electrical Energy } \\
\text { Usage (CREE) (kwh) }\end{array}$ & $\begin{array}{c}\text { Pellet Mill Relative } \\
\text { Electrical Energy Usage } \\
\text { (PMREE) (kwh) }\end{array}$ \\
\hline Binder 1 + MTECH1 & $96.66^{\mathrm{a}}$ & $93.90^{\mathrm{a}}$ & $13.87^{\mathrm{d}}$ & $629.39^{\mathrm{ab}}$ & 0.940 & 0.923 & $8.82^{a}$ \\
\hline Binder $2+$ MTECH1 & $95.90^{\mathrm{ab}}$ & $91.43^{\mathrm{b}}$ & $16.21^{\mathrm{cd}}$ & $631.99^{\mathrm{a}}$ & 0.907 & 1.05 & $8.65^{\mathrm{ab}}$ \\
\hline No Binder + MTECH1 & $95.00^{\mathrm{b}}$ & $89.75^{\mathrm{b}}$ & $18.11^{\mathrm{c}}$ & $633.39^{\mathrm{a}}$ & 0.931 & 0.953 & $9.16^{\mathrm{a}}$ \\
\hline Binder $1+$ MTECH2 & $92.03^{c}$ & $84.13^{\mathrm{c}}$ & $24.11^{\mathrm{b}}$ & $615.77^{\mathrm{bc}}$ & 0.915 & 1.17 & $7.26^{\mathrm{c}}$ \\
\hline Binder $2+$ MTECH2 & $92.23^{\mathrm{c}}$ & $85.00^{c}$ & $22.70^{\mathrm{b}}$ & $612.57^{\mathrm{c}}$ & 0.916 & 1.10 & $7.73^{b c}$ \\
\hline No Binder + MTECH2 & $90.30^{\mathrm{d}}$ & $80.24^{\mathrm{d}}$ & $26.99^{\mathrm{a}}$ & $617.77^{\mathrm{bc}}$ & 0.933 & 0.940 & $7.70^{\mathrm{bc}}$ \\
\hline Fisher's LSD & 1.27 & 1.94 & 2.79 & 13.75 & -- & -- & 1.01 \\
\hline ANOVA P-Value & 0.0001 & 0.0001 & 0.0001 & 0.0165 & 0.7408 & 0.1071 & 0.0064 \\
\hline \multicolumn{8}{|c|}{ Marginal means } \\
\hline MTECH1 (1\% MAF + Thin Die) & $95.85^{\mathrm{a}}$ & $91.69^{\mathrm{a}}$ & $16.07^{\mathrm{b}}$ & $631.59^{\mathrm{a}}$ & 0.926 & 0.974 & $8.88^{\mathrm{a}}$ \\
\hline MTECH2 (3\% MAF + Thick Die) & $91.52^{\mathrm{b}}$ & $83.12^{\mathrm{b}}$ & $24.60^{\mathrm{a}}$ & $615.37^{\mathrm{b}}$ & 0.921 & 1.07 & $7.57^{\mathrm{b}}$ \\
\hline Binder 1 & $94.34^{\mathrm{y}}$ & $89.01^{\mathrm{y}}$ & $18.99^{\mathrm{z}}$ & 622.58 & 0.927 & 1.05 & 8.04 \\
\hline Binder 2 & $94.06^{\mathrm{y}}$ & $88.21^{\mathrm{y}}$ & $19.45^{\mathrm{z}}$ & 622.28 & 0.911 & 1.07 & 8.19 \\
\hline No Binder & $92.65^{z}$ & $84.99^{\mathrm{z}}$ & $22.55^{\mathrm{y}}$ & 625.58 & 0.932 & 0.946 & 8.43 \\
\hline \multicolumn{8}{|c|}{ Main effect and interaction probabilities } \\
\hline MTECH & 0.0001 & 0.0001 & 0.0001 & 0.0006 & 0.7690 & 0.0974 & 0.0002 \\
\hline Binder & 0.0023 & 0.0001 & 0.0031 & 0.7303 & 0.4686 & 0.1685 & 0.5223 \\
\hline MTECH x Binder & 0.4080 & 0.0360 & 0.1583 & 0.8136 & 0.6069 & 0.1754 & 0.6093 \\
\hline $\mathrm{SEM}^{7}$ & 0.3421 & 0.5442 & 0.5532 & 4.5609 & 0.0160 & 0.0663 & 0.2849 \\
\hline
\end{tabular}

Binder: Lignosulfonate Pellet Binder Powder top dressed at $0.05 \%$ inclusion: Binder $1=$ lignosulfonate binder with proximate analysis of $12.4 \%$ Crude Protein, $13.8 \%$ Moisture, $0.97 \%$ Ash, $48 \%$ Acid detergent fiber, 50\% Neutral detergent fiber; Binder 2 = lignosulfonate binder with proximate analysis of 0.34\% Crude protein, $15.5 \%$ Moisture, $16.5 \%$ Ash, $51.1 \%$ Acid detergent fiber, 52.2\% Neutral detergent fiber; No Binder $=$ no binder in diet

${ }^{2}$ MTECH = Manufacture Technique; MTECH1: $1 \%$ mixer added fat (MAF) and Thin Pellet Die (38.10 x $4.76 \mathrm{~mm}$ ); MTECH2: $3 \%$ MAF and Thick Pellet Die (44.96 x 4.76 mm)

${ }^{3}$ Pellet durability index was determined by placing 500 grams of sifted pellets into a Pfost tumbler. Samples were tumbled for 10 minutes at 50 rpm. The sample was then sifted again and weighed. Pellet durability index was calculated as the percent of sifted pellets retained after tumbling.

${ }^{4}$ Modified pellet durability index was measured similar to the previous description, with the exception of the addition of five 13 -mm hexagonal nuts to the $500 \mathrm{~g}$ sample prior to tumbling.

${ }^{5}$ Fines were calculated by sifting approximately $22.7 \mathrm{~kg}$ of feed from each treatment replicate obtained after post-pellet fat application

${ }^{6}$ Bulk Density is measured in $\mathrm{kg} / \mathrm{m}^{3}$ and was calculated from a $22.7 \mathrm{~kg}$ sample of feed from each treatment replicate obtained after post-pellet fat application

${ }^{7}$ Standard Error of the Mean, an estimate of the amount that an obtained mean may be expected to differ by chance from the true mean 
Table 4. The effect of manufacture technique (MTECH) and Binder 1 inclusion on true amino acid digestibility ${ }^{1}$ (Experiment 2)

\begin{tabular}{|c|c|c|c|c|c|c|c|c|c|c|c|c|c|c|c|c|c|}
\hline $\begin{array}{c}\text { Main effects } \\
\left(\text { Binder }^{2}, \mathrm{MTECH}^{3}\right)\end{array}$ & $\begin{array}{c}\text { Thre- } \\
\text { onine } \\
(\%)\end{array}$ & $\begin{array}{l}\text { Alanine } \\
(\%)\end{array}$ & $\begin{array}{c}\text { Cysteine } \\
(\%)\end{array}$ & $\begin{array}{l}\text { Valine } \\
(\%)\end{array}$ & $\begin{array}{c}\text { Meth- } \\
\text { ionine } \\
(\%)\end{array}$ & $\begin{array}{c}\text { Iso- } \\
\text { leucine } \\
(\%)\end{array}$ & $\begin{array}{l}\text { Leucine } \\
(\%)\end{array}$ & $\begin{array}{l}\text { Lysine } \\
(\%)\end{array}$ & $\begin{array}{l}\text { Aspara } \\
\text {-gine } \\
(\%)\end{array}$ & $\begin{array}{l}\text { Serine } \\
(\%)\end{array}$ & $\begin{array}{l}\text { Gluta- } \\
\text { mine } \\
(\%)\end{array}$ & $\begin{array}{l}\text { Proline } \\
(\%)\end{array}$ & $\begin{array}{c}\text { Tyrosine } \\
(\%)\end{array}$ & $\begin{array}{c}\text { Phenly- } \\
\text { alanine } \\
(\%)\end{array}$ & $\begin{array}{l}\text { Histidine } \\
(\%)\end{array}$ & $\begin{array}{l}\text { Arginine } \\
(\%)\end{array}$ & $\begin{array}{c}\text { Trypto- } \\
\text { phan } \\
(\%)\end{array}$ \\
\hline Binder $1+$ MTECH1 & 88.76 & 88.21 & 81.33 & 90.87 & $96.75^{\mathrm{a}}$ & 91.40 & 91.96 & 95.55 & 90.27 & 88.92 & $92.95^{\mathrm{a}}$ & $89.40^{\mathrm{a}}$ & $91.73^{\mathrm{a}}$ & 92.39 & $92.55^{\mathrm{a}}$ & 92.30 & 94.72 \\
\hline No Binder + MTECH1 & 81.71 & 80.74 & 72.12 & 83.17 & $89.16^{\mathrm{b}}$ & 84.26 & 84.45 & 84.23 & 84.08 & 82.48 & $86.12^{\mathrm{b}}$ & $81.56^{\mathrm{b}}$ & $84.12^{\mathrm{b}}$ & 84.69 & $83.22^{\mathrm{b}}$ & 84.33 & 93.45 \\
\hline Binder $1+$ MTECH2 & 90.93 & 85.79 & 84.63 & 89.64 & $94.87^{\mathrm{a}}$ & 90.08 & 91.0 & 91.78 & 89.93 & 90.83 & $92.58^{\mathrm{a}}$ & $90.63^{\mathrm{a}}$ & $90.36^{\mathrm{a}}$ & 91.21 & $91.50^{\mathrm{a}}$ & 91.60 & 95.82 \\
\hline No Binder + MTECH2 & 89.01 & 86.84 & 80.10 & 89.34 & $94.58^{\mathrm{a}}$ & 89.83 & 90.33 & 91.36 & 89.65 & 88.99 & $91.80^{\mathrm{a}}$ & $87.44^{\mathrm{ab}}$ & $90.15^{\mathrm{a}}$ & 90.66 & $90.63^{\mathrm{a}}$ & 87.21 & 96.91 \\
\hline Fisher's LSD & -- & -- & -- & -- & 4.99 & -- & -- & -- & -- & -- & 5.12 & 6.34 & 5.45 & -- & 5.62 & -- & -- \\
\hline ANOVA P-value & 0.1642 & 0.1221 & 0.2936 & 0.0548 & 0.0344 & 0.0611 & 0.0540 & 0.0946 & 0.099 & 0.153 & 0.044 & 0.041 & 0.045 & 0.0580 & 0.0146 & 0.2158 & 0.3201 \\
\hline \multicolumn{18}{|c|}{ Marginal means } \\
\hline $\begin{array}{c}\text { MTECH1 } \\
(1 \% \text { MAF + Thin Die) } \\
\end{array}$ & 85.24 & 86.31 & 76.73 & 87.02 & 92.95 & 87.83 & 88.21 & 89.89 & 87.17 & 85.70 & 89.53 & 85.48 & 87.93 & 88.54 & 87.89 & 88.32 & 94.09 \\
\hline $\begin{array}{c}\text { MTECH2 } \\
\text { (3\% MAF + Thick Die) }\end{array}$ & 89.97 & 84.47 & 82.37 & 89.49 & 94.72 & 89.95 & 90.66 & 91.57 & 89.79 & 89.91 & 92.19 & 89.04 & 90.25 & 90.93 & 91.07 & 89.41 & 96.36 \\
\hline Binder & 89.84 & 87.0 & 82.98 & 90.25 & $95.808^{\mathrm{a}}$ & 90.74 & $91.48^{\mathrm{a}}$ & 93.66 & 90.10 & 89.88 & $92.76^{\mathrm{a}}$ & $90.01^{\mathrm{a}}$ & $91.04^{\mathrm{a}}$ & $91.80^{\mathrm{a}}$ & $92.03^{\mathrm{a}}$ & 91.95 & 95.27 \\
\hline No Binder & 85.36 & 83.79 & 76.11 & 86.26 & $91.870^{\mathrm{b}}$ & 87.04 & $87.39^{\mathrm{b}}$ & 87.79 & 86.87 & 85.74 & $88.96^{\mathrm{b}}$ & $84.50^{\mathrm{b}}$ & $87.13^{\mathrm{b}}$ & $87.67^{\mathrm{b}}$ & $86.97^{\mathrm{b}}$ & 85.77 & 95.18 \\
\hline \multicolumn{18}{|c|}{ Main effect and interaction probabilities } \\
\hline MTECH & 0.1217 & 0.3997 & 0.2342 & 0.2109 & 0.2937 & 0.2038 & 0.5684 & 0.2038 & 0.1743 & 0.1202 & 0.1343 & 0.1087 & 0.2109 & 0.2271 & 0.1060 & 0.7102 & 0.1063 \\
\hline Binder & 0.1398 & 0.1542 & 0.1531 & 0.0543 & 0.0320 & 0.0457 & 0.0646 & 0.0457 & 0.1000 & 0.1257 & 0.0410 & 0.0205 & 0.0471 & 0.0498 & 0.0165 & 0.0531 & 0.9466 \\
\hline MTECH x Binder & 0.3821 & 0.0671 & 0.6120 & 0.0716 & 0.0441 & 0.0867 & 0.0831 & 0.0867 & 0.1295 & 0.3771 & 0.0926 & 0.2783 & 0.0582 & 0.0826 & 0.0388 & 0.5439 & 0.3812 \\
\hline $\mathrm{SEM}^{4}$ & 2.8201 & 2.0984 & 4.4788 & 1.8561 & 1.6045 & 1.8170 & 2.8602 & 1.8170 & 1.8026 & 2.5005 & 1.6440 & 2.0381 & 1.7507 & 1.8718 & 1.8054 & 2.8545 & 1.2929 \\
\hline
\end{tabular}

a-b Values within comparisons with different superscripts differ $(\mathrm{P}<0.05)$

${ }^{1}$ Determined with cecectomized roosters

${ }^{2}$ Binder: Lignosulfonate Pellet Binder Powder top dressed at 0.05\% inclusion: Binder 1 = lignosulfonate binder with proximate analysis of $12.4 \%$ Crude Protein, $13.8 \%$ Moisture, $0.97 \%$ Ash, $48 \%$ Acid detergent fiber, $50 \%$ Neutral detergent fiber; No Binder = no binder in diet

${ }^{3} \mathrm{MTECH}=$ Manufacture Technique; MTECH1: $1 \%$ mixer added fat (MAF) and Thin Pellet Die (38.10 x 4.76 mm); MTECH2: $3 \%$ MAF and Thick Pellet Die (44.96 x 4.76 mm)

${ }^{4}$ Standard Error of the Mean, an estimate of the amount that an obtained mean may be expected to differ by chance from the true mean 
CHAPTER 3: Assessment of diet formulation strategies that improve crumble quality

and poult performance

K.G.S. Wamsley ${ }^{*}$ and J.S. Moritz ${ }^{*}, 1$

* Division of Animal and Nutritional Sciences, West Virginia University, Morgantown 26506

Primary Audience: Feed Mill Managers, Nutritionists, Researchers, Production Managers

${ }^{1}$ Corresponding author: Joe.Moritz@mail.wvu.edu 


\section{SUMMARY}

Previous research at West Virginia University found that a lignosulfonate pellet binder (Binder) and 3\% mixer-added fat (MAF) maintains feed quality while improving amino acid digestibility using a rooster model. The current study examined the effect of commercial turkey starter diets varying in amino acid density (AAD) (Normal or High) and manufacturing technique (MTECH) (MTECH1-1\% MAF + 0.5\% Sand or MTECH2-3\% $\mathrm{MAF}+0.5 \%$ Binder) on commercial feed mill manufacture efficiency, D10-40 poult performance and broiler feed retention time. In Experiment 1, all diets were manufactured at a commercial feed mill and descriptive manufacture data was obtained demonstrating that MTECH2 maintained feed quality to that produced utilizing MTECH1. In addition, MTECH2 produced larger, more uniform crumbles. For Experiment 2, diets were randomly assigned to one of 16 pens containing 105 male 10-d-old Hybrid Convertor poults and fed until D40 at a facility designed to mimic commercial grow-out. Interactions demonstrated that the highest average poult weights were achieved when fed High AAD diets manufactured utilizing MTECH2. In Experiment 3, thirty-two pens containing five Cobb 500 chicks were randomly assigned one of four ground diets produced in Experiment $1+0.5 \%$ celite, an acid insoluble ash (AIA). Chicks fed diets utilizing MTECH2 excreted less AIA at 2, 4, 6, 10, 14, 22, and 28h post-AIA administration, demonstrating increased feed retention time. This study demonstrates that MTECH2 has benefit in commercial turkey feed manufacture and feeding.

Keywords: feed quality, turkey diets, mixer-added fat, lignosulfonate pellet binders 


\section{DESCRIPTION OF THE PROBLEM}

Previous research from West Virginia University using replicated data demonstrated that commercial lignosulfonate binder inclusion improved pellet quality; and when combined with 3\% MAF improved electrical energy use of the pellet mill and true amino acid digestibility [1]. The use of increased MAF has been shown in previous literature to assuage some of the negative effects that the pelleting process has on nutrient availability [1-4]. In addition, literature investigating the feeding value of commercial binders is dated [5-8]. Therefore, the current study was designed to investigate the efficacy of 3\% MAF+Binder using a commercial feed mill and a facility that mimics commercial grow-out to investigate modern day turkey poult performance. Other diet formulation strategies employed to improve poult performance include the manipulation of amino acid density. Increasing amino acid density in early phase diets may represent a low cost investment due to low feed volume consumption. The objectives of this study were to use $3 \% \mathrm{MAF}+$ Binder to improve both crumble quality and D10-39 poult performance (Experiment 1) and determine if observed 3\% MAF+Binder performance differences were associated with changes in feed retention time (using a broiler model; Experiment 2).

\section{MATERIALS AND METHODS}

Experiment 1: Feed Manufacture at Commercial Mill \& D10-40 Poult Performance

Feed Manufacture. Four dietary treatments were created in this Experiment, varying in amino acid density (AAD) (High or Low) and manufacturing technique (MTECH) (MTECH1-1\% MAF+Sand or MTECH2-3\% MAF+Binder). These diets were manufactured at a commercial feed mill [9] in the following order: 1) High AAD + 
MTECH1; 2) High AAD + MTECH2; 3) Normal AAD + MTECH1; and 4) Normal AAD

+ MTECH2. The lignosulfonate binder [10] was commercially available and included into all of the diets at $0.5 \%$; for diets not containing Binder, an inclusion of $0.5 \%$ sand was utilized. Diet formulations were proprietary; however, formulated to meet or exceed industry standards and analyzed for amino acids and other nutrients at a commercial laboratory [11] (Table 1). Diets contained corn, soybean meal, poultry by-product meal, wheat middlings, animal/vegetable blended fat, a commercial phytase, defluorinated phosphorus, and monocalcium phosphorus. Each batch size was 3.62 tonne and mixed in a 4.54 tonne capacity mixer, conditioned at $82.2^{\circ} \mathrm{C}$ for approximately $30 \mathrm{sec}$, and pelleted using 400 HP California Pellet Mill [12] equipped with a 4.37 x $28.58 \mathrm{~mm}$ effective thickness pellet die. The maximum production rate of the commercial mill was 52.63 tonne/hr. Descriptive data recorded at the commercial mill included: run order, pellet mill amperage, production rate, percent crumbles, average crumble particle size $[13,14]$ and uniformity of crumble size $[13,14]$.

Poult Performance. One-hundred and five 1d old male Hybrid Convertor [15] poults were placed on fresh wood shavings on concrete flooring in each of $16(6.1 \times 5.2 \mathrm{~m})$ pens throughout the West Virginia University Reymann Memorial Turkey Research Facility, which was designed to mimic commercial grow-out. The barn utilized tunnel ventilation and radiant brooders. Feed and water were provided for ad libitum consumption with bell drinkers and an augered feed pan system. In addition, each pen contained an automated bird and feed dump scale [16]. Temperature and lighting programs followed standard industry protocols [17]. All poults were fed a common diet from D1-10 and then one of four dietary treatments (Normal AAD or High AAD + MTECH1; Normal 
or High AAD + MTECH2) were randomly assigned to pen and fed from D10-39.

Automated poult and feed scales were calibrated routinely, and on D39 individual poult weights were manually obtained to confirm the automated bird scale accuracy. Measured performance variables included: D1 beginning pen weight, as well as D1-39 pen feed intake (FI), average poult weight, feed conversion ratio (FCR; corrected with mortality weight), and percent mortality. On D40, 25 poults per pen were randomly selected for boneless skinless breast extraction to determine average pectoralis major, pectoralis minor, total breast weight and breast yield. All poults utilized in this experiment were cared for in accordance to West Virginia University Animal Care and Use Committee Guidelines.

\section{Experiment 2: Feed Retention Time of Commercial Turkey Diets using a Broiler Model}

This experiment utilized the diets varying in AAD and MTECH manufactured in Experiment 1 and was conducted in order to explain observed poult performance differences. One hundred sixty, 1-d-old Cobb 500 [18] chicks were obtained from a commercial hatchery [19], placed into a common floor pen, and provided a pretest diet formulated to Cobb 500 starter recommendations for $7 \mathrm{~d}$. On D7, chicks were individually weighed and placed in one of five classes based on weight. One chick from each of the weight classes was randomly assigned to one of 32 raised wire cages to create the experimental unit.

The four dietary treatments created in Experiment 1 were ground via rollermill (to eliminate confounding effects of variations in feed form) and randomly assigned to pens and blocked by room location. Eight groups of four adjacently caged birds comprised blocks for a randomized complete block design. Chicks were given another $7 \mathrm{~d}$ to adapt to 
dietary treatment and raised wire cages, in which feed and water were provided ad libitum. Temperature and ventilation were monitored and altered to create optimal rearing conditions. Throughout the entire experiment, chicks were provided with $24 \mathrm{~h}$ of continuous light.

At the end of the adaptation period, chicks were feed restricted for $24 \mathrm{~h}$ then fed $450 \mathrm{~g} / \mathrm{cage}$ of the assigned experimental diets containing $0.5 \%$ celite [20], an acid insoluble ash (AIA). Feed was provided for $2 \mathrm{~h}$, then removed and weighed to determine feed intake. A diet without added AIA corresponding to diets assigned to each cage was fed upon removal of diets containing added AIA. Excreta collections began $2 \mathrm{~h}$ after providing diets containing $0.5 \%$ AIA and continued every $2 \mathrm{~h}$ for the following $14 \mathrm{~h}$, then every $6 \mathrm{~h}$ for the following $18 \mathrm{~h}$ post AIA administration. Feed samples were taken to determine the percentage of AIA in diets with and without added AIA. Collected excreta were analyzed for AIA using a $2 \mathrm{~N} \mathrm{HCl}$ method that involves ashing dried excreta prior to acid treatment and is described in further detail by Van Keulen and Young [21]. Acid insoluble ash measurements were corrected for AIA contained in diets without added AIA. Other measured variables included: D7 beginning average chick weight, D15 average chick weight, D7-14 feed intake, D7-14 feed conversion, D15 gizzard weights and feed intake of diets during AIA administration. All chicks utilized in this experiment were cared for in accordance to West Virginia University Animal Care and Use Committee Guidelines.

\section{Statistical Analysis}

In both Experiments 1 and 2, dietary treatments were randomly assigned to pens and blocked by location. Binder x MTECH factorial analyses were performed to explore 
main effects and interactions; multiple comparisons were also performed with treatment means further compared using Fisher's least significant difference test. In Experiment 2, AIA excretion was analyzed through ANOVA at each collection period. All data were statistically analyzed using the GLM procedure of Statistical Analysis System [22]. Alpha was designated as 0.05 and letter superscripts were used to denote differences among treatment means.

\section{RESULTS AND DISCUSSION}

\section{Experiment 1: Feed Manufacture at Commercial Mill \& D1-40 Poult Performance}

Feed Manufacture. Diet analyses shown in Table 1 demonstrate that diets formulated to High AAD were on average 4-12\% higher in AAD then diets formulated to be of Normal AAD. Diets were manufactured alternating MTECH. Descriptive data obtained at the commercial feed mill demonstrated an average decrease of pellet mill energy by $12.5 \%$ when diets were manufactured utilizing $3 \% \mathrm{MAF}+$ Binder (Table 2). In addition, these data suggest that using this manufacture strategy could maintain production rate, while still maintaining feed quality (percent crumbles) in diets containing similar AAD (Table 2). Furthermore, diets manufactured with 3\% MAF + Binder resulted in larger and more uniform crumble particles (Table 2).

The diets manufactured in this Experiment were starter diets, typically fed from D10-39. Past literature suggests that consistently feeding high quality crumbles is an important factor contributing to optimal poult health and performance [23]. Brooder phase performance has been indicated to be critical in overall grow-out success [23]. High quality feed in this period is thought to increase feed intake, thus facilitating improved 
nutrient intake and consequent absorption [23]. Diets of High AAD manufactured utilizing $3 \%$ MAF + Binder produced the largest and most uniform crumbles (Table 2).

Poult Performance. Beginning pen weights obtained on D1 were not statistically different ( $\mathrm{P}>0.05$; data not shown). Live performance variables for D1-39 are reported in Table 3. These data indicate that AAD and MTECH had no effect on D1-39 pen FI, FCR, or Percent Mortality (Table 3). A significant AAD x MTECH interaction ( $\mathrm{P}=0.0054$; Table 3) was observed for D39 average poult weights, demonstrating that poults fed High AAD manufactured utilizing 3\% MAF + Binder had the highest D39 weights.

Processing data obtained on D40 are summarized in Table 4. Significant differences were established for the main effect $\mathrm{AAD}$, demonstrating that poults fed High AAD diets had higher D40 average live poult weight (of 25 poults randomly chosen for extraction) $(\mathrm{P}=0.0443$; Table 4); perhaps indicating an unintentional selection bias. Thus, poults fed High AAD diets demonstrated increased average pectoralis major weight $(\mathrm{P}=$ 0.0211), and average total breast weight $(\mathrm{P}=0.0236)$. Additionally, main effect trends suggested that poults fed High AAD diets or diets manufactured utilizing 3\% MAF + Binder tended to have increased breast yield $(\mathrm{P}=0.0601$ and $\mathrm{P}=0.08$, respectively; Table 4).

Performance data observed in this experiment are in agreement with past literature [23] that poults receiving the highest quality crumbles would result in the best performance; since improved crumble quality was related to improved poult weight. However, amino acid density and lignosulfonate binder benefits beyond feed form likely also influenced performance. Past research utilizing various strategies to increase AAD of 
diets fed to poults during this same time period have found similar improved poult weights [24-26]. This research has also determined that continuing the same strategies throughout the remainder of the grow-out period resulted in no further performance benefit. It is important to note that feed form quality was not mentioned in any of the aforementioned studies.

\section{Experiment 2: Feed Retention Time of Commercial Turkey Diets using a Broiler Model}

There were no significant differences $(\mathrm{P}>0.05)$ observed for the following variables: beginning average chick weight, D15 average chick weight, D7-14 feed intake, D7-14 feed conversion, and D15 gizzard weights. Therefore, treatment means for these variables were not presented in this paper. Chicks fed diets utilizing 3\% MAF + Binder had greater feed intake $(\mathrm{P}=0.045$; Table 5$)$ during the $2 \mathrm{~h}$ presentation of diets containing $0.5 \%$ AIA, but also excreted less AIA at $2,4,6,10,14,22$, and $28 \mathrm{~h}$ post-AIA administration $(\mathrm{P}<0.05)$. The only significant $\mathrm{AAD}$ effect was established for the excreta collection occurring $22 \mathrm{~h}$ post-AIA administration, demonstrating that chicks excreted less AIA when fed High AAD (P = 0.0178; Table 5). Significant AAD x MTECH interactions were established for $8,12,16$, and 34 h post-AIA administration $(\mathrm{P}=0.0001,0.0459,0115$, and 0342, respectively; Table 5). These interactions demonstrated that the least AIA was excreted when chicks were fed diets manufactured utilizing 3\% MAF + Binder. Overall, these data suggest that $3 \% \mathrm{MAF}+$ Binder, especially when used to manufacture diets of High $\mathrm{AAD}$, increased retention time in the broiler gastrointestinal tract and could in part explain improved poult performance observed in Experiment 1 via greater time for nutrient digestion and absorption. It is important to note that all four diets were analyzed for crude 
fat content and found to be similar (Table 1), suggesting that despite variation in AAD and MTECH, total fat of diets likely did not contribute to changes in feed retention time.

\section{Commercially Available Binder Research}

Several peer-reviewed papers have documented the feeding value of commercially available pellet binders to broiler chickens and turkeys; however this research is dated. In general, literature on lignosulfonate binder effects on broiler chicken performance have not reported any benefit beyond feed form when fed at practical inclusions $(<3 \%)[5-7]$.

Research with turkeys utilizing bentonite binders speculated improved turkey performance due to slowed gastrointestinal transit time, allowing for enhanced nutrient digestion $[3,8]$. The current paper supports these speculations with the use of a lignosulfonate binder.

Lignosulfonate pellet binders have been shown to possess a metabolizable energy value of $2.3 \mathrm{kcal} / \mathrm{kg}$ [6] using a poultry model. In addition, their use has been shown to provide beneficial bacteria with substrate to improve gut health using a rat model [27]. Lignosulfonate binders have also been used to help stabilize emulsions [28]. In the current study, diets manufactured utilizing 3\% MAF + Binder could have greater fat emulsion and stability due to the shear force encountered within the pellet die. Research investigating the effect of digestion of fat varying in emulsion and droplet size using healthy human models determined no significant differences; however, eluded that a model with fat digestion impairment may benefit from decreased fat droplet sizes [29]. Literature suggests that poultry require approximately eight weeks to efficiently digest fat [30]; therefore, the authors speculate that in the current study, the combined use of 3\% MAF + Binder may 
have allowed poults to better digest fat, providing another possible explanation for observed poult performance differences.

\section{Future Direction}

Future research should investigate the effect of lignosulfonate binder inclusion with and without 3\% MAF on bird performance, true metabolizable energy, and fat digestibility. Binder inclusion and 3\% MAF effects were confounded in this study due to previous research from our laboratory [1] that found their combined use to have a practical application and to be beneficial to both feed manufacture and feeding; once again their combined use is verified and found to be beneficial in a commercial feed mill and in a facility mimicking commercial grow-out.

\section{CONCLUSIONS AND APPLICATIONS}

1. In a commercial feed mill, diets manufactured utilizing 3\% MAF + Binder reduced pellet mill electrical energy usage and resulted in larger and more uniform crumbles.

2. Although MAF and Binder effects are confounded, their combined use has practical application and has been shown to be beneficial to both commercial feed manufacture and feeding in a facility that mimics commercial grow-out.

3. Diets containing High AAD manufactured with 3\% MAF + Binder may enhance poult performance due to improved feed quality and associated benefits, increased feed retention time in the gastrointestinal tract, and perhaps improved fat digestibility. 


\section{ACKNOWLEDGEMENTS}

The authors would like to express their gratitude to Loyd Whetzel for his assistance with the daily care of poults. In addition, the support provided by Angela Lamp and Rush Holt was greatly appreciated during excreta collection periods.

\section{REFERENCES}

1. Wamsley, K. G. S. and J. S. Moritz. 2012. Resolving poor pellet quality and maintaining amino acid digestibility in commercial turkey diets. J. Appl. Poult. Res. Submitted.

2. Lilly, K. G. S., C. K. Gehring, K. R. Beaman, P. J. Turk, M. Sperow, and J. S. Moritz. 2011. Examining the relationships between pellet quality, broiler performance, and bird sex. J. Appl. Poult. Res. 20:231-239.

3. Gehring, C. K., K. G. S. Lilly, L. K. Worley, K. R. Beaman, S. A. Loop, and J. S. Moritz. 2011. Increasing mixer-added fat improves exogenous enzyme efficacy and broiler performance. J. Appl. Poult. Res. 20:75-89.

4. Salmon, R.E. 1985. Effects of pelleting, added sodium bentonite and fat in a wheatbased diet on performance and carcass characteristics of small white turkeys. Anim. Feed Sci. Technol. 12:223-232.

5. Acar, N., E. T. Moran, W. H, Revington, and S. F. Bilgili. 1991. Effect of improved pellet quality from using a calcium lignosulfonate binder on performance and carcass yield of broilers reared under different marketing schemes. Poult. Sci. 70: 1339-1344.

6. Morrison, H. L., P. W. Waldroup, D. E. Greene, and E. L. Stephenson. 1968. Determination of the metabolizable energy and feeding value of a lignin sulfonate pellet binder. Poul. Sci. 47: 592-597.

7. Proudfoot, F. G., H. W. Hulan, and W. F. DeWitt. 1979. Effects of using 0, 1.0, 1.5, and $2.0 \%$ 'Lignosol FG' as a pellet binder in broiler chick finisher diets. Poult. Sci. 58:87-89.

8. Almquist, H. J., H. L. Christensen, and S. Maurer. 1967. The effect of bentonites on nutrient retention by turkeys. Feedstuffs. 30(20):54.

9. Virginia Poultry Growers Cooperative Feed mill, Broadway, VA

10.Pell-Tuff, Cra-Vac Industries Inc., Toronto, ON Canada.

11. Experiment Station Chemical Laboratories, Agricultural Experiment Station, Univ. Missouri, Columbia, MO.

12. California Pellet Mill Company (CPM), Crawfordsville, IN.

13. Ro-Tap particle size analyzer model RX-29 type $110 \mathrm{~V} 60 \mathrm{H} 2$, WS Tyler, Mentor, $\mathrm{OH}$. One hundred grams of ground corn for each diet was placed in a dust-tight enclosed series of stacked (No. 4, 6, ..) American Society for Testing and Materials (ASTM) screens affixed to the Ro-Tap particle size analyzer and shaken for $10 \mathrm{~min}$. The screens were then separated and weighed. Particle size was calculated by subtracting the weight of the screen from the final weight of screen 
and sample after shaking. The mean geometric particle size and log normal geometric standard deviation were calculated as described by McEllhiney [14].

14. McEllhiney, R. R. 1994. Determining and expressing particle size. Pages 545-547 in Feed Manufacture Technology IV. American Feed Industry Association, Inc., Arlington, VA.

15. Hybrid Converter, Kitchener, ON, CANADA.

16. Chore-Time Brock Incorporated, Milford, IN

17. Virginia Poultry Growers Cooperative, 2011.

18. Cobb-Vantress, Siloam Springs, AR.

19. Pilgrim's Pride, Moorefield, WV.

20. Celite Corporation, Lompac, CA.

21. Van Keulen, J. and B. A. Young. 1977. Evaluation of Acid-Insoluble Ash as a Natural Marker in Ruminant Digestibility Studies. J Anim Sci. 44:282-287.

22. SAS Institute. 2009. The SAS System for Windows 2009. Release 9.2. SAS Inst. Inc., Cary, NC.

23. Mitchell, R. 2002. Opportunities for improving poult performance with feed. Pages 1-9 in Proc. Multi-State Poultry Meeting. Indianapolis, IN. Purdue University.

24. Noy, J. and D. Sklan. 2004. Effects of metabolizable energy and amino acid levels on turkey performance from hatch to marketing. J. Appl. Poult. Res. 13:241-252.

25. Lemme, A, U. Frackenpohl, A. Petri, and H. Meyer. 2006. Response of male BUT big 6 turkeys to varying amino acid feeding programs. Poult. Sci. 85:652-660.

26. Applegate, T., W. Powers, R. Angel, D. Hoehler. 2008. Effect of amino acid formulation and amino acid supplementation on performance and nitrogen excretion in turkey toms. Poult Sci. 87:514-520.

27. Flickinger, E. A., J. M. Campbell, L. G. Schmitt and G. C. Fahey, Jr. 1998. Selected lignosulfonate fractions affect growth performance, digestibility, and cecal and colonic properties in rats. J. Anim. Sci. 76:1626-1635.

28. Borregaard LignoTech. Functionalities. Accessed June 30, 2012. http://www.lignotech.com/Functionalities.

29. Armand, M., B. Pasquier, M. Andre, P. Borel, M. Senft, J. Peyrot, J. Salducci, H. Portugal, V. Jaussan, and D. Lairon. 1999. Digestion and absorption of 2 fat emulsions with different droplet sizes in the human digestive tract. Am. J. Clin. Nutr. 70:1096-1106.

30. Krogdahl, A. 1985. Digestion and absorption of lipids in poultry. J. Nutr. 115:675685. 
Table 1. Nutrient profiles of diets utilized in both Experiments 1 and 2

\begin{tabular}{|c|c|c|c|c|}
\hline $\begin{array}{l}\text { Analyzed Feed } \\
\text { Nutrient }^{1}\end{array}$ & $\begin{array}{c}\text { Average of } \\
\text { Normal AAD } \\
\text { Diets }(\%)^{2}\end{array}$ & $\begin{array}{l}\text { Average of } \\
\text { High AAD } \\
\text { Diets }(\%)^{3}\end{array}$ & \multicolumn{2}{|c|}{$\begin{array}{c}\text { Average Nutrient Percent } \\
\text { Increases Between Normal and } \\
\text { High AAD Diets }(\%)^{4}\end{array}$} \\
\hline Threonine & 0.98 & 1.04 & \multicolumn{2}{|c|}{6.12} \\
\hline Proline & 1.50 & 1.63 & \multicolumn{2}{|c|}{8.67} \\
\hline Alanine & 1.28 & 1.34 & \multicolumn{2}{|c|}{4.69} \\
\hline Valine & 1.38 & 1.47 & \multicolumn{2}{|c|}{6.52} \\
\hline Methionine & 0.39 & 0.42 & \multicolumn{2}{|c|}{7.69} \\
\hline Cysteine & 0.46 & 0.47 & \multicolumn{2}{|c|}{2.17} \\
\hline Isoleucine & 1.09 & 1.22 & \multicolumn{2}{|c|}{11.93} \\
\hline Leucine & 1.96 & 2.17 & \multicolumn{2}{|c|}{10.71} \\
\hline Lysine & 1.61 & 1.75 & \multicolumn{2}{|c|}{8.70} \\
\hline Crude Protein $^{5}$ & 27.67 & 29.32 & \multicolumn{2}{|c|}{5.96} \\
\hline Crude Fat ${ }^{6}$ & 8.85 & 9.07 & \multicolumn{2}{|c|}{2.49} \\
\hline Crude Fiber $^{7}$ & 1.99 & 2.01 & \multicolumn{2}{|c|}{1.01} \\
\hline $\mathrm{Ash}^{8}$ & 7.74 & 7.54 & \multicolumn{2}{|c|}{-2.58} \\
\hline & $\begin{array}{c}\text { Normal AAD } \\
1 \% \mathrm{MAF}+ \\
\text { Sand }(\%)^{9}\end{array}$ & $\begin{array}{l}\text { High AAD } \\
1 \% \text { MAF }+ \\
\text { Sand }(\%)^{10}\end{array}$ & $\begin{array}{c}\text { Normal AAD } \\
3 \% \mathrm{MAF}+ \\
\text { Binder }(\%)^{11}\end{array}$ & $\begin{array}{l}\text { High AAD } \\
3 \% \mathrm{MAF}+ \\
\text { Binder }(\%)^{12}\end{array}$ \\
\hline Crude Protein $^{5}$ & 28.68 & 29.55 & 26.65 & 29.08 \\
\hline Crude Fat ${ }^{6}$ & 8.94 & 8.77 & 8.75 & 9.37 \\
\hline Crude Fiber ${ }^{7}$ & 2.02 & 2.07 & 1.96 & 1.94 \\
\hline $\operatorname{Ash}^{8}$ & 7.89 & 7.27 & 7.58 & 7.81 \\
\hline
\end{tabular}

${ }^{1}$ Feed samples were analyzed at University of Missouri Experiment Station Columbia, Analytical Services [6]; Amino acids were analyzed using JAOAC 70:171-174, 1987

${ }^{2}$ Average Amino Acid Density (AAD) of diets formulated to normal amino acid density and manufactured utilizing $1 \%$ mixer added fat and $0.5 \%$ sand (to replace binder) and diets formulated to normal amino acid density and manufactured utilizing $3 \%$ mixer added fat and $0.5 \%$ lignosulfonate binder

${ }^{3}$ Diet formulated to higher than normal amino acid density and manufactured utilizing $1 \%$ mixer added fat and $0.5 \%$ sand (to replace binder) and diets formulated to higher than normal amino acid density and manufactured utilizing $3 \%$ mixer added fat and $0.5 \%$ lignosulfonate binder

${ }^{4}$ The average percent increase of amino acids between diets formulated to have normal amino acid densities and those formulated to have higher than normal amino acid densities

${ }^{5}$ Crude protein was determined by Kjeldahl, AOAC Official Method 984.13 (A-D), 2006 Standard report of 'crude protein' utilizes the calculation: $6.25 \times$ Nitrogen value

${ }^{6}$ Crude Fat was determined via Acid Hydrolysis, AOAC Official Method 954.02, 2006

${ }^{7}$ Crude Fiber was determined with AOAC Official Method 978.10, 2006

${ }^{8}$ Ash was determined using AOAC Official Method 942.05

${ }^{9}$ Diet formulated to normal amino acid density and manufactured utilizing $1 \%$ mixer added fat and $0.5 \%$ sand (to replace binder)

${ }^{10}$ Diet formulated to higher than normal amino acid density and manufactured utilizing $1 \%$ mixer added fat and $0.5 \%$ sand (to replace binder)

${ }^{11}$ Diet formulated to normal amino acid density and manufactured utilizing 3\% mixer added fat and $0.5 \%$ lignosulfonate binder

${ }^{12}$ Diet formulated to higher than normal amino acid density and manufactured utilizing $3 \%$ mixer added fat and $0.5 \%$ lignosulfonate binder 
Table 2. The effect of amino acid density (AAD) and manufacturing technique (MTECH) on feed manufacture variable at a commercial feed mill (Experiment 1 descriptive data)

\begin{tabular}{|c|c|c|c|c|c|c|c|}
\hline $\begin{array}{c}\text { Treatment: } \\
\text { AAD } \\
\text { MTECH }\end{array}$ & $\begin{array}{l}\text { Run } \\
\text { order }^{5}\end{array}$ & $\begin{array}{l}\text { Post- } \\
\text { pellet } \\
\text { Fat }^{6} \\
(\%)\end{array}$ & $\begin{array}{c}\text { Pellet } \\
\text { Mill } \\
\text { Energy }^{7} \\
\text { (amps) }\end{array}$ & $\begin{array}{c}\text { Total } \\
\text { Production } \text { Rate }^{8} \\
\text { (tonne } / \mathrm{hr} \text { ) }\end{array}$ & $\begin{array}{c}\text { Crumbles }^{9} \\
(\%)\end{array}$ & $\begin{array}{l}\text { Average } \\
\text { Crumble } \\
\text { Particle } \\
\text { Size }^{10} \\
\text { (micron) }\end{array}$ & $\begin{array}{c}\text { Standard } \\
\text { Deviation of } \\
\text { Average } \\
\text { Crumble } \\
\text { Particle Size }\end{array}$ \\
\hline $\begin{array}{l}\text { Normal AAD } \\
1 \% \text { MAF + Sand }\end{array}$ & 3 & 6.05 & 300 & 39.74 & 44.47 & 1783 & 2.32 \\
\hline $\begin{array}{c}\text { High AAD } \\
1 \% \text { MAF + Sand }\end{array}$ & 1 & 6.50 & 300 & 34.61 & 40.74 & 1898 & 2.13 \\
\hline $\begin{array}{c}\text { Normal AAD } \\
3 \% \text { MAF + Binder }\end{array}$ & 4 & 4.05 & 260 & 42.75 & 41.98 & 2288 & 2.02 \\
\hline $\begin{array}{c}\text { High AAD } \\
3 \% \text { MAF + Binder }\end{array}$ & 2 & 4.50 & 265 & 35.03 & 38.13 & 2556 & 1.95 \\
\hline
\end{tabular}

${ }^{1}$ Diet formulated to normal amino acid density and manufactured utilizing $1 \%$ mixer added fat and $0.5 \%$ sand (to replace binder)

${ }^{2}$ Diet formulated to higher than normal amino acid density and manufactured utilizing $1 \%$ mixer added fat and $0.5 \%$ sand (to replace binder)

${ }^{3}$ Diet formulated to normal amino acid density and manufactured utilizing $3 \%$ mixer added fat and $0.5 \%$ lignosulfonate binder

${ }^{4}$ Diet formulated to higher than normal amino acid density and manufactured utilizing 3\% mixer added fat and $0.5 \%$ lignosulfonate binder

${ }^{5}$ Order in which treatments were pelleted at commercial feed mill

${ }^{6}$ Percent fat added during post-pellet fat application

${ }^{7}$ Pellet mill energy was obtained in control room after pellet mill operator reached steady conditioning temperature

${ }^{8}$ Total production rate was obtained from the pellet mill operator as a print-off from the computer

${ }^{9}$ An approximate five pound sample was obtained after pellet cooler and prior to post-pellet fat application; therefore, samples either contained 1 or $3 \%$ fat. Percent fines were determined by sifting pellets utilizing a No.6 American Society Testing and Materials (ASTM) screen before deposited into a Pfost tumbler.

${ }^{10}$ Particle size was determined with a Ro-Tap particle size analyzer $[8,9]$ 
Table 3. The effect of amino acid density (AAD) and manufacturing technique (MTECH) on D1-39 performance data of Hybrid Convertor poults (Experiment 1)

\begin{tabular}{|c|c|c|c|c|}
\hline $\begin{array}{c}\text { Treatment: } \\
\text { AAD } \\
\text { MTECH }\end{array}$ & $\begin{array}{l}\text { D1-39 Pen } \\
\text { Feed Intake } \\
\quad(\mathrm{kg})\end{array}$ & $\begin{array}{c}\text { D39 } \\
\text { Average } \\
\text { Poult } \\
\text { Weight }{ }^{1} \\
(\mathrm{~kg})\end{array}$ & $\begin{array}{c}\text { D1-39 } \\
\text { Feed } \\
\text { Conversion } \\
\text { Ratio }^{2}\end{array}$ & $\begin{array}{c}\text { D1-39 } \\
\text { \% Mortality }\end{array}$ \\
\hline $\begin{array}{c}\text { Normal AAD } \\
1 \% \text { MAF + Sand }\end{array}$ & 316.3 & $2.27^{\mathrm{b}}$ & 1.36 & 2.62 \\
\hline $\begin{array}{c}\text { High AAD } \\
1 \% \text { MAF + Sand }\end{array}$ & 316.3 & $2.29^{\mathrm{b}}$ & 1.37 & 1.69 \\
\hline $\begin{array}{c}\text { Normal AAD } \\
3 \% \text { MAF + Binder }\end{array}$ & 316.2 & $2.22^{\mathrm{c}}$ & 1.39 & 2.34 \\
\hline $\begin{array}{c}\text { High AAD } \\
3 \% \text { MAF + Binder }\end{array}$ & 320.3 & $2.33^{\mathrm{a}}$ & 1.35 & 2.62 \\
\hline Fisher's LSD ${ }^{7}$ & - & 0.0432 & - & - \\
\hline ANOVA P-Value & 0.8821 & 0.0017 & 0.5522 & 0.6226 \\
\hline $\mathrm{SEM}^{8}$ & 4.381 & 0.0135 & 0.0209 & 0.5620 \\
\hline \multicolumn{5}{|c|}{ Marginal Means } \\
\hline Normal AAD & 316.3 & $2.25^{\mathrm{b}}$ & 1.38 & 2.48 \\
\hline High AAD & 318.3 & $2.31^{\mathrm{a}}$ & 1.36 & 2.15 \\
\hline $1 \%$ MAF + Sand & 316.3 & 2.28 & 1.37 & 2.15 \\
\hline $3 \%$ MAF + Binder & 318.3 & 2.28 & 1.37 & 2.48 \\
\hline \multicolumn{5}{|c|}{ Main effect and interaction probabilities } \\
\hline AAD & 0.6512 & 0.0010 & 0.4772 & 0.5735 \\
\hline MTECH & 0.6659 & 0.8820 & 0.9657 & 0.5735 \\
\hline AAD x MTECH & 0.6406 & 0.0054 & 0.2270 & 0.3093 \\
\hline
\end{tabular}

${ }^{1}$ Average weight obtained from manually weighing each poult

${ }^{2}$ Feed conversion ratio (Feed:Gain) was calculated using mortality weight

${ }^{3}$ Diet formulated to normal amino acid density and manufactured utilizing $1 \%$ mixer added fat and $0.5 \%$ sand (to replace binder)

${ }^{4}$ Diet formulated to be higher than normal amino acid density and manufactured utilizing $1 \%$ mixer added fat and $0.5 \%$ sand (to replace binder)

${ }^{5}$ Diet formulated to normal amino acid density and manufactured utilizing $3 \%$ mixer added fat and $0.5 \%$ lignosulfonate binder

${ }^{6}$ Diet formulated to be higher than normal amino acid density and manufactured utilizing $3 \%$ mixer added fat and $0.5 \%$ lignosulfonate binder

${ }^{7}$ Fisher's Least Significant Difference multiple comparison test value

${ }^{8}$ Standard Error of the Mean

${ }^{\mathrm{a}-\mathrm{b}}$ Values within columns with different superscripts differ significantly $(\mathrm{P}<0.05)$ 
Table 4. The effect of amino acid density (AAD) and manufacturing technique (MTECH) on D40 breast extraction data from 25 randomly selected Hybrid poults per pen (Experiment 1)

\begin{tabular}{|c|c|c|c|c|c|}
\hline $\begin{array}{c}\text { Treatment: } \\
\text { AAD } \\
\text { MTECH }\end{array}$ & $\begin{array}{l}\text { D40 Avg. Live } \\
\text { Poult Wt for } \\
\text { Extraction }{ }^{1} \\
(\mathrm{~kg}) \\
\mathrm{n}=25\end{array}$ & $\begin{array}{c}\text { D40 } \\
\text { Average } \\
\text { Pectoralis } \\
\text { Major } \\
\text { Weight (kg) }\end{array}$ & $\begin{array}{c}\text { D40 } \\
\text { Average } \\
\text { Pectoralis } \\
\text { Minor } \\
\text { Weight }(\mathrm{kg})\end{array}$ & $\begin{array}{c}\text { D40 } \\
\text { Average } \\
\text { Total } \\
\text { Breast } \\
\text { Weight }^{2} \\
(\mathrm{~kg})\end{array}$ & $\begin{array}{c}\text { D40 } \\
\text { Average } \\
\text { Breast } \\
\text { Yield }^{3} \\
(\%) \\
\end{array}$ \\
\hline $\begin{array}{c}\text { Normal AAD } \\
1 \% \text { MAF + Sand } \\
\end{array}$ & 2.404 & 0.2615 & 0.0671 & 0.3286 & 13.66 \\
\hline $\begin{array}{c}\text { High AAD } \\
1 \% \text { MAF + Sand } \\
\end{array}$ & 2.451 & 0.2734 & 0.0698 & 0.3433 & 14.02 \\
\hline $\begin{array}{c}\text { Normal AAD } \\
3 \% \text { MAF + Binder }\end{array}$ & 2.363 & 0.2618 & 0.0690 & 0.3308 & 13.99 \\
\hline $\begin{array}{c}\text { High AAD } \\
3 \% \text { MAF + Binder }\end{array}$ & 2.482 & 0.2813 & 0.0708 & 0.3521 & 14.21 \\
\hline Fisher's LSD ${ }^{8}$ & - & - & - & - & - \\
\hline ANOVA P-Value & 0.1628 & 0.0927 & 0.3051 & 0.1021 & 0.0979 \\
\hline SEM $^{9}$ & 0.0355 & 0.0056 & 0.0013 & 0.0066 & 0.1350 \\
\hline \multicolumn{6}{|c|}{ Marginal Means } \\
\hline Normal AAD & $2.384^{\mathrm{b}}$ & $0.2616^{\mathrm{b}}$ & 0.0681 & $0.3297^{\mathrm{b}}$ & 13.82 \\
\hline High AAD & $2.466^{\mathrm{a}}$ & $0.2774^{\mathrm{a}}$ & 0.0703 & $0.3477^{\mathrm{a}}$ & 14.11 \\
\hline $1 \%$ MAF + Sand & 2.427 & 0.2674 & 0.0685 & 0.3359 & 13.84 \\
\hline $3 \% \mathrm{MAF}+$ Binder & 2.422 & 0.2716 & 0.0700 & 0.3415 & 14.10 \\
\hline \multicolumn{6}{|c|}{ Main effect and interaction probabilities } \\
\hline AAD & 0.0443 & 0.0211 & 0.1247 & 0.0236 & 0.0601 \\
\hline MTECH & 0.8964 & 0.4845 & 0.3030 & 0.4216 & 0.0875 \\
\hline AAD x MTECH & 0.3425 & 0.5177 & 0.7173 & 0.6298 & 0.6424 \\
\hline
\end{tabular}

${ }^{1}$ Average weight of 25 poults randomly selected from each pen for breast extraction (4 pens/treatment)

${ }^{2}$ Average total breast weight (pectoralis major + minor) from each of the 25 poults randomly selected from each pen

${ }^{3}$ Average total breast weight for a pen divided by the average weight of poults selected from that particular pen

${ }^{4}$ Diet formulated to normal amino acid density and manufactured utilizing $1 \%$ mixer added fat and $0.5 \%$ sand (to replace binder)

${ }^{5}$ Diet formulated to be higher than normal amino acid density and manufactured utilizing $1 \%$ mixer added fat and $0.5 \%$ sand (to replace binder)

${ }^{6}$ Diet formulated to normal amino acid density and manufactured utilizing $3 \%$ mixer added fat and $0.5 \%$ lignosulfonate binder

${ }^{7}$ Diet formulated to be higher than normal amino acid density and manufactured utilizing 3\% mixer added fat and $0.5 \%$ lignosulfonate binder

${ }^{8}$ Fisher's Least Significant Difference

${ }^{9}$ Standard Error of the Mean, an estimate of the amount that an obtained mean may be expected to differ by chance from the true mean.

${ }^{a-b}$ Values within columns with different superscripts differ significantly $(\mathrm{P}<0.05)$ 
Table 5. Influence of amino acid density (AAD) and manufacture technique (MTECH) on Cobb 500 feed retention time ${ }^{1}$ as determined by percentage of acid insoluble ash (AIA) (Experiment 2)

\begin{tabular}{|c|c|c|c|c|c|c|c|c|c|c|c|c|}
\hline \multirow{2}{*}{$\begin{array}{r}\text { Treatment: AAD } \\
\text { MTECH }\end{array}$} & \multirow{2}{*}{$\begin{array}{l}\text { Feed Intake }{ }^{2} \\
(\mathrm{~g})\end{array}$} & \multicolumn{11}{|c|}{ Excreta collection times post-AIA administration and average grams of AIA excreted per bird ${ }^{3}$} \\
\hline & & Hour 2 & Hour 4 & Hour 6 & Hour 8 & Hour 10 & Hour 12 & Hour 14 & Hour 16 & Hour 22 & Hour 28 & Hour 34 \\
\hline $\begin{array}{c}\text { Normal AAD } \\
1 \% \text { MAF + Sand }\end{array}$ & 51.04 & 0.039 & $0.137^{\mathrm{a}}$ & $0.140^{\mathrm{a}}$ & $0.115^{\mathrm{a}}$ & $0.100^{\mathrm{a}}$ & $0.108^{\mathrm{a}}$ & $0.084^{\mathrm{a}}$ & $0.091^{\mathrm{a}}$ & $0.310^{\mathrm{a}}$ & $0.334^{\mathrm{a}}$ & $0.365^{\mathrm{a}}$ \\
\hline $\begin{array}{c}\text { High AAD } \\
1 \% \text { MAF + Sand }\end{array}$ & 53.31 & 0.048 & $0.128^{\mathrm{ab}}$ & $0.114^{\mathrm{b}}$ & $0.077^{\mathrm{b}}$ & $0.083^{\mathrm{b}}$ & $0.085^{\mathrm{b}}$ & $0.080^{\mathrm{a}}$ & $0.065^{\mathrm{b}}$ & $0.250^{\mathrm{b}}$ & $0.270^{\mathrm{ab}}$ & $0.284^{\mathrm{b}}$ \\
\hline $\begin{array}{c}\text { Normal AAD } \\
3 \% \text { MAF + Binder }\end{array}$ & 57.85 & 0.032 & $0.102^{\mathrm{bc}}$ & $0.083^{\mathrm{c}}$ & $0.061^{\mathrm{c}}$ & $0.055^{\mathrm{c}}$ & $0.053^{\mathrm{c}}$ & $0.048^{\mathrm{b}}$ & $0.042^{\mathrm{c}}$ & $0.174^{\mathrm{c}}$ & $0.185^{\mathrm{c}}$ & $0.158^{\mathrm{c}}$ \\
\hline $\begin{array}{c}\text { High AAD } \\
3 \% \text { MAF + Binder }\end{array}$ & 59.55 & 0.034 & $0.090^{\mathrm{c}}$ & $0.082^{\mathrm{c}}$ & $0.061^{\mathrm{c}}$ & $0.052^{\mathrm{c}}$ & $0.048^{\mathrm{c}}$ & $0.042^{\mathrm{b}}$ & $0.036^{\mathrm{c}}$ & $0.133^{\mathrm{c}}$ & $0.205^{\mathrm{bc}}$ & $0.149^{\mathrm{c}}$ \\
\hline Fisher's LSD ${ }^{8}$ & - & - & 0.0325 & 0.0221 & 0.0118 & 0.0146 & 0.0123 & 0.012 & 0.0102 & 0.0576 & 0.0762 & 0.0466 \\
\hline ANOVA P-Value & 0.2053 & 0.0546 & 0.0226 & 0.0001 & 0.0001 & 0.0001 & 0.0001 & 0.0001 & 0.0001 & 0.0001 & 0.0022 & 0.0001 \\
\hline SEM $^{9}$ & 3.055 & 0.004 & 0.0110 & 0.0075 & 0.004 & 0.005 & 0.004 & 0.004 & 0.0035 & 0.020 & 0.026 & 0.0158 \\
\hline \multicolumn{13}{|c|}{ Marginal Means } \\
\hline Normal AAD & 54.45 & 0.035 & 0.120 & 0.111 & $0.088^{\mathrm{a}}$ & 0.077 & $0.081^{\mathrm{a}}$ & 0.066 & $0.067^{\mathrm{a}}$ & $0.242^{\mathrm{a}}$ & 0.260 & $0.261^{\mathrm{a}}$ \\
\hline High AAD & 56.43 & 0.041 & 0.109 & 0.098 & $0.069^{b}$ & 0.067 & $0.066^{\mathrm{b}}$ & 0.061 & $0.050^{\mathrm{b}}$ & $0.192^{\mathrm{b}}$ & 0.238 & $0.217^{\mathrm{b}}$ \\
\hline $1 \% \mathrm{MAF}+$ Sand & $52.18^{\mathrm{b}}$ & $0.043^{\mathrm{a}}$ & $0.132^{\mathrm{a}}$ & $0.127^{\mathrm{a}}$ & $0.096^{\mathrm{a}}$ & $0.091^{\mathrm{a}}$ & $0.097^{\mathrm{a}}$ & $0.082^{\mathrm{a}}$ & $0.078^{\mathrm{a}}$ & $0.280^{\mathrm{a}}$ & $0.302^{\mathrm{a}}$ & $0.324^{\mathrm{a}}$ \\
\hline $3 \%$ MAF + Binder & $58.70^{\mathrm{a}}$ & $0.033^{\mathrm{b}}$ & $0.096^{\mathrm{b}}$ & $0.083^{\mathrm{b}}$ & $0.061^{\mathrm{b}}$ & $0.053^{\mathrm{b}}$ & $0.051^{\mathrm{b}}$ & $0.045^{\mathrm{b}}$ & $0.039^{\mathrm{b}}$ & $0.154^{\mathrm{b}}$ & $0.195^{\mathrm{b}}$ & $0.153^{\mathrm{b}}$ \\
\hline \multicolumn{13}{|c|}{ Main effect and interaction probabilities } \\
\hline AAD & 0.5229 & 0.1766 & 0.3542 & 0.0892 & 0.0001 & 0.0649 & 0.002 & 0.2251 & 0.0001 & 0.0178 & 0.4025 & 0.0108 \\
\hline MTECH & 0.0447 & 0.0195 & 0.0034 & 0.0001 & 0.0001 & 0.0001 & 0.0001 & 0.0001 & 0.0001 & 0.0001 & 0.0005 & 0.0001 \\
\hline AAD x MTECH & 0.9269 & 0.4501 & 0.8420 & 0.1105 & 0.0001 & 0.1702 & 0.0459 & 0.9239 & 0.0115 & 0.6391 & 0.1189 & 0.0342 \\
\hline
\end{tabular}

${ }^{1}$ Retention time is reported at the hour of collection as grams of AIA excreted per bird, corrected for the percentage of AIA in the diet [15,16

${ }^{2}$ Pen feed intake of diets containing $0.5 \%$ AIA

Grams of AIA present in excreta resulting after $2 \mathrm{~h}$ presentation of diets containing $0.5 \%$ AIA, followed by the presentation of corresponding diets without added $0.5 \%$ AIA

${ }^{4}$ Diet formulated to normal amino acid density and manufactured utilizing $1 \%$ mixer added fat and $0.5 \%$ sand (to replace binder)

${ }^{5}$ Diet formulated to higher than normal amino acid density and manufactured utilizing $1 \%$ mixer added fat and $0.5 \%$ sand (to replace binder)

Diet formulated to normal amino acid density and manufactured utilizing 3\% mixer added fat and $0.5 \%$ lignosulfonate binder

Diet formulated to higher than normal amino acid density and manufactured utilizing $3 \%$ mixer added fat and $0.5 \%$ lignosulfonate binder

${ }^{8}$ Fisher's Least Significant Difference

Standard Error of the Mean, an estimate of the amount that an obtained mean may be expected to differ by chance from the true mean.

${ }^{a-b}$ Values within columns with different superscripts differ significantly $(\mathrm{P}<0.05)$ 

performance using feed produced at a commercial mill

K. G. S. Wamsley and J. S. Moritz ${ }^{*} 1$

* Division of Animal and Nutritional Sciences, West Virginia University, Morgantown 26506

Primary Audience: Feed Mill Managers, Nutritionists, Researchers, Production Managers

${ }^{1}$ Corresponding author: Joe.Moritz@mail.wvu.edu 


\section{SUMMARY}

The brooder phase (D1-42) is crucial to overall turkey performance and many integrators believe that the utilization of Yeast Products (YP) is cost effective. Pellet quality is crucial to grower/finisher phase production (D42-118) due to feed form advantages during this period of high volume consumption. In addition, feed and feed manufacture represent the largest investment required to produce poultry. The objective of this study was to establish the effects of YP (YP1 or YP2) inclusion on D1-42 poult performance. Then on D42, a 2 YP Carryover x 2 Feed Form (intact high quality pellets (HQP) or ground pellets (GP)) factorial design was implemented to measure main effects and interactions on D1-118 tom performance. All diets were of similar nutritional composition (other than YP) and manufactured at a commercial feed mill. Feed Form variations were made by feeding either intact HQP (average of 21.4\% fines) or ground HQP (GP) (average particle size of 1108 micron). Male Hybrid Converters were fed these diets at a facility that mimicked commercial grow-out. On D42, YP1 improved ending weight (EW) and feed conversion ratio (FCR). No YP Carryover effect was demonstrated for any of the D42-118 performance variables. Feeding HQP produced toms that were $0.29 \mathrm{~kg} / \mathrm{bird}$ heavier with 9 points lower FCR, as compared to toms fed GP. Regression analyses predicted that if toms fed GP finished at the same D118 EW as those fed HQP, then FCR advantages of HQP would be 12 points.

Keywords: Yeast Products, feed form, turkey performance 


\section{DESCRIPTION OF THE PROBLEM}

Literature suggests that optimal brooder phase performance (D1-42) is vital to ensure turkeys finish to their full genetic potential [1]. Attaining optimal gut health early through the implementation of Yeast Products (YP), derived from Saccharomyces cerevisiae, can be one strategy employed to improve brooder phase performance. These products have been shown to improve breast yield [2-4] and feed conversion ratio [2, 5]; in addition to improving gut health using a challenged bird model $[6,7]$. Some integrators are committed to the use of YP to alleviate potential brooder phase challenges. Therefore, the first objective of the current study was to determine which of two commercially available YP performed best in the brooder phase at a research facility that mimicked commercial production. In addition, YP were assessed for their carryover effects throughout production (D42-118).

Feed and feed manufacture represent a continual investment required by an integrator in a commercial poultry operation. Despite the significant cost to production, benefits of feeding pellets to poultry have been documented throughout the literature [8-22]. However, attaining high quality pellets in an integrated poultry system is difficult due to the necessity for high feed throughput to meet volume requirements. When feed throughput is increased, feed retention time within the pellet die is decreased, consequently reducing fictional heat necessary for reactions such as starch gelatinization and protein denaturation, thus decreasing pellet quality [22, 23]. Slowing production rate is an obvious but costly solution to improving pellet quality; however, strategies must be carefully implemented in order to maintain minimal feed volume requirements. Therefore, if an integrated company commits to producing high quality pellets then benefits to that company must be clear to justify the investment. 
Recently, the importance of feeding high quality pellets to modern Cobb 500 broiler chickens has been identified by Lilly and cohorts [22]. These authors reported the greatest feeding benefit to ending weight (EW), rather than feed conversion ratio (FCR), a variable often reported to be improved in older genotypes $[9,15,21]$. In general, research describing the relationship of high quality pellets and turkey performance has demonstrated that feeding pellets improves EW and FCR [8, 10-12]. Some of the most recent research was conducted in 1997, and provided conflicting results as to the specific performance variable that was improved $[17,18]$. Therefore, the second objective of the current study was to determine the type and magnitude of response of modern male Hybrid Converter turkeys to changes in feed form while maintaining a consistent nutritional plane. During the first portion of this study (D1-42) two treatments were utilized: 1) Starter phase diets + YP1 [24]; and 2) Starter phase diets + YP2 [25] to determine their effect on overall brooder phase poult performance. After this period, Feed Form was manipulated to determine Feed Form (HQP or GP) and YP carryover effects on D42-118 tom performance.

\section{MATERIALS AND METHODS}

\section{Diet Preparations}

Diet formulations were proprietary, but formulated in order to meet or exceed industry recommendations for Hybrid Convertor [26] toms, utilizing multiple dietary phases; and contained corn, soybean meal, poultry by-product meal, wheat middlings, animal/vegetable blended fat, a commercial phytase, defluorinated P and monocalcium P. All diets were batched and pelleted at a commercial feed mill [27], then delivered to West Virginia University's Turkey Research Facility, where samples of feed were obtained and sent to a commercial laboratory [28] for proximate analyses (Tables 1 and 2). Starter diets of similar phases were fed in the form of crumbles and 
were consistent in nutritional composition (other than YP). The YP was top-dressed at manufacture inclusion recommendations $(0.04 \%$ inclusion of YP1 [24] or $0.125 \%$ inclusion of YP2 [25]). Diets fed from D42-118 differed in feed form (HQP vs GP). To create two different feed forms, first the HQP diet was conditioned at $82.2^{\circ} \mathrm{C}$ for approximately $30 \mathrm{sec}$, then pelleted using a 400 HP California Pellet Mill [29], equipped with a 4.37 x $31.75 \mathrm{~mm}$ effective thickness pellet die. The maximum production rate of the commercial mill [27] was 52.63 tonne/hr; however, a slower production rate was utilized in order to create intact high quality pellets. To create the GP diet, a portion of the HQP were ground via roller mill, producing a diet of comparable texture to unconditioned mash diets, but received thermal processing to be on a consistent nutritional plane as the HQP diet. Pellet quality of HQP diets was assessed through the percentage of fines, pellet durability index and modified pellet durability index [30], and surviving pellets through the New Holmen Tester [31] at 30 and 60 s (Table 3). Average particle size [32, 33] of GP diets was also recorded (Table 4).

\section{Facilities}

Eighty-nine, 1-d-old male Hybrid Convertor [26] poults were placed on fresh wood shavings on top of concrete flooring in each of the $16(6.1 \times 5.2 \mathrm{~m})$ pens throughout the WVU research facility that mimicked commercial grow-out. This facility utilized tunnel ventilation and radiant brooders; feed and water were provided for ad libitum consumption via bell drinkers and an augered feed pan system. In addition, each pen contained an automated bird scale and feed dump scale [34]. Temperature and lighting programs followed standard industry protocols [35]. Automated poult and feed scales were calibrated weekly and on D42, individual poult weights were manually recorded to confirm the automated bird scale accuracy. 
On D1, pens of poults were randomly assigned either YP1 or YP2 and blocked according to location. On D42, Feed Form treatments were randomly and equally assigned across pens previously receiving either of the two YP to determine Feed Form and YP Carryover effects. Measured performance variables included: D1 beginning pen weight, as well as D1-42 and D1-118 pen feed intake (FI), feed conversion ratio (FCR; corrected with mortality weight), percent mortality and D42/118 average ending poult/tom weight (EW). Birds were cared for according to West Virginia University Animal Care and Use Committee Guidelines.

\section{Statistical Analyses}

All data were statistically analyzed using the GLM procedure of Statistical Analysis System [36]. The experimental unit for all live production measurements was a pen of 89 birds. Initially (D1-42), data were analyzed utilizing YP as the only factor, then from D42-118, after initiation of Feed Form treatments, data were analyzed as a 2 (YP Carryover) x 2 (Feed Form) factorial with 4 replicate pens per treatment ( 8 replicate pens per main effect). The main effects of YP Carryover and Feed Form, as well as the YP Carryover x Feed Form interactions were tested. Fisher's least significant difference multiple comparison tests were used to further compare treatment means. Linear and quadratic regression analyses were performed in order to generate prediction equations for FCR and grow-out time due to D118 EW significantly differing. When relationships were not quadratic, the quadratic term was removed from the model and solved linearly. Alpha was designated at $\mathrm{P} \leq 0.05$ and letter superscripts within tables indicate significant differences among means. 


\section{RESULTS AND DISCUSSION}

\section{Yeast Product Effects}

Yeast Product effects on brooder phase performance are presented in Table 5. On D1, beginning pen weights were similar $(\mathrm{P}>0.05)$ among treatments. Inclusions of YP had no effect on FI or percent mortality ( $\mathrm{P}>0.05$; Table 5). In addition, no significant differences were established for D42 automated scale EW or D1-42 FCR ( $\mathrm{P}=0.236$ and 0.798 , respectively). However, when poult weights were manually obtained on D42, significant differences demonstrated that poults fed YP1 were heavier than those fed YP2, 2.85 vs. $2.77 \mathrm{~kg}$, respectively $(\mathrm{P}=0.022$; Table 5). These weights were then used to re-calculate D1-42 FCR, in which significant differences were obtained demonstrating that poults fed YP1 also produced a lower FCR than those fed YP2, 1.33 vs. 1.36, respectively $(\mathrm{P}=0.022$; Table 5). Prior data collected at this facility have shown high agreement between automated and manually obtained weights, perhaps poults in the current study did not equally utilize the automated scale during the brooder phase. However, according to Hybrid Converter performance standards [37], poults at D42 should weigh $2.93 \mathrm{~kg}$. Both YP treatments produced poults under these standards, but resulting FCR were also under breed performance standards from D1-42 (1.38). It is unknown if FCR breed standards were determined utilizing mortality weights, which could create a discrepancy. Previous research investigating the benefits of similar YP on bird performance established improvements in FCR, but not $\mathrm{EW}[2,5]$.

\section{Feed Form Effects}

All data pertaining to feed composition, quality, and form of HQP and GP diets are to be considered descriptive and displayed in Tables 3-5. Analyses of diets (Table 3) demonstrate that 
regardless of feed form, diets from a common phase were of similar composition. Table 4 demonstrates that a commercial feed mill is capable of creating pellets of high durability, with PDI and MPDI of HQP treatments ranging from $93-95 \%$ and $87-91 \%$, respectively. Pellet durability as assessed using the New Holman Tester (30 s), confirmed that high quality pellets were produced. The percentages of surviving intact pellets were similar utilizing this methodology, but lower than MPDI results (ranging from 81-86\%). Even though the durability of pellets produced was consistently high, the percentage of fines did not reflect the observed pellet durability and had a greater range (11-55\%; Table 4). Using the number of days each diet was fed, the average percentage of fines fed to toms receiving HQP was $21.4 \%$. The particle size of the GP diets fed was consistent in both size (920-1519 microns) and uniformity (1.92-2.12 SD). Using the number of days each diet was fed, the average particle size of GP diets was 1108 microns (Table 5).

Table 6 displays YP Carryover and Feed Form effects on D1-118 tom performance. Despite the early depression of growth (according to Hybrid Converter performance standards for D42 poult weights [37]), average D118 EWs were similar and D1-118 FCR were at least 10 points lower (more efficient) than breed performance standards for that growth period [37] (Table 6), regardless of treatment. However, as previously mentioned, FCR calculations for breeder performance standards may have not included mortality weights, which would explain the higher FCR as compared to that observed in the current study. No significance was established for the main effect YP Carryover for FI, EW, FCR, or percent mortality (P > 0.05; Table 6). In addition, Feed Form had no effect on FI or percent mortality (P > 0.05; Table 6). Feed Form did effect EW and FCR, demonstrating that toms fed HQP were $0.29 \mathrm{~kg}(0.64 \mathrm{lb})$ per bird heavier $(\mathrm{P}=0.001)$ and had 9 points lower FCR (feed:gain) $(\mathrm{P}=0.0153)$ than toms fed GP (Table 6). It must be noted that increasing the amount of fines present in a diet can be detrimental to turkey performance [10]; 
therefore, due to feed quality fluctuations in the current study (percentage of fines ranging from 11$55 \%$ ), performance benefits of feeding high quality pellets could have been underestimated.

Due to Feed Form effects on EW and FCR, prediction equations were generated for toms fed GP in order to determine the difference in grow-out time (days) and FCR using the EW of toms fed HQP (Table 7). Prediction equations were derived utilizing either 3, 7 or 11 data points, each of which demonstrated similar predicted results and strong $\mathrm{R}^{2}$ values (Table 7 ). These equations determined that toms fed GP would require approximately one additional day of grow-out to reach the same EW as toms fed HQP (17.41 kg; Table 7). In addition, allowing toms fed GP to reach the same EW as toms fed HQP would result in an approximate FCR of 2.04, 12 points higher than that of toms fed HQP, which had an FCR of 1.92.

As previously mentioned, some of the most recent peer-reviewed literature investigating benefits of feeding pellets to turkeys was published in 1997, but resulted in conflicting performance benefits [17, 18]. Hamilton and Kennie [17] observed significant feed form effects on D1-84 turkey performance and found that feeding pellets resulted in an average of 11 points lower FCR. However, a significant depression in growth was also observed, with turkeys fed pellets weighing an average of $0.09 \mathrm{~kg}(0.20 \mathrm{lb})$ per bird less than those fed mash [17]. In contrast, Plavnik and cohorts [18] fed pellets to turkeys from D1-140 and results indicated benefits to both EW and FCR; however, improvements were most dramatic in EW and only minimal for FCR. These data do not correspond well to data from the current study; rather, the current study is consistent with older literature $[8,10-12]$ which determined the performance benefits of feeding pellets to turkeys to be associated with dramatic improvements in both EW and FCR. Perhaps, inconsistencies in the literature are in part associated with variations in genotype, ingredient profiles, diet formulation strategies, feed manufacture, and pellet quality. 
The current study also agrees with previous research conducted using modern day Cobb 500 broilers [22], supporting that pellet quality is still important, despite advancements in poultry genotypes. However, nutritional detriment due to thermal processing [38] must also be considered prior to making an investment in pellet quality or else these benefits may not be fully attained [18, 22, 39-41]. Therefore, in order to justify costs associated with creating HQP, a comprehensive view must be applied to determine economic return.

\section{CONCLUSIONS AND APPLICATIONS}

1. Pellets of high durability can be produced in a commercial feed mill, with PDI and MPDI ranging from $93-95 \%$ and $87-91 \%$, respectively, with an average fines percentage of $21.4 \%$.

2. Feeding HQP from D42-118 produced toms that were $0.29 \mathrm{~kg}(0.64 \mathrm{lb})$ per bird heavier with 9 points lower FCR, as compared to toms fed GP. Regression analyses predicted that if toms fed GP finished at the same D118 EW as those fed HQP, then FCR advantages of HQP would be 12 points.

3. Early (D1-42) YP inclusion affected poult EW and FCR, with the most benefit for YP1; however, benefits were lost at the end of grow-out, with no significance established for YP Carryover effects (D42-118).

\section{ACKNOWLEDGEMENTS}

The authors would like to express their sincere appreciation to Loyd Whetzel; without his contributions, this study would not have been possible. 


\section{REFERENCES}

1. Mitchell, R. 2002. Opportunities for improving poult performance with feed. Pages 1-9 in Proc. Multi-State Poultry Meeting. Indianapolis, IN. Purdue University.

2. Firman, J. D. and D. Moore. 2009. Effects of dietary inclusion of a Saccharomyces cerevisiae fermentation product on performance and gut characteristics of male turkeys to market weight. Poult. Sci. 88 (Suppl.1).

3. Araujo, L., C. Araujo, D. Moore, R. Upton, L. C. G. S. Barbosa and M. T. Kidd. 2009. Progeny responses from breeder hens fed a Saccharomyces cerevisiae fermentation product. Poult. Sci. 88 (Suppl.1).

4. Broomhead, J., S. Frankenbauch, S. Oates, and W. Berry. 2012. Effects of feeding Saccharomyces cerevisiae fermentation product to broiler breeder hens and their progeny. Poult. Sci. 91 (Suppl. 1).

5. Barasch, I. B., P. R. Ferket, J. L. Grimes, C. R. Stark, and R. D. Malheiros. 2011. Effect of dietary inclusion of actigen and virginiamycin on growth performance of turkey toms. Poult. Sci. 90 (Suppl.1).

6. Gao, J., H. J. Zhang, S. G. Wu, S. H. Yu, I. Yoon, D. Moore, Y. P. Gao, H. J. Yan, and G. H. Qi. 2009. Effect of Saccharomyces cerevisiae fermentation product on immune functions of broilers challenged with Eimeria tenella. Poult. Sci. 88:2141-2151.

7. Lensing, M., J. D. van der Klis, I. Yoon, and D. T. Moore. 2012. Efficacy of Saccharomyces cerevisiae fermentation product on intestinal health and productivity of coccidian-challenged laying hens. Poult. Sci. 91:1590-1597.

8. Pepper, W. F., S. J. Slinger and J. D. Summers. 1960. Studies with chickens and turkeys on relationship between fat, unidentified factors, and pelleting. Poult. Sci. 39: 66-74.

9. Jensen, L. S., L. H. Merrill, C. V. Reddy, and J. McGinnis. 1962. Observations on eating patterns and rate of food passage of birds fed pelleted and unpelleted diets. Poult. Sci. 41:1414-1419.

10. Proudfoot, F. G. and H. W. Hulan.1982. Feed texture effects on the performance of turkey broilers. Poult. Sci. 61:327-330.

11. Salmon, R.E. 1985. Effects of pelleting, added sodium bentonite and fat in a wheat-based diet on performance and carcass characteristics of small white turkeys. Anim. Feed Sci. Technol. 12:223-232.

12. Noll, S. L., M. E. El Halawani, P. E. Waibel, P. Redig, and K. Janni. 1991. Effect of diet and population density on male turkeys under various environmental conditions. 1. Turkey growth and health performance. Poult. Sci. 70:923-934.

13. Scheideler, S. E. 1991. Pelleting is important for broilers. Pages 1-7 in Proc. 18th Annu. Carolina Poult. Nutr. Conf., Charlotte, NC. North Carolina State Univ., Raleigh.

14. Nir, I., Y. Twina, E. Grossman, and Z. Nitsan. 1994. Quantitative effects of pelleting on performance, gastrointestinal tract and behavior of meat-type chickens. Br. Poult. Sci. 35:589-602.

15. Behnke, K. C. 1994. Factors affecting pellet quality. Pages 44-54 in Proc. Maryland Nutr. Conf., College Park, MD. Maryland Feed Ind. Counc. and Univ. Maryland, College Park.

16. Behnke, K. C. 1996. Feed manufacturing technology: Current issues and challenges. Anim. Feed Sci. Technol. 62:49-57.

17. Hamilton, R. M. G. and J. Kennie. 1997. Effects of lighting program, ingredient particle size, and feed form on performance of broiler turkeys. Can. J. Anim. Sci. 77:503-508. 
18. Plavnik, I., E. Wax, D. Sklan, and S. Hurwitz. 1997. The response of broiler chickens and turkey poults to steam-pelleted diets supplemented with fat or carbohydrates. Poult. Sci. 76:1006-1013.

19. Moritz, J. S., R. S. Beyer, K. J. Wilson, K. R. Cramer, L. J. McKinney, and F. J. Fairchild. 2001. Effect of moisture addition at the mixer to a corn-soybean based diet on broiler performance. J. Appl. Poult. Res. 10:347-353.

20. Hott, J. M., N. P. Buchanan, S. E. Cutlip, and J. S. Moritz. 2008. The effect of moisture addition with a mold inhibitor on pellet quality, feed manufacture, and broiler performance. J. Appl. Poult. Res. 17:262-271.

21. Cutlip, S. E., J. M. Hott, N. P. Buchanan, A. L. Rack, J. D. Latshaw, and J. S. Moritz. 2008. The effect of steam conditioning practices on pellet quality and growing broiler nutritional value. J. Appl. Poult. Res. 17:249-261.

22. Lilly, K. G. S., C. K. Gehring, K. R. Beaman, P. J. Turk , M. Sperow, and J. S. Moritz. 2011. Examining the relationships between pellet quality, broiler performance, and bird sex. J. Appl. Poult. Res. 20:231-239.

23. Buchanan, N. P., K. G. S. Lilly, C. K. Gehring, and J. S. Moritz. 2010. The effects of altering diet formulation and manufacturing technique on pellet quality. J. Appl. Poult. Res. 19:112-120.

24. Alltech Inc., Nicholasville, KY.

25. Diamond V Mills, Inc., Cedar Rapids, Iowa

26. Hybrid Turkeys; Hendrix Genetics, Boxmeer, Netherlands

27. Virginia Poultry Growers Cooperative Feedmill, Broadway, VA.

28. Experiment Station Chemical Laboratories, Agricultural Experiment Station, Univ. Missouri, Columbia, MO.

29. California Pellet Mill Company (CPM), Crawfordsville, IN.

30. American Society of Agricultural Engineers. 1997. ASAE S269.4, Cubes, pellets, and crumbles-Definitions and methods for determining density, durability, and moisture. Standards 1997. Am. Soc. Agric. Eng., St. Joseph, MI. Due to the use of a 3/16 in. x 1.77 in. die, pellets were sifted in a No. 6 American Society for Testing and Materials (ASTM) screen. Five hundred grams of sifted pellets were placed in a dust-tight enclosure and tumbled for $10 \mathrm{~min}$ at $50 \mathrm{rpm}$. The enclosure was of the dimensions $12 \times 12$ in., with a $2 \mathrm{x}$ 9 in. plate affixed diagonally along one of the $12 \times 12$ in. sides. The tumbled samples were then sifted again (No. 6 ASTM) and weighed. The pellet durability index was calculated by dividing the weight of pellets after tumbling by the weight of pellets before tumbling, then multiplying by 100 . The modified pellet durability index was determined in a similar manner with the exception of adding 5, 13-mm hex nuts to the pretumbled sample to obtain added pellet agitation.

31. New Holman Tester, Tekpro limited, UK.

32. Ro-Tap particle size analyzer model RX-29 type $110 \mathrm{~V} 60 \mathrm{H} 2$, WS Tyler, Mentor, OH. One hundred grams of ground corn for each diet was placed in a dust-tight enclosed series of stacked (No. 4, 6, . .) American Society for Testing and Materials (ASTM) screens affixed to the Ro-Tap particle size analyzer and shaken for $10 \mathrm{~min}$. The screens were then separated and weighed. Particle size was calculated by subtracting the weight of the screen from the final weight of screen and sample after shaking. The mean geometric particle size and log normal geometric standard deviation were calculated as described by McEllhiney [32]. 
33. McEllhiney, R. R. 1994. Determining and expressing particle size. Pages 545-547 in Feed Manufacture Technology IV. American Feed Industry Association, Inc., Arlington, VA.

34. Chore-Time Brock Incorporated, Milford, IN.

35. Virginia Poultry Growers Cooperative, 2011.

36. SAS Institute. 2009. The SAS System for Windows 2009. Release 9.2. SAS Inst. Inc., Cary, NC.

37. Hybrid Converter, Male Performance Goals 2011. Accessed July 1, 2012. http://www.hybridturkeys.com/en/Hybrid\%20Products/Mainstream\%20Products/ /media /Files/Hybrid/Converter/CS_Converter_Males_WEB_FINAL.ashx

38. Pickford, J. R. 1992. Effects of processing on stability of heat stability of heat labile nutrients in animal feeds. In: Garnsworthy, P.C., Haresign, W., Cole, D. J. A. (Eds.), Recent Advances in Animal Nutrition. Redwood Press, Melksham, UK, pp. 177-192.

39. Bayley, H. S., J. D. Summers, and S. J. Slinger. 1968. The influence of steam pelleting conditions on the nutritional value of chick diets. Poult. Sci. 47:931-939.

40. Buchanan, N. P., K. G. S. Lilly, and J. S. Moritz. 2010. The effects of diet formulation, manufacturing technique, and antibiotic inclusion on broiler performance and intestinal morphology. J. Appl. Poult. Res. 19:121-131.

41. Gehring, C. K., K. G. S. Lilly, L. K. Worley, K. R. Beaman, S. A. Loop, and J. S. Moritz. 2011. Increasing mixer-added fat improves exogenous enzyme efficacy and broiler performance. J. Appl. Poult. Res. 20:75-89. 
Table 1. Proximate analysis of diets fed during the brooder phase (D1-42) ${ }^{1}$

\begin{tabular}{|c|c|c|c|c|}
\hline \multirow{2}{*}{ Analysis } & \multicolumn{2}{|c|}{ Diet 1} & \multicolumn{2}{c|}{ Diet 2 } \\
\cline { 2 - 5 } & YP1 $^{7}$ & YP2 $^{8}$ & YP1 & YP2 \\
\hline${\text { Crude Protein }(\%)^{2}}^{2}$ & 29.09 & 27.28 & 28.17 & 28.25 \\
\hline Moisture $(\%)^{3}$ & 10.07 & 9.66 & 10.22 & 9.99 \\
\hline Crude Fat $(\%)^{4}$ & 10.36 & 9.84 & 9.8 & 9.91 \\
\hline${\text { Crude Fiber }(\%)^{5}}^{6}$ & 2.44 & 2.23 & 2.31 & 2.39 \\
\hline Ash $(\%)^{6}$ & 7.99 & 7.41 & 7.41 & 7.24 \\
\hline
\end{tabular}

${ }^{1}$ All diets were sent to the Agricultural Experiment Station at the University of Missouri-Columbia, College of Agriculture, Food and Natural Resources [28] for proximate analyses

${ }^{2}$ Crude Protein was determined by Kjeldahl utilizing the equation: Crude Protein $=6.25 \mathrm{x} \%$ Nitrogen, AOAC Official Method 984.13 (A-D), 2006

${ }^{3}$ AOAC Official Method 934.01, 2006, vacuum oven.

${ }^{4}$ Ether Extraction, AOAC Official Method 920.39 (A)

${ }^{5}$ AOAC Official Method 978.10, 2006

${ }^{6}$ AOAC Official Method 942.05

${ }^{7}$ Normal diet + YP1 (0.04\% inclusion, which is the manufacture's recommendation) [24]

${ }^{8}$ Normal diet + YP2 (0.125\% inclusion, which is the manufacture's recommendation) [25] 
Table 2. Proximate analysis of diets fed from D42-118

\begin{tabular}{|c|c|c|c|c|c|c|c|c|c|c|c|c|}
\hline \multirow{3}{*}{ Analysis } & \multicolumn{12}{|c|}{ Days fed during grow-out } \\
\hline & \multicolumn{2}{|c|}{ D42-56 } & \multicolumn{2}{|c|}{ D56-61 } & \multicolumn{2}{|c|}{ D61-85 } & \multicolumn{2}{|c|}{ D85-105 } & \multicolumn{2}{|c|}{ D105-110 } & \multicolumn{2}{|c|}{ D110-118 } \\
\hline & $\mathrm{GP}^{2}$ & $\mathrm{HQP}^{3}$ & GP & HQP & GP & HQP & GP & HQP & GP & HQP & GP & $\mathrm{HQP}$ \\
\hline Crude Protein $(\%)^{4}$ & 25.08 & 27.21 & 25.65 & 26.19 & 21.97 & 23.53 & 23.91 & 22.64 & 19.86 & 20.13 & 17.20 & 17.59 \\
\hline Moisture $(\%)^{5}$ & 10.46 & 10.32 & 12.32 & 11.87 & 8.86 & 8.46 & 11.69 & 11.57 & 11.81 & 12.23 & 11.99 & 11.99 \\
\hline Crude Fat $(\%)^{6}$ & 8.84 & 8.4 & 8.36 & 7.81 & 1.52 & 1.66 & 8.88 & 9.91 & 13.02 & 12.19 & 10.32 & 11.14 \\
\hline Crude Fiber $(\%)^{7}$ & 2.38 & 2.23 & 2.13 & 2.03 & 13.69 & 10.06 & 2.04 & 1.93 & 1.70 & 1.84 & 1.95 & 1.76 \\
\hline $\operatorname{Ash}(\%)^{8}$ & 6.81 & 6.67 & 6.78 & 7.13 & 6.38 & 6.26 & 5.62 & 5.67 & 5.26 & 5.19 & 4.74 & 4.70 \\
\hline
\end{tabular}

${ }^{1}$ All diets were sent to the Agricultural Experiment Station at the University of Missouri-Columbia, College of Agriculture, Food and Natural Resources [28] for proximate analyses

${ }^{2}$ Ground Pellets is abbreviated GP and consists of the same diet formulation and has undergone the same manufacture process as Intact High Quality Pellets, with the exception that this diet was ground prior to feeding

${ }^{3}$ Intact High Quality Pellets is abbreviated HQP and consists of the same diet formulation and has undergone the same manufacture process as GP

${ }_{5}^{4}$ Crude Protein was determined by Kjeldahl utilizing the equation: Crude Protein $=6.25$ x \% Nitrogen, AOAC Official Method 984.13 (A-D), 2006

${ }^{5}$ AOAC Official Method 934.01, 2006, vacuum oven.

${ }^{6}$ Ether Extraction, AOAC Official Method 920.39 (A)

${ }^{7}$ AOAC Official Method 978.10, 2006

${ }^{8}$ AOAC Official Method 942.05 
Table 3. Feed quality description of intact high quality pellet (HQP) diets fed from D42-118

\begin{tabular}{|c|c|c|c|c|c|}
\hline $\begin{array}{c}\text { Days fed } \\
\text { during } \\
\text { grow-out }\end{array}$ & $\begin{array}{c}\text { Percent } \\
\text { Fines }^{1,2}(\%)\end{array}$ & $\begin{array}{c}\text { Pellet } \\
\text { Durability } \\
\text { Index }^{3}(\%)\end{array}$ & $\begin{array}{c}\text { Modified Pellet } \\
\text { Durability } \\
\text { Index }^{4}(\%)\end{array}$ & $\begin{array}{c}\text { New Holman } \\
\text { tester }-\end{array}$ & $\begin{array}{c}\text { New Holman } \\
\text { tester }- \\
60 \text { seconds }^{5}(\%) \\
(\%)\end{array}$ \\
\hline D42-56 & 13.39 & 93.77 & 90.69 & 81.8 & 60.7 \\
\hline D56-61 & 23.21 & 94.94 & 90.37 & 85.7 & 64.9 \\
\hline D61-85 & 55.00 & 93.62 & 88.43 & 83.8 & 59.2 \\
\hline D85-105 & 11.15 & 93.46 & 87.57 & 82.0 & 57.5 \\
\hline D105-110 & 18.79 & 93.31 & 86.80 & 81.7 & 54.7 \\
\hline D110-118 & 27.86 & 94.01 & 87.55 & 81.1 & 51.3 \\
\hline
\end{tabular}

${ }^{1}$ Percent fines is defined as the percentage of fines from a $6.8 \mathrm{~kg}$ feed sample that passed through a No. 6 screen.

${ }^{2}$ The average percentage of fines fed to toms receiving HQP was $21.36 \%$, this accounts for the number of days fed for each diet

${ }^{3}$ Pellet durability index was determined by placing $500 \mathrm{~g}$ of sifted pellets into a Pfost tumbler. Samples were tumbled for $10 \mathrm{~min}$ at $50 \mathrm{rpm}$. The sample was then sifted again and weighed. Pellet durability index was calculated as the percentage of sifted pellets retained after tumbling [30].

${ }^{4}$ Modified pellet durability index was determined was determined in a similar manner to pellet durability index with the exception of adding 5, 13-mm hex nuts to the pre-tumbled sample to obtain added pellet agitation [30].

${ }^{5} \mathrm{New}$ Holman tester [31] uses a sample of $100 \mathrm{~g}$ of pellets and subjected to air flow within a perforated chamber for $30 \mathrm{~s}$

${ }^{6} \mathrm{New}$ Holman tester [31] uses a sample of $100 \mathrm{~g}$ of pellets and subjected to air flow within a perforated chamber for $60 \mathrm{~s}$

Table 4. Particle size analysis of ground pellet diets fed from D42-118 ${ }^{1}$

\begin{tabular}{|c|c|c|}
\hline $\begin{array}{c}\text { Days fed during } \\
\text { grow-out }\end{array}$ & $\begin{array}{c}\text { Average Particle } \\
\text { Size (microns) }\end{array}$ & Standard Deviation \\
\hline D42-56 & 930 & 2.01 \\
\hline D56-61 & 1058 & 2.12 \\
\hline D61-85 & 920 & 2.00 \\
\hline D85-105 & 1519 & 1.94 \\
\hline D105-110 & 1016 & 1.97 \\
\hline D110-118 & 1045 & 1.92 \\
\hline
\end{tabular}

${ }^{1}$ Particle size was determined with a Ro-Tap particle size analyzer model RX-29 type 110V 60H2, WS Tyler, Mentor, $\mathrm{OH}$ [32]. One hundred grams of each ground pelleted diet was placed in a dust-tight enclosed series of stacked (No. 4, $6, \ldots$. .) American Society for Testing and Materials (ASTM) screens affixed to the Ro-Tap particle size analyzer and shaken for $10 \mathrm{~min}$. The screens were then separated and weighed. Particle size was calculated by subtracting the weight of the screen from the final weight of screen and sample after shaking. The mean geometric particle size and log normal geometric standard deviation were calculated as described by McEllhiney [33].

${ }^{2}$ The average particle size of GP diets was 1108 microns, this accounts for the number of days fed for each diet 
Table 5. Effect of Yeast Products on brooder phase performance (D1-42)

\begin{tabular}{|c|c|c|c|c|c|c|c|}
\hline Treatment & $\begin{array}{c}\text { Avg. Beginning } \\
\text { Poult Wt/Pen } \\
(\mathrm{kg})\end{array}$ & $\begin{array}{c}\text { D1-42 Pen } \\
\text { Feed Intake } \\
(\mathrm{FI})(\mathrm{kg})\end{array}$ & $\begin{array}{c}\text { D 42 } \\
\text { Automated } \\
\text { Scale Avg. } \\
\text { Poult Wt } \\
(\mathrm{EW})(\mathrm{kg})^{1}\end{array}$ & $\begin{array}{c}\text { D 42 } \\
\text { Manually } \\
\text { Obtained } \\
\text { Avg. Poult } \\
\text { Wt (EW) } \\
(\mathrm{kg})^{2}\end{array}$ & $\begin{array}{c}\text { D1-42 Feed } \\
\text { Conversion } \\
\text { Ratio } \\
(\mathrm{FCR})^{3}\end{array}$ & $\begin{array}{c}\text { D1-42 Feed } \\
\text { Conversion } \\
\text { Ratio } \\
(\mathrm{FCR})^{4}\end{array}$ & $\begin{array}{c}\text { D1-42 } \\
\text { Mortality } \\
(\%)\end{array}$ \\
\hline YP1 $^{6}$ & 0.0612 & 319.21 & 2.85 & $2.85^{\mathrm{a}}$ & 1.33 & $1.33^{\mathrm{b}}$ & 5.90 \\
\hline YP2 $^{7}$ & 0.0614 & 317.82 & 2.82 & $2.77^{\mathrm{b}}$ & 1.33 & $1.36^{\mathrm{a}}$ & 4.92 \\
\hline Fisher's LSD $^{8}$ & - & - & - & 0.0637 & - & 0.0199 & - \\
\hline ANOVA P-Value $^{9}$ & 0.528 & 0.480 & 0.236 & 0.022 & 0.798 & 0.022 & 0.436 \\
\hline SEM $^{9}$ & 0.0001 & 1.317 & 0.019 & 0.019 & 0.009 & 0.006 & 0.842 \\
\hline
\end{tabular}

${ }^{1}$ These are the average weights obtained from automated scales inside of pens

${ }^{2}$ These are the average weights manually obtained (D42)

${ }^{3}$ Feed conversion ratio (Feed:Gain) was calculated using mortality weight (using automated scale weights)

${ }^{4}$ Feed conversion ratio (Feed:Gain) was calculated using mortality weight (using manually obtained Manually Obtained weights)

${ }^{5}$ Mortality percentage is based on a beginning pen number of 76 , thus if 10 birds die in a pen the resulting mortality percentage would be $13 \%$

${ }^{6}$ Normal diet + YP1 (0.04\% inclusion, which is the manufacture's recommendation) [24]

${ }^{7}$ Normal diet + YP2 (0.125\% inclusion, which is the manufacture's recommendation) [25]

${ }^{8}$ Fisher's Least Significant Difference

${ }^{9}$ Standard Error of the Mean, an estimate of the amount that an obtained mean may be expected to differ by chance from the true mean.

${ }^{a-b}$ Values within columns with different superscripts differ significantly $(\mathrm{P}<0.05)$ 
Table 6. Yeast Product (YP) Carryover and Feed Form effects on D1-118 tom performance

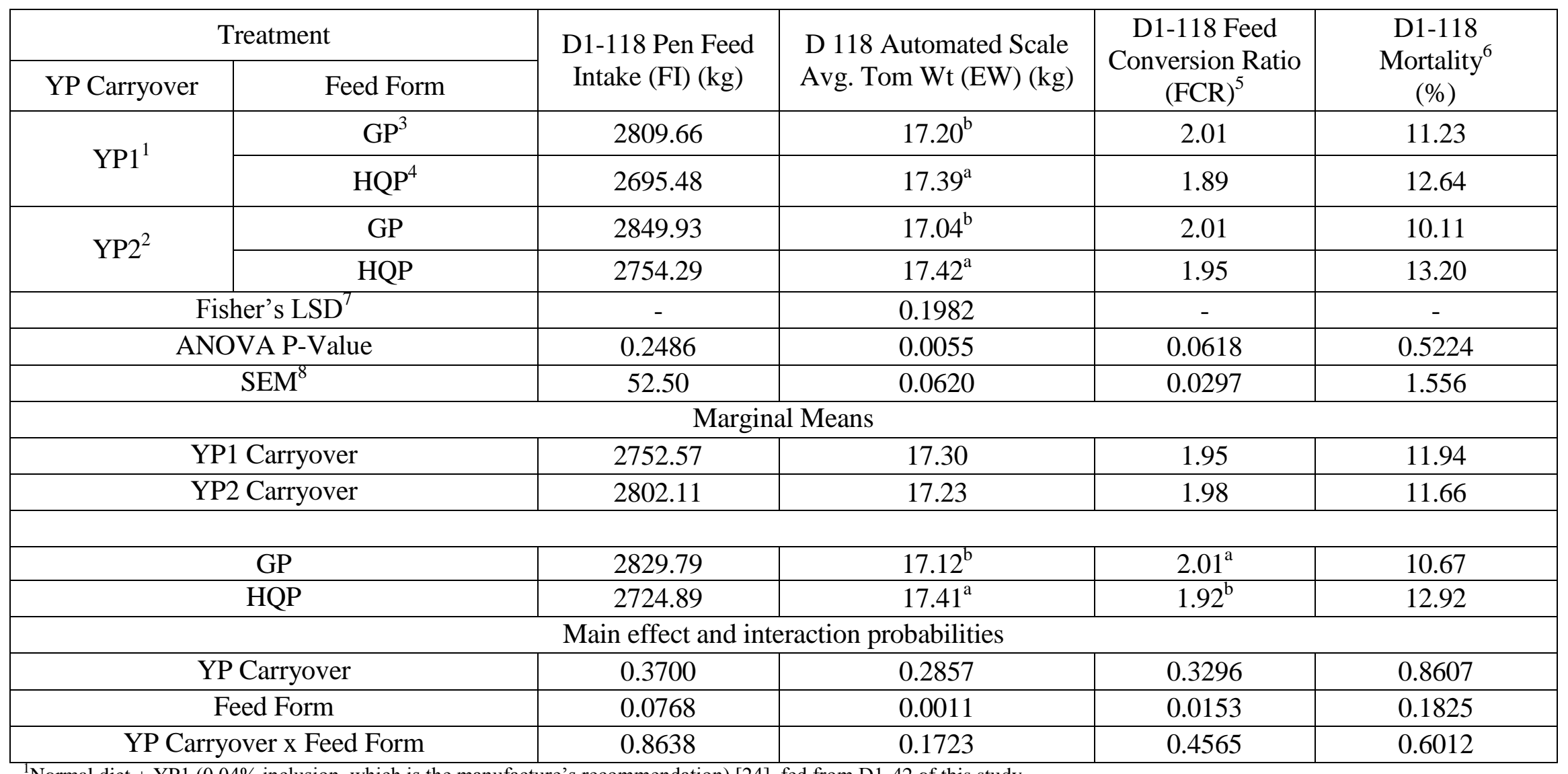

${ }^{1}$ Normal diet + YP1 (0.04\% inclusion, which is the manufacture's recommendation) [24], fed from D1-42 of this study

${ }^{2}$ Normal diet + YP2 (0.125\% inclusion, which is the manufacture's recommendation) [25], fed from D1-42 of this study

${ }^{3}$ Ground Pellets is abbreviated GP and consists of the same diet formulation and has undergone the same manufacture process as In-tact High Quality Pellets, with the exception that this diet was ground prior to feeding; the average particle size of feed presented to toms was 1108 microns (corrected for number of days each separate diet was fed)

${ }^{4}$ Intact High Quality Pellets is abbreviated HQP and consists of the same diet formulation and has undergone the same manufacture process as GP; the average percentage of fines in feed presented to toms was $21.36 \%$ (corrected for number of days each separate diet was fed)

${ }^{5}$ Feed conversion ratio (Feed:Gain) was calculated using mortality weight

${ }^{6}$ Mortality percentage is based on a beginning pen number of 76 , thus if 10 birds die in a pen the resulting mortality percentage would be $13 \%$

${ }^{7}$ Fisher's Least Significant Difference

${ }^{8}$ Standard Error of the Mean, an estimate of the amount that an obtained mean may be expected to differ by chance from the true mean.

${ }^{\mathrm{a}-\mathrm{b}}$ Values within columns with different superscripts differ significantly $(\mathrm{P}<0.05)$ 
Table 7. Regression analyses to predict the performance of toms fed Ground Pellet (GP) diets based on the same D118 weights as toms fed Intact High Quality Pellet (HQP) diets (17.41 kg/tom and FCR of 1.92)

\begin{tabular}{|c|c|c|c|c|c|c|}
\hline $\begin{array}{c}\text { Data } \\
\text { points }\end{array}$ & $\begin{array}{c}\text { Relationship } \\
\text { between } \\
\mathrm{EW}^{2} \text { and } \\
\text { Day }\end{array}$ & $\begin{array}{c}\text { Predicted } \\
\text { Time } \\
(\text { Day })\end{array}$ & $\mathrm{R}^{2}$ Value & $\begin{array}{c}\text { Relationship } \\
\text { between } \\
\mathrm{FCR}^{4} \text { and } \\
\mathrm{EW}\end{array}$ & $\begin{array}{c}\text { Predicted } \\
\mathrm{FCR}^{5} \\
(\mathrm{~kg} / \mathrm{kg})\end{array}$ & $\mathrm{R}^{2}$ Value \\
\hline 3 & Quadratic $^{6}$ & 119.3 & 0.9994 & Linear $^{7}$ & 2.034 & 0.9682 \\
\hline 7 & Quadratic $^{8}$ & 118.9 & 0.9979 & Quadratic $^{9}$ & 2.034 & 0.9588 \\
\hline 11 & Quadratic $^{10}$ & 118.6 & 0.9963 & Quadratic $^{11}$ & 2.037 & 0.9587 \\
\hline
\end{tabular}

${ }^{\mathrm{I}}$ Number of data points (weight on a given day) used in the prediction equation

${ }^{2} \mathrm{EW}=$ Ending Tom Weight $(\mathrm{kg})$

${ }^{3}$ Predicted time for toms fed ground pellet diets (GP) to reach the EW of toms fed intact high quality pellets (HQP) (D118 at $17.41 \mathrm{~kg})$.

${ }^{4} \mathrm{FCR}=$ Feed Conversion Ratio

${ }^{5}$ Predicted FCR for toms fed GP at the same D118 EW (17.41 kg/tom) as toms fed HQP. For comparison, toms fed HQP had a FCR of 1.92 on D118.

${ }^{6}$ Calculated values were derived from the regression equation: $y=0.000617 x^{2}+0.07464 x-0.2836$; where $y=E W$ and $\mathrm{x}=$ Day

${ }^{7}$ Calculated values were derived from the regression equation: $y=0.0515 x+1.1373$; where $y=$ FCR and $x=E W$

${ }^{8}$ Calculated values were derived from the regression equation: $y=0.000789 x^{2}+0.0479 x+0.4147$; where $y=E W$ and $\mathrm{x}=$ Day

${ }^{9}$ Calculated values were derived from the regression equation: $y=-0.0011 x^{2}+0.07748 x+1.018$; where $y=F C R$ and $\mathrm{x}=\mathrm{EW}$

${ }^{10}$ Calculated values were derived from the regression equation: $\mathrm{y}=0.000712 \mathrm{x}^{2}+0.0652 \mathrm{x}-0.3717$; where $\mathrm{y}=\mathrm{EW}$ and $\mathrm{x}=$ Day

${ }^{11}$ Calculated values were derived from the regression equation: $y=-0.000954 x^{2}+0.0747 x+1.026$; where $y=F C R$ and $\mathrm{x}=\mathrm{EW}$ 


\section{inflammation and phosphorus content of litter}

K. G. S. Wamsley, A. M. Evans, and J. S. Moritz ${ }^{*}$

* Division of Animal and Nutritional Sciences, West Virginia University, Morgantown 26506

Primary Audience: Feed Mill Managers, Nutritionists, Researchers, Production Managers

${ }^{1}$ Corresponding author: Joe.Moritz@mail.wvu.edu 


\section{SUMMARY}

The brooder phase (D1-42) is important to overall turkey growth performance. This period also represents a time of low feed consumption; therefore, investments in increasing nutrient density may be cost effective. Exogenous phytase enzymes can improve bird performance and decrease phosphorus $(\mathrm{P})$ excretion. Research has also indicated that phytase inclusion may help decrease gut inflammation and subsequent immune response caused by phytate P. Increasing phytase inclusions may provide further benefit to these variables during the brooder phase. The objective of the current study was to assess the effect of increasing phytase inclusion (Normal or High) on D1-42 Hybrid Converter poult performance, D40 gut inflammation via ileal mRNA expression of Interleukin (IL)-1 $\beta$ and IL-6, and D40 total P content of litter. Diets were randomly assigned to one of 16 pens at a facility that mimics commercial grow-out. Normal and High phytase diets fed from D1-42 (containing an average of 384 and 2814 FTU/kg, respectively) had no effect on poult performance or on D40 ileal expression of IL-1 $\beta$ and IL-6. Feeding poults diets containing High phytase compared to Normal phytase decreased D40 total P content of litter by approximately 11\%. These data show benefits for High phytase diets to potentially decrease environmental impact. Perhaps performance would have been increased and potential for environmental impact further decreased if diet formulations would have accounted for High phytase inclusions to liberate greater concentrations of phytate $\mathrm{P}$ and thus be decreased in inorganic $\mathrm{P}$. Regardless, speculation for the use of high phytase inclusion to reduce gut inflammation was not supported using these inflammatory markers.

Keywords: phytase, litter phosphorus, inflammatory cytokines, gut health, real time-PCR, poult performance 


\section{DESCRIPTION OF THE PROBLEM}

Exogenous phytase enzymes have been successfully included into commercial poultry diets as a cost effective strategy to help poultry better utilize nutrients (phytate $\mathrm{P}$ ) in diets, and improve bird performance [1-5]. In addition, it has been well accepted in the literature that inclusions of phytase enzymes can reduce P content of litter, which can help assuage environmental concerns [610]. Recently, there has been speculation that phytase inclusions may also improve gut health [11]. This has led researchers to investigate whether increasing phytase inclusions beyond typical inclusions would provide additional benefit to bird performance and gut health $[5,12]$. Brooder phase performance (D1-42) is thought to be an integral part of ensuring that turkeys reach their maximum potential at the end of grow-out [13]. Feed intake during this brooder phase is relatively low; therefore, implementing alternative feeding strategies may be worthwhile. Therefore, the first objective of the current study was to compare the D1-42 performance and D 40 gut health (ileal expression of IL-1 $\beta$ and IL-6) of turkey poults when fed similar diets, differing in phytase inclusion levels (Normal or High). In addition, it was of interest to determine the effect of varying phytase inclusion on D40 P content of litter. This research utilized commercial diet formulations manufactured in a commercial feed mill that were fed to Hybrid Convertor male poults in a facility designed to mimic commercial grow-out.

\section{MATERIALS AND METHODS}

\section{Diet Preparations}

All diets fed in this study were proprietary and formulated by commercial nutritionists to have similar nutritional profiles and to meet or exceed industry recommendations for growing male Hybrid Convertors [14]. In general, diets contained corn, soybean meal, distiller's dried grains and 
solubles, poultry by-product meal, wheat middlings, animal/vegetable blended fat, defluorinated $\mathrm{P}$ and monocalcium P. The experimental period was from D1-42, which included two dietary phases (phase 1: D1-10 and phase 2: D10-42). Each phase utilized two treatments: 1) Normal Phytase; and 2) High Phytase. All diets were batched and pelleted at a commercial feed mill [15] then delivered to the West Virginia University turkey research facility, which was designed to mimic commercial grow-out. At the farm, feed samples were obtained from each diet and sent to a commercial laboratory [16] for analysis of phytase activity, total phosphorus, and phytic acid (Table 1). Non-phytate phosphorus (nPP) content of each of the starter diets was then calculated using the following equation: [analyzed total phosphorus - (analyzed phytic acid *0.282)] [6] (Table 1).

\section{Facilities and Birds}

One-hundred and five, 1-d-old male Hybrid Convertor [14] poults were randomly allocated to one of 16 pens $(6.1 \times 5.2 \mathrm{~m})$ containing fresh wood shavings, placed on top of concrete flooring. This facility incorporated tunnel ventilation, radiant brooders, bell drinkers, and an augered feed pan system were utilized. Feed and water were provided for ad libitum consumption. In order to continuously monitor feed intake and bird weights, each pen contained an automated bird and feed dump scale [17] that provided data continuously; however, only D1-42 performance results are presented in this paper. All scales were calibrated weekly. Industry protocols were followed for temperature and lighting programs [18]. Measured performance variables included: beginning pen weight (D1), D1-42 pen feed intake (FI), feed conversion ratio (FCR; corrected with mortality weight), and percent mortality; as well as D42 average ending weight (EW) (Table 3). All birds were cared for according to West Virginia University Animal Care and Use Committee Guidelines. 


\section{Estimates of Gut Inflammation}

Poult Sampling. On D40, one poult per pen $(\mathrm{n}=16)$ was randomly selected, weighed and killed via cervical dislocation. Immediately after, the distal ileum from each poult was excised, flushed with sterile water, and weighed to obtain an average weight per bird. The distal ileum was excised by severing the ileum at the point half-way from the meckles diverticulum to $0.5 \mathrm{~cm}$ proximal to the ileal-cecal junction. Next, a ruler was used to obtain ileal samples from each poult that measured $0.5 \times 0.5 \mathrm{~cm}$ in size, and each sample was placed in a separate, sterile container containing RNA Later [19], and stored at $-80^{\circ} \mathrm{C}$ until RNA purification and isolation was performed.

Real Time (RT)-PCR. Methodologies utilized to perform RT-PCR were obtained from past research [20]. After sample removal from the RNA later [19] solution, approximately $100 \mathrm{mg}$ was homogenized with Trizol Reagent [21], and then incubated at room temperature for $5 \mathrm{~m}$. Next, $200 \mu \mathrm{l}$ of chloroform was introduced to samples for $3 \mathrm{~m}$ then centrifuged for $15 \mathrm{~m}$, at $4{ }^{\circ} \mathrm{C}$ and $11,400 \mathrm{rpm}$. Resulting supernatant was removed and the remaining pellet was rinsed with $1 \mathrm{ml}$ of $75 \% \mathrm{EtOH}$, and then centrifuged again for $5 \mathrm{~m}$ at $4^{\circ} \mathrm{C}$ and 9,000 rpm, and repeated. Supernatant was removed and pellets were allowed to air dry. Pellets were then dissolved in $100 \mu \mathrm{l}$ of nuclease-free water, placed in a $60^{\circ} \mathrm{C}$ water-bath for $10 \mathrm{~m}$, centrifuged for $4 \mathrm{~m}$ (room temperature) and supernatant was removed and transferred to a sterile $1.5 \mathrm{ml}$ tube. Quantification of RNA was accomplished via NanoDrop [22] and quantity of sample to yield $1 \mu \mathrm{g}$ was determined. A pooled control sample (containing all Normal Phytase samples) was also made in order to use as a reference on each plate. Reverse transcription (RT) was accomplished using a PTC-200 DNA Engine [23] and an iScript cDNA synthesis kit [24]. Manufacturer recommendations provided 
with the iScript kit were followed; however, a denaturation step was added that involved the combination of RNA and water, heating at $80^{\circ} \mathrm{C}$ for $3 \mathrm{~m}$ and cooling prior to the addition of iScript reagents. Next, RT working stock was created for each sample to contain a cDNA concentration of $1 \mathrm{ng} / \mu \mathrm{l}$.

Primers were designed using the Primer 3 program [25], with preferred sizing of 75-125 base pairs and similar melting points, and then ordered from Integrated Device Technology (IDT) [26] (Table 3). In order to normalize expression patterns of target genes, GAPDH (Glyceraldehyde-3-phosphate dehydrogenase) was chosen as a house-keeping gene. Nuclease-free water was used to dissolve primers. Then RT working stock, primer of interest, nuclease-free water, and SYBR Green PCR Master Mix [27] were combined and placed in each well on a plate, running samples in triplicate. Plates were then placed in CFX96 Real-Time System [28], with an initial stage of $95^{\circ} \mathrm{C}$ for $4 \mathrm{~m}$, followed by 40 cycles for $15 \mathrm{~s}, 60^{\circ} \mathrm{C}$ for $30 \mathrm{~s}$, and $72^{\circ} \mathrm{C}$ for $30 \mathrm{~s}$.

Prior to determining the expression of primers in each sample, pooled control samples (with and without primer addition) were ran in triplicate to ensure primers gave acceptable and consistent amplification efficiency/slope. The pooled control sample (without primer addition) was tested to ensure that amplification did not result until at least 4 cycles after amplification occurred for samples containing primers. Each primer of interest was tested using a similar plate set-up with each sample ran in triplicate: pooled control sample (without primer addition), pooled control sample (with primer), and samples obtained from each pen $(n=16)$, each containing primer of interest. Amplification efficiency was assessed using the DART program [29] and mRNA expression of IL-1 $\beta$ and IL-6 was normalized based on calculated relative abundance as described by Pfaffl [30] (Table 4). 


\section{Litter Sampling.}

At the beginning of this study poults were placed in clean pens with fresh wood shaving litter. On D40, approximately $500 \mathrm{~g}$ of litter was obtained from the middle and each corner $(\mathrm{n}=5)$, then combined and mixed thoroughly to create a uniform litter sample for each pen $(\mathrm{n}=16)$. Litter samples were then sent 'as is' to a commercial laboratory [16] for total P analysis (Table 2). Total $\mathrm{P}$ analysis used inductively coupled plasma emission spectroscopy [31].

\section{Statistical Analyses.}

All data were statistically analyzed using the GLM procedure of Statistical Analysis System [32]. Treatments were analyzed as a randomized complete block design, with 8 replicate pens per treatment (Normal or High Phytase). Fisher's least significant difference multiple comparison tests were used to further compare treatment means.

\section{RESULTS AND DISCUSSION}

\section{Diet analyses}

Diets were analyzed for Total P and Phytic acid to determine calculated non-phytate P, according to Angel and others [6] (Table 1). Normal and High Phytase diets fed in phase 1 (D110) were found to be similar in calculated non-phytate $\mathrm{P}(0.61$ and $0.62 \%$, respectively; Table 1$)$. Phase 2 (D10-42) Normal and High Phytase diets were calculated to be different in non-phytate P (0.66 and $0.59 \%$, respectively; Table 1$)$. Although, both diets were formulate to be similar, therefore variations may be due to compounded analysis errors or batching being conducted at a commercial feed mill during normal working hours. 
High Phytase diets in phase 1 were shown to be approximately $4 \mathrm{x}$ the phytase enzyme activity as Normal Phytase diets (1900 FTU (phytase units/kg [33]) vs 460 FTU, respectively; Table 1). Phase 2 High Phytase diets were shown to be more than $8 \mathrm{x}$ the phytase activity analyzed for the Normal Phytase diet (3100 vs 360 FTU, respectively; Table 1). Using the number of days each of the two dietary phases were fed, Normal and High phytase diets were calculated to contain an average of 384 and $2814 \mathrm{FTU} / \mathrm{kg}$, respectively.

\section{Poult Performance}

Small poult performance differences in FCR were established within the D1-28 (data not shown); however, there were no significant EW differences established for poults fed diets varying in phytase inclusion on D42 (Table 2). In addition, no significant differences were found for D142 pen FI, FCR, or percent mortality. Atia and cohorts [3] found that poults fed diets with Calcium (Ca):nPP ratios of 2.6:1 performed better than poults fed diets containing 3.6:1 Ca:nPP ratios. As previously mentioned, diets formulations utilized in the current study were proprietary; however, diets were formulated using similar phytase sparing effects $(0.10 \%)$ and analyzed/calculated nPP levels were similar to that of Normal Phytase diets. Therefore, the authors of this paper assume that the Ca:nPP ratio of High Phytase diets were similar. It is likely that poult performance differences were not observed in the current study due to the use of commercial diets, which were formulated to maximize growth during this phase.

\section{Estimates of gut inflammation}

Phytates can act as an irritant to the gastrointestinal tract $[11,34]$ and may directly cause inflammation to the wall of gastrointestinal tract. Therefore, it was of particular interest of the 
current study to determine if varying phytase inclusion (Normal or High) would have an effect on gut inflammation measurements. In the current study, one poult per pen $(n=16)$ was randomly selected, weighed, and killed. Gut inflammation was assessed in two ways: 1) ileal weights; and 2) relative ileal mRNA expression of cytokines. No significant differences were obtained for average weight of poults randomly selected for necropsies, D40 average ileum weight per poult, or percent ileum of poult weight $(\mathrm{P}>0.05$; Table 5). In addition, no significance was established for relative ileal mRNA expressions of the cytokines IL-1 $\beta$ and IL-6 (P > 0.05; Table 4).

Cytokine expression can be an effective measurement to determine the severity of an inflammatory response [35]. Several studies have used expression of the proinflammatory cytokines IL-1 $\beta[36]$ and IL-6 $[37,38]$ in the gut to assess immune response of poultry. Data from the current study suggest that Normal and High Phytase inclusions had no effect on poult immune response using this study's specific methodology. It is possible that the methodology used in the current study was unable to determine any gut inflammation due to the use of fresh litter or the use of phytase inclusions in both diets tested.

Phytase level effects on performance and gut inflammation have been measured by other researchers. Pirgozliev and others [5] established significant improvements in both feed intake and weight gain (without affecting FCR) for poultry fed diets containing either 500 or 2500 FTU/kg, while finding no significance for villus length and thickness and a strong trend $(\mathrm{P}=0.056)$ for concentration of excreted sialic acid. Sialic acid was measured because its production is often associated with infection [5] and the production of mucin [39]. These researchers [5] speculated the conflicting performance and gut measurements to be attributed to "the combination of an irritant and an unbalanced supply of nutrients". Persia [12] found that a phytase inclusion of 15000 FTU/kg (as compared to a diet without phytase inclusion) reduced ileal mucin production using 
22-d-old broilers, without causing detriment to performance. Persia also tested phytase inclusions of 500 and $7500 \mathrm{FTU} / \mathrm{kg}$, but was unable to distinguish any differences in mucin production when compared to diets without phytase inclusions. These data suggest that increased inclusions of phytase may improve bird performance and/or gut health; however, benefits may not be realized unless much higher inclusions are utilized than that in the current study (2814 FTU/kg).

\section{Litter Sampling}

Feeding poults High Phytase (2814 FTU/kg) diets significantly decreased total P content of litter as compared to the analyzed total P content of litter produced by poults fed Normal Phytase (384 FTU/kg) by more than $11 \%(\mathrm{P}=0.0279$; Table 2). Powell and others [4] found that broilers fed diets containing a phytase activity of $600 \mathrm{FTU} / \mathrm{kg}$ (as compared to diets containing $0 \mathrm{FTU} / \mathrm{kg}$ ) decreased total P content of litter by $22 \%$. Similar reductions in total P content of litter are supported by previous research [7, 8]. In contrast, research conducted by Ledoux and cohorts [2] determined that a phytase activity level of $1000 \mathrm{FTU} / \mathrm{kg}$ was unable to reduce litter P when fed to turkey hens from D1-105 and attributed this result to available P levels in the diet being too high, creating too wide of a range of Ca: available $\mathrm{P}$ ratios. However, as previously mentioned, dietary analyses revealed similar nPP (estimate of available P) levels of the diets utilized in the current study, therefore the authors assume Ca:nPP levels were also similar.

The literature surrounding the relationship between total $\mathrm{P}$ and soluble $\mathrm{P}$ content of litter is complicated and conflicting [7, 9, 40-44]. It is difficult to determine whether the $\sim 11 \%$ decrease in total P content of litter observed in the current study would have an effect on soluble P. As previously mentioned, total $\mathrm{P}$ accounts for both organic and inorganic $\mathrm{P}$ and it is difficult to 
decipher between the two in litter and soil analyses in order to predict potential environmental impact [42-44].

\section{Summary}

Although performance differences were not observed in the current study, these data suggest that increasing phytase inclusions will at least maintain brooder phase poult performance and gut health, while reducing total $\mathrm{P}$ content of litter. Diets, management strategies, and poults were of a commercial source and a facility that mimicked commercial grow-out was utilized in order to maximize growth performance and to potentially provide strategies that may be directly implemented into commercial turkey production. Gut health, as assessed in the current study using ileal weights and mRNA expression of IL-1 $\beta$ and IL-6, did not demonstrate any benefit towards High Phytase diets. In addition, feeding poults High Phytase diets (2814 FTU/kg) total P content of litter was reduced by $\sim 11 \%$ in the brooder phase without altering dietary nPP. Perhaps the plane of nutrition was too high for the current study; therefore, performance and gut health benefits of High Phytase diets were unable to be realized. Alternative feeding strategies (i.e. reduce nPP) used in conjunction with high phytase may be cost effective and help to improve the variables tested in the current study.

\section{CONCLUSIONS AND APPLICATIONS}

1. Normal and High phytase diets fed from D1-42 (containing an average of 384 and 2814 FTU/kg, respectively) had no effect on brooder phase poult performance or gut health, using this study's specific methodology. These results may have been due to the plane of nutrition being too high. 
2. Feeding High Phytase (diets containing an average of $2814 \mathrm{FTU} / \mathrm{kg}$ ) to poults placed on fresh shavings from D1-40 reduced total P content of litter by $~ 11 \%$; however, due to complexity of litter and soil P analyses, the environmental impact of these results are undetermined.

\section{ACKNOWLEDGEMENTS}

The authors would like to extend their sincere appreciation to Loyd Whetzel, his efforts were monumental in ensuring the successful completion of this study. In addition, the authors would like to thank Dr. Kim Barnes and Ms. Siri Ippagunta for sharing their time and knowledge pertaining to RT-PCR.

\section{REFERENCES}

1. Nelson, T. S., T. R. Shieh, R. J. Wodzinski, and J. H. Ware. 1971. Effect of supplemental phytase on utilization of phytate phosphorus by chicks. J. Nutr. 101: 1289-1294.

2. Ledoux, D. R., K. Zyla, and T. L. Veum. 1995. Substitution of phytase for inorganic phosphorus for turkey hens. J. Appl. Poult. Res. 4:157-163.

3. Atia, F. A., P. E. Waibel, I. Hermes, C. W. Carlson, and M. M. Walser. 2000. Effect of dietary phosphorus, calcium, and phytase on performance of growing turkeys. Poult. Sci. 79:231-239.

4. Powell, S., S. Johnston, L. Gaston, and L. L. Southern. 2008. The effect of dietary phosphorus level and phytase supplementation on growth performance, bone-breaking strength, and litter phosphorus concentration in broilers. Poult. Sci. 87:949-957.

5. Pirgozliev, V., O. Oduguwa, T. Acamovic, and M. R. Bedford. 2007. Diets containing Escherichia coli-derived phytase on young chickens and turkeys: effects on performance, metabolizable energy, endogenous secretions, and intestinal morphology. Poult Sci. 86:705-713.

6. Angel, R., N. M. Tamim, T. J. Applegate, A. S. Dhandu, and L. E. Ellestad. 2002. Phytic acid chemistry: influence on phytin-phosphorus availability and phytase efficacy. J. Appl. Poult. Res. 11:471-480.

7. Applegate, T. J., B. C. Joern, D. L. Nussbaum-Wagler, and R. Angel. 2003. Water-soluble phosphorus in fresh litter is dependent upon phosphorus concentration fed but not fungal phytase supplementation. Poult. Sci. 82:1024-1029.

8. Shelton, J. L., L. L. Southern, L. A. Gaston, and A. Foster. 2004. Evaluation of the nutrient matrix values for phytase in broilers. J. Appl. Poult. Res. 13:213-221. 
9. Smith, D. R., P. A. Moore, Jr., D. M. Miles, B. E. Haggard, and T. C. Daniel. 2004. Decreasing phosphorus runoff losses from land-applied poultry litter with dietary modifications and alum addition. J. Environ. Qual. 33:2210-2216.

10. Maguire, R. O., J. T. Simms, and T. J. Applegate. 2005. Phytase supplementation and reduced-phosphorus turkey diets reduce phosphorus loss in runoff following litter application. J. Environ. Qual. 34:359-369.

11. Cowieson, A. J., T. Acamovic, and M. R. Bedford. 2004. The effects of phytase and phytic acid on the loss of endogenous amino acids and minerals from broiler chickens. Br. Poult. Sci. 45:101-108.

12. Persia, M. E. 2010. Effects of enzyme supplementation on intestinal environment and poultry performance. Pages $108-115$ in Proc. $8^{\text {th }}$ Mid-Atlantic Nutr. Conf. Univ. Maryland, College Park, MD.

13. Mitchell, R. 2002. Opportunities for improving poult performance with feed. Pages 1-9 in Proc. Multi-State Poultry Meeting. Indianapolis, IN. Purdue University.

14. Hybrid Turkeys; Hendrix Genetics, Boxmeer, Netherlands

15. Virginia Poultry Growers Cooperative Feedmill, Broadway, VA

16. NP Analytical Laboratories, St. Louis, MS.

17. Chore-Time Brock Incorporated, Milford, IN

18. Virginia Poultry Growers Cooperative, 2011.

19. RNAlater. Qiagen, Inc. Valencia, CA.

20. Barnes, K. M., N. R. Winslow, A. G. Shelton, K. C. Hlusko, and M. J. Azain. 2011. Effect of dietary conjugated linoleic acid on marbling and intramuscular adipocytes in pork. J. Anim. Sci. November 11, 2011 jas.2011-4642.

21. TRIzol reagent. Invitrogen, Carlsbad, CA.

22. ND-1000 UV Vis Spectrophotometer. NanoDrop Technologies, Wilmington, DE.

23. PTC (Peltier Thermal Cycler)-200 DNA Engine. MJ Research. St. Bruno, Quebec, Canada.

24. iScript cDNA Synthesis Kit. Bio-Rad Laboratories, Inc. Hercules, CA.

25. Rozen, S. and H. J. Skaletsky. 2000. Primer3 on the WWW for general users and for biologist programmers. In: Krawetz S, Misener S (eds) Bioinformatics Methods and Protocols: Methods in Molecular Biology. Humana Press, Totowa, NJ, pp 365-386. Source code available at http://fokker.wi.mit.edu/primer3/

26. Integrated Device Techology. San Jose, CA.

27. SYBR Green PCR Master Mix. Bio-Rad Laboratories, Inc. Hercules, CA.

28. CFX96 Real-Time System, Optics Module. Bio-Rad Laboratories, Inc. Hercules, CA.

29. Peirson, S. N., J. N. Butler, R. G. Foster. 2003. Experimental validation of novel and conventional approaches to quantitative real-time pcr data analysis. Nucleic Acids Res. 31:e7371-e7377.

30. Pfaffl, M. W. 2001. A new mathematical model for relative quantification in real-time rtpcr. Nucleic Acids Res. 29:2002-2007.

31. Maguire, R. O., and J. T. Sims. 2002. Measuring agronomic and environmental soil phosphorus saturation and predicting phosphorus leaching with mehlich 3. Soil Sci. Soc. Am. J. 66:2033-2039.

32. SAS Institute. 2009. The SAS System for Windows 2009. Release 8.1. SAS Inst. Inc., Cary, NC. 
33. A unit of phytase is the quantity of enzyme that liberates one micromole of inorganic $P$ per minute from an excess of sodium phytate at a $\mathrm{pH}$ of 5.5 and a temperature of $37^{\circ} \mathrm{C}$.

34. Onyango, E. M., E. K. Asem, and O. Adeola. 2009. Phytic acid increases mucin and endogenous amino acid losses from the gastrointestinal tract of chickens. 101: 836-842.

35. McKay, D. M. and A. W. Baird. 1999. Cytokine regulation of epithelial permeability and ion transport. Gut. 44: 283-289.

36. Hong, Y. H., H. S. Lillehoj, S. H. Lee, R. A. Dalloul, and E. P. Lillehoj. 2006. Analysis of chicken cytokine and chemokine gene expression following Eimeria acervulina and Eimeria tenella infections. Vet. Immunol. Immunopathol. 114:209-223.

37. Lee, K. W., S. H. Lee, H. S. Lillehoj, G. X. Li, S. I. Jang, U. S. Babu, M. S. Park, D. K. Kim, E. P. Lillehoj, A. P. Neumann, T. G. Rehberger, and G. R. Siragusa. 2010. Poult. Sci. 89: 203-216.

38. Zhang, M., T. Nii, N. Isobe, and Y. Yoshimura. 2012. Expression of Toll-like receptors and effects of lipopolysaccharide on the expression of proinflammatory cytokines and chemokine in the testis and epididymis of roosters. Poult. Sci. 91:1997-2003.

39. Montagne, L., R. Toullec, and J. P. Lalles. 2000. Calf intestinal mucin: Isolation, partial characterization, and measurement in ileal digesta with an enzyme-linked immunosorbent assay. J. Dairy Sci. 83:507-517.

40. Sharpley, A. N. 1995. Dependence of runoff phosphorus on extractable soil phosphorus. Environ. Qual. 24:920-926.

41. Pote, D. H., T. C. Daniel, A. N. Sharpley, P. A. Moore, Jr., D. M. Miller, and D. R. Edwards. 1999. Relationship between phosphorus levels in three ultisols and phosphorus concentrations in runoff. J. Environ. Qual. 28:170-175.

42. Dibb, D. W. 2002. Introduction to inorganic and organic nutrients. Better Crops with Plant Food. 86(2):3.

43. Motavalli, P. P. and R. J. Miles. 2002. Inorganic and organic soil phosphorus fractions after long-term animal manure and fertilizer applications. Better Crops with Plant Food. 86(3):20-23.

44. Maguire, R. O., and J. T. Sims. 2002. Soil testing to predict phosphorus leaching. J. Environ. Qual. 31:1601-1609. 
Table 1. Analyses of dietary phases 1 and $2^{1}$

\begin{tabular}{|c|c|c|c|c|}
\hline \multirow{2}{*}{ Analyzed Value } & \multicolumn{2}{|c|}{ Dietary phase 1 } & \multicolumn{2}{c|}{ Dietary phase 2 } \\
\cline { 2 - 5 } & Normal Phytase & High Phytase & Normal Phytase & High Phytase \\
\hline Total Phosphorus $^{2}(\%)$ & 0.887 & 0.886 & 0.942 & 0.890 \\
\hline Phytic Acid $\left.^{3} \%\right)$ & 0.996 & 0.954 & 1.01 & 1.06 \\
\hline Calculated nPP $^{4}(\%)$ & 0.606 & 0.617 & 0.657 & 0.591 \\
\hline Phytase $^{5}(\mathrm{FTU} / \mathrm{kg})$ & 460 & 1900 & 360 & 3100 \\
\hline
\end{tabular}

${ }^{1}$ Diets were analyzed at NP Analytical Labs [16]; dietary phase 1 diets were fed from D1-10 of this study and dietary phase 2 diets were fed from D10-42 of this study; using the number of days each diet was fed, Normal Phytase diets contained an average 384 (FTU/kg) and High Phytase diets contained an average of 2814 FTU/kg

${ }^{2}$ Total Phosphorus is determined by first ashing the sample in a muffle furnace to remove organic material. The ash residue is dissolved in dilute acid. The sample solution is analyzed using a Technicon Auto-Analyzer system, where the solution is treated with molybdic-sulfuric acid reagent, forming phosphomolybdate. Stannous chloride-hydrazine sulfate is added to reduce the phosphomolybdate, with a resultant blue color. The concentration of phosphorus $(\mathrm{P})$ is then determined by comparing the absorbance of the sample solution to the absorbance of standard solutions using colorimetric spectroscopy.

${ }^{3}$ Phytic acid is extracted with dilute hydrochloric acid solution, and separated from inorganic phosphates on an anion exchange column. Phytate is eluted with a sodium chloride solution. The eluate is digested with sulfuric/nitric acid, freeing phosphorus, which is reacted with ammonium molybdate and sulfonic acid solutions, forming a blue color complex which is measured spectrophotometrically. Phosphorus concentration is quantitated from a set of standards of known concentration that are taken through the color reaction. Values are converted to phytic acid based on molecular weight equivalence.

${ }^{4}$ Calculated non-Phytate Phosphorus was determined using the following equation: [\% Total Phosphorus - (\% Phytic Acid * 0.282)] $=\%$ Calculated non-Phytate Phosphorus [6]

${ }^{5}$ Phytase enzyme concentration was determined using AOAC Method 2000.12

${ }^{6}$ Normal diet contains normal VPGC diet formulation, including normal phytase enzyme inclusion; phase 1 diets were fed from D1-10 and phase 2 diets were fed from D10-42, using the number of days each diet was fed, Normal Phytase diets contained an average of $384 \mathrm{FTU} / \mathrm{kg}$

${ }^{7}$ High Phytase diet contains normal VPGC diet formulation except is intended to also contain High the normal VPGC phytase enzyme inclusion; phase 1 diets were fed from D1-10 and phase 2 diets were fed from D10-42, using the number of days each diet was fed, High Phytase diets contained an average of 2814 FTU/kg 
Table 2. The effect of varying D1-42 phytase inclusion on poult performance ${ }^{1}$ and D40 litter analysis $^{2}$

\begin{tabular}{|c|c|c|c|c|c|c|}
\hline Treatment & $\begin{array}{c}\text { D1 Avg. } \\
\text { Beginning } \\
\text { Poult Wt } \\
(\mathrm{kg})\end{array}$ & $\begin{array}{c}\text { D1-42 } \\
\text { Pen Feed } \\
\text { Intake }^{1} \\
(\mathrm{~kg})\end{array}$ & $\begin{array}{c}\text { D42 Avg. } \\
\text { Poult } \\
\mathrm{Wt}^{1,3} \\
(\mathrm{~kg})\end{array}$ & $\begin{array}{c}\text { D1-42 } \\
\text { FCR }^{1,4}\end{array}$ & $\begin{array}{c}\text { D1-42 } \\
\text { Mortality } \\
1,5 \\
(\%)\end{array}$ & $\begin{array}{c}\text { D40 } \\
\text { Litter } \\
\text { Total P,6 }^{2,6} \\
(\%)\end{array}$ \\
\hline Normal Phytase $^{7}$ & 0.0612 & 315.00 & 2.75 & 1.45 & 11.53 & $0.803^{\mathrm{a}}$ \\
\hline High Phytase $^{8}$ & 0.0612 & 307.91 & 2.71 & 1.45 & 12.36 & $0.712^{\mathrm{b}}$ \\
\hline Fisher's LSD $^{9}$ & - & - & - & - & - & 0.0774 \\
\hline ANOVA P-Value $^{10}$ & 0.5033 & 0.5502 & 0.3851 & 0.7929 & 0.7406 & 0.0279 \\
\hline SEM $^{10}$ & 0.0002 & 7.988 & 0.0268 & 0.0026 & 1.711 & 0.0231 \\
\hline
\end{tabular}

${ }^{\mathrm{I}}$ Variables with this superscript represent the performance variables obtained from D1-42 of this study

${ }^{2}$ Litter samples were taken from each corner and from the middle of each pen, mixed thoroughly to create a representative sample from each pen to be sent to a commercial laboratory [16] to be analyzed 'as is'

${ }^{3} \mathrm{D} 42$ average poult weight was obtained from automated scales located in each pen; scales were calibrated weekly ${ }^{4}$ Feed conversion ratio (Feed:Gain) was calculated using mortality weight

${ }^{5}$ Mortality percentage is based on a beginning pen number of 76 , thus if 10 birds die in a pen the resulting mortality percentage would be $13 \%$

${ }^{6}$ Total Phosphorus is determined by first ashing the sample in a muffle furnace to remove organic material. The ash residue is dissolved in dilute acid. The sample solution is analyzed using a Technicon Auto-Analyzer system, where the solution is treated with molybdic-sulfuric acid reagent, forming phosphomolybdate. Stannous chloride-hydrazine sulfate is added to reduce the phosphomolybdate, with a resultant blue color. The concentration of phosphorus $(\mathrm{P})$ is then determined by comparing the absorbance of the sample solution to the absorbance of standard solutions using colorimetric spectroscopy.

${ }^{7}$ Normal Phytase diets were fed from D1-42 of this study; using the number of days each diet was fed, Normal Phytase diets contained an average $384 \mathrm{FTU} / \mathrm{kg}$

${ }^{8}$ High Phytase diets were fed from D1-42 of this study; using the number of days each diet was fed, High Phytase diets contained an average of $2814 \mathrm{FTU} / \mathrm{kg}$

${ }^{9}$ Fisher's Least Significant Difference

${ }^{10}$ Standard Error of the Mean, an estimate of the amount that an obtained mean may be expected to differ by chance from the true mean. 
Table 3. Primers used for real-time $\mathrm{PCR}^{1}$

\begin{tabular}{|c|c|c|c|}
\hline Gene & Accession Number ${ }^{2}$ & $\begin{array}{c}\text { Forward primer } \\
\text { sequence }\left(5^{\prime} \rightarrow 3^{\prime}\right)\end{array}$ & $\begin{array}{c}\text { Reverse primer } \\
\text { sequence }\left(5^{\prime} \rightarrow 3^{\prime}\right)\end{array}$ \\
\hline GADPH $^{3}$ & XM_003202670 & ccatgtttgtgatgggtgtc & gttgtcatggatgaccttgg \\
\hline IL-1 $\beta^{4}$ & XM_003207130 & aagtgcttcgtgctggagtc & ccggtacagcgcaatgtt \\
\hline IL-6 & DQ393271 & cacctcatcctccgtgactt & ggactgtgcccgaactaaaa \\
\hline
\end{tabular}

${ }^{1}$ Primers were designed by Primer 3 program [26] and product size was held at 75-125 bp; primers were ordered from IDT (Integrated DNA Technologies) [27]

${ }^{2}$ GenBank Accession Number, NCBI

${ }^{3} \mathrm{GADPH}=$ Glyceraldehyde-3-phosphate dehydrogenase, which served as a housekeeping gene

${ }^{4} \mathrm{IL}-1 \beta=$ interleukin 1-beta

${ }^{5} \mathrm{IL}-6=$ interleukin 6

Table 4. The effect of varying D1-42 phytase inclusion on gut inflammation measurements ${ }^{1}$

\begin{tabular}{|c|c|c|c|c|c|}
\hline Treatment & $\begin{array}{c}\text { Avg Bird Wt } \\
\text { for D40 } \\
\text { Necropsy } \\
(\mathrm{kg}) \\
\mathrm{n}=16\end{array}$ & $\begin{array}{c}\text { D40 Avg. } \\
\text { Ileal Wt } \\
\mathrm{n}=16\end{array}$ & $\begin{array}{c}\text { D40 Percent } \\
\text { Ileal of Poult } \\
\mathrm{Wt}^{2}(\%) \\
\mathrm{n}=16\end{array}$ & IL-1 $^{3}$ & IL-6 $^{4}$ \\
\hline Normal Phytase $^{5}$ & 2.70 & 11.59 & 0.407 & 1.04 & 1.05 \\
\hline High Phytase $^{6}$ & 2.60 & 10.78 & 0.378 & 1.27 & 1.35 \\
\hline Fisher's LSD $^{7}$ & - & - & - & - & - \\
\hline ANOVA P-Value $^{8}$ & 0.3335 & 0.1523 & 0.1523 & 0.4894 & 0.2697 \\
\hline SEM $^{8}$ & 0.0681 & 0.3577 & 0.0126 & 0.2169 & 0.1797 \\
\hline
\end{tabular}

${ }^{1}$ Data in this table was obtained from randomly selecting one poult per pen on D40 to obtain ileal weights and samples for real time-pcr

${ }^{2}$ Immediately after poults were killed, the ileum from each poult was excised; the ileum was defined as the half-way point from the meckles diverticulum to $0.5 \mathrm{~cm}$ proximal to the illeal-cecal junction. The ileum was then flushed with sterile water and weighed.

${ }^{3} \mathrm{IL}-1 \beta=$ interleukin 1-beta; the mRNA relative abundance was normalized to GADPH (Glyceraldehyde-3-phosphate dehydrogenase), and set relative to the mean of poults fed Normal Phytase

${ }^{4} \mathrm{IL}-6$ = interleukin 6; the mRNA relative abundance was normalized to GADPH (Glyceraldehyde-3-phosphate dehydrogenase), and set relative to the mean of poults fed Normal Phytase

${ }^{5}$ Normal Phytase diets were fed from D1-42 of this study; using the number of days each diet was fed, Normal Phytase diets contained an average $384 \mathrm{FTU} / \mathrm{kg}$

${ }^{6}$ High Phytase diets were fed from D1-42 of this study; using the number of days each diet was fed, High Phytase diets contained an average of $2814 \mathrm{FTU} / \mathrm{kg}$

${ }^{7}$ Fisher's Least Significant Difference

${ }^{8}$ Standard Error of the Mean, an estimate of the amount that an obtained mean may be expected to differ by chance from the true mean 
CHAPTER 6: The use of practical diets and regression analyses to determine utilization of lysine and phosphorus in corn distillers dried grains and solubles using Cobb 500 male $\underline{\text { broilers }}$

(Submitted for peer-review)

K.G.S. Wamsley ${ }^{*}$, R.E. Loar II $\dagger$, K. Karges $\dagger$, and J.S. Moritz ${ }^{*}, \mathbf{1}$

*Division of Animal and Nutritional Sciences, West Virginia University, Morgantown 26506 $\dagger$ POET Nutrition, Sioux Falls, SD

Primary Audience: Feed Mill Managers, Nutritionists, Researchers, Production Managers

${ }^{1}$ Corresponding author: Joe.Moritz@mail.wvu.edu 


\section{SUMMARY}

Two experiments were conducted to evaluate the utilization of lysine (Experiment 1) and phosphorus (Experiment 2) in corn distiller's dried grains and solubles (DDGS). Experiments utilized a $5 \times 3$ factorial analysis with variations in diet formulations for digestible lysine (Dig Lys) and available phosphorus (AP) and increasing DDGS Levels. Common performance metrics observed in both Experiments 1 and 2 were average ending bird weight (EW), average live weight gain (LWG), pen feed intake (FI), and feed conversion ratio (FCR). On D43 of Experiment 1, two birds/pen were chosen for analysis of carcass characteristics (CC) and on D21 of Experiment 2, tibias were excised to obtain tibia ash measurements. For both Experiments 1 and 2, performance metrics improved with increasing levels of Dig Lys and AP, respectively. In Experiment 1, Dig Lys $x$ DDGS interactions showed the most benefit for Low DDGS and in Experiment 2, DDGS inclusion had no effect on performance. Regression equations were derived for each performance metric across Dig Lys or AP levels and solved two ways: 1) using the observed metric resulting from each DDGS inclusion at the lowest Dig Lys or AP level in the equation derived from No DDGS inclusion; and 2) selecting a common performance metric and comparing Dig Lys or AP predictions across DDGS inclusions. These data demonstrate that the original Dig Lys and AP coefficients for DDGS are justified, but may underestimate availability by up to 0.08 and 0.02 percentage points, respectively.

Keywords: Distiller's dried grains and solubles, lysine, phosphorus, broiler performance, carcass characteristics, tibia ash, feed manufacture 


\section{DESCRIPTION OF THE PROBLEM}

The production of corn distiller's dried grains and solubles (DDGS), a coproduct from corn ethanol production, has drastically increased throughout the past ten years. In fact, from 2007 to 2009, the production of DDGS more than doubled from 14.6 to 30.5 million metric tons; and in 2010, 32.5 million metric tons of DDGS were produced in the United States [1]. These increases in production coincide with government policy that favors corn ethanol production. Currently, new technologies, production processes, and changes in government policies, have led the ethanol industry towards the creation of new ethanol coproducts (de-oiled DDGS) [2]. The future of the ethanol industry is uncertain, but at the conclusion of this study about half of the ethanol plants were still producing traditional DDGS [2]; therefore, still necessitating confirmation of nutrient availability. In addition, there is potential that the current technology employed to extract corn oil (to create de-oiled DDGS) may maintain the availability of nutrients (such as lysine and phosphorus) to that of traditional DDGS; thus, further supporting this research.

Phosphorus is important for proper skeletal development as well as metabolism; however, it represents a costly nutrient and if not included into the diet at the proper amount, the unutilized phosphorus will be excreted, eliciting possible negative environmental implications [3, 4]. The amino acid lysine is vital for proper bird performance and breast accretion, but is also limiting in basic corn/soybean based poultry diets [3, 4]. In addition, the availability of lysine in corn DDGS is of particular concern due to some drying processes associated with DDGS production [3, 4]. In order to maximize the use of this feed ingredient, it is essential to understand the ability of birds to utilize lysine and phosphorus.

Typically, the availability of an ingredient such as phosphorus is established utilizing laboratory analyses or semi-purified diets and the digestibility of an amino acid, such as lysine is 
determined utilizing similar techniques, as well as short growth periods, rooster models, and/or ileal digestibility [4-7]. However, these techniques are of course estimations, often demonstrating differences among methods employed; and therefore do not provide a direct way to measure bioavailability [8]. Two experiments were conducted that utilized a different methodology in order to establish the utilization of Dig Lys (Experiment 1) and AP (Experiment 2) in a common source of corn DDGS [9], which could be utilized in future ingredient testing. The objective of Experiment 1 was to use practical diet formulations that were pelleted, containing increased levels of Dig Lys and DDGS to establish their effects on feed processing, D3-42 male Cobb 500 broilers performance and carcass characteristics. Similarly, the objective of Experiment 2 was to use practical diet formulations containing increased levels of AP and DDGS to establish their effect on subsequent D3-21 Cobb 500 broiler performance and tibia measurements. These methods established the Dig Lys or AP content of the specific DDGS product [9] used in this study.

\section{MATERIALS AND METHODS}

\section{Experiment 1: Utilization of Lysine}

Diet Preparations. A 5x3 factorial analysis was utilized with variations in diet formulations for digestible lysine (Dig Lys) (70, 80, 90, 100, or 110\% of AGRI STATS levels [10]) and DDGS Level (No, Low, or High). Starter diets (D1-10; Table 1) contained either 0\% DDGS (No) or an inclusion of 4\% DDGS (Low or High). Grower diets (D11-22; Table 2) contained either 0, 5, or 10\% (No, Low or High) DDGS and Finisher diets (D23-42; Table 3) contained either 0, 10 or $20 \%$ (No, Low or High) DDGS. Treatment structure is better elucidated in Table 4. Digestible amino acid to Dig Lys ratios considered in diet formulation included: methionine, TSAA, threonine, tryptophan, arginine, isoleucine and valine. No maximum value 
was placed on crude protein, as digestible isoleucine was allowed to drive crude protein of the complete diet. In addition, sodium bicarbonate was included into the diet to keep chlorine levels from exceeding $0.28 \%$. A common source of corn DDGS [9] were included in each diet at treatment level requirements at the predominate expense of corn. Increasing DDGS and Dig Lys in diets required increased levels of supplemental fat. Diet formulations also included a commercial phytase utilized to liberate an additional $0.10 \%$ phosphorus from ingredients. Porcine meat and bone meal was included at a maximum of 5\% and no antibiotics were utilized. All diets were analyzed for nutrients at a commercial laboratory [11] and values for crude protein, lysine and TSAA are provided in the section titled "Analyzed Nutrients", located under the "Calculated Nutrients" section in their respective table (Table 1, 2 or 3). Calculated values for digestible threonine, digestible tryptophan, sodium, and chlorine are not displayed for any of the diet formulation tables, because values were either the same or similar for each diet within a given dietary phase.

All diets were manufactured at West Virginia University's pilot feed mill and descriptive data was obtained for manufacture efficiency and pellet quality. Diets were batched and pelleted in order of increasing Dig Lys and common DDGS inclusion, beginning with 0\% DDGS. When treatments changed in level of DDGS inclusion, the mixer was "cleaned out" with $90.7 \mathrm{~kg}(200 \mathrm{lb})$ of ground corn. All supplemental fat required by diet formulation was added at the mixer [12], prior to pelleting. Batch sizes were dictated by feed intake data based on Cobb 500 management guides [13]. Mash feed was conditioned using a short-term conditioner $(0.31 \times 1.30 \mathrm{~m}, 10 \mathrm{~s}$ retention time [14] with a constant temperature of $82.2^{\circ} \mathrm{C}\left(180^{\circ} \mathrm{F}\right)$ and a steam pressure of $262 \mathrm{kPa}$. Next, conditioned mash was extruded through a 4.76 x $38.10 \mathrm{~mm}(3 / 16 \times 11 / 2$ in) pellet die using a CPM 2288A master model pellet mill with a 40 HP main drive motor [15]. The auger that 
controls the rate that feed is conveyed into the conditioner was adjusted to achieve approximately the same production rate for each of the dietary treatments for a respective growth phase. All diets corresponding to a common growth phase (Starter, Grower, or Finisher) were pelleted within the same day and were ground via roller mill prior to feeding, in order to eliminate feed form effects. Halfway through the manufacture of each of the diets, samples were obtained from the cooler deck [16] in order to assess pellet quality through the pellet durability index and modified pellet durability index [17] and the New Holmen Tester [18]. In addition, the amount of fines, production rate, conditioner relative electrical energy use (CREE), and pellet mill relative electrical energy use (PMREE) were recorded for each diet.

Bird Performance. A total of 2,208 male Cobb 500 [13] day old chicks were obtained from a commercial hatchery [19], and then randomly and equally assigned to one of 90 floor pens $(0.69 \times 2.44 \mathrm{~m})$ that contained fresh pine shavings, located in a cross-ventilated negative pressure house. On D1, the 15 dietary treatments $(70,80,90,100$, or $110 \%$ Dig Lys and either No, Low, or High DDGS; Table 4) were randomly assigned to pens in a common housing location as a randomized complete block design, with a total of six blocks. On D3, pens of chicks were weighed (to obtain beginning pen weights) and adjusted to contain 22 chicks each (experimental unit). Feed and water were provided ad libitum, with water provided with ziggity nipples [20] and feed initially provided via feed pan and transitioned to feed hopper/pan combinations [21] on D7. Lighting and temperature schedules were modeled after previous research [22, 23], which were based on commercial recommendations. Mortality was collected and weighed daily. All birds were reared according to West Virginia University Animal Care and Use Committee guidelines.

On D 11, 23, and 42 measured live bird performance variables included: average ending bird weight (EW), average live weight gain (LWG), pen feed intake (FI), and feed conversion ratio 
(FCR) (adjusted with mortality weight); however only overall bird performance variables (D3-42)

will be provided in this paper. On D 43 , two birds per pen $( \pm 0.10 \mathrm{~kg}$ of the average bird weight for each pen on D42) were processed at the West Virginia University pilot processing plant.

Measurements obtained from processing included average hot carcass weight $(\mathrm{CW})$, average hot boneless skinless breast weight (BBW), and average hot boneless skinless breast yield (BBY).

\section{Experiment 2: Utilization of Phosphorus}

Diet Preparations. A $5 \times 3$ factorial analysis was utilized with variations in diet formulations for available phosphorus (AP) $(0.21,0.27,0.33,0.39$, or $0.45 \%)$ and DDGS Level (0, 8, or $16 \%$ ). Initially two diets were formulated for each level of DDGS: a negative control (NC), formulated to $0.21 \% \mathrm{AP}$ and a positive control (PC), formulated to $0.45 \% \mathrm{AP}$; these formulations are displayed in Table 5. Once again, a common source of DDGS [9] was used, porcine meat and bone meal inclusion was maximized at 5\%, and no antibiotics were utilized. All diets were batched at West Virginia University's pilot feed mill and were mixed in order of increasing AP level and common DDGS inclusion, beginning with 0\% DDGS. To create an additional three diets for each level of DDGS, ratios of NC and PC diets were mixed in the following manner: 75 NC:25 PC, 50 NC:50 PC, and 25 NC:75 PC; thereby, creating a total of 15 dietary treatments (treatment outline in Table 6). All diets were analyzed at a commercial laboratory [24] for total phosphorus and phytic acid to obtain calculated non-phytate phosphorus (nPP) [25], using the following equation: [analyzed total phosphorus - (analyzed phytic acid *0.282)]. The average calculated $\mathrm{nPP}$ for diets formulated to increasing levels of AP were $0.17,0.22,0.28,0.31$, and $0.37 \%$. Analyzed values for total phosphorus, phytic acid, calculated nPP, ash, and calcium for each diet are displayed in Table 6. Throughout the rest of this paper, diets will be referred to according to 
their analyzed/calculated nPP value and this value will be the estimate for AP. All diets were fed as mash.

Bird Performance. A total of 450 male Cobb 500 [13] day old chicks were obtained from a commercial hatchery [19], placed in a common floor pen containing fresh shavings, and provided a diet containing the analyzed value of $0.28 \% \mathrm{nPP}$ and $0 \%$ DDGS. On D3, chicks were individually weighed and placed in one of five weight classes. Next, one chick from each weight class was chosen and randomly assigned to one of 90 raised wire pens $(0.305 \times 0.508 \mathrm{~m})$. Groups of 15 adjacent pens were used as blocking criterion and treatments were replicated six times, using one pen of five chicks as the experimental unit. Pens contained nipple drinkers and trough type feeders and were housed in a negative-pressure house with circulating fans and forced air brooders. Room temperature was initially held at $35^{\circ} \mathrm{C}$ for the first week and then reduced as needed until the end of the study; birds were provided $24 \mathrm{~h}$ of light throughout the entire experimental period (D321). Measured variables included: D3 average chick weight, pen feed intake (FI), D3-21 average live weight gain (LWG), D21 average bird ending weight (EW) and D3-21 feed conversion ratio (FCR) (adjusted with mortality weight). On D21, chicks were euthanized via cervical dislocation and pen weights were obtained. Left tibias were extracted, dried [26], and ashed [27] to obtain average tibia ash per chick (TA) and percent TA. All birds were reared according to West Virginia University Animal Care and Use Committee guidelines.

\section{Experiment 1 and 2: Statistical Analysis}

Variables were analyzed in a 5 (Dig Lys or AP/nPP) x 3 (DDGS) factorial randomized complete block design. The experimental unit consisted of one pen of 22 (Experiment 1) or five broilers (Experiment 2). Treatment means were further compared using Fisher's least significant 
difference test. Dig Lys (Experiment 1) or AP/nPP (Experiment 2) and DDGS main effects, as well as Dig Lys (Experiment 1) or AP/nPP (Experiment 2) x DDGS interactions were also estimated.

For Experiment 1, the average Dig Lys levels that diets were formulated to across the $42 \mathrm{~d}$ grow-out period was determined and the diets varying in Dig Lys, containing No DDGS, were analyzed for linear and quadratic effects. Next, linear and quadratic effects were separately determined for diets at each level of DDGS (No, Low and High) varying in average Dig Lys. For Experiment 2, diets varying in calculated nPP, containing 0\% DDGS were analyzed for linear and quadratic effects. Next, linear and quadratic effects were separately determined for diets at each level of DDGS $(0,8$, and $16 \%)$ varying in calculated nPP. These equations were utilized to estimate nutrient availability of the DDGS. When analyzing data for Experiments 1 and 2, if relationships were not found to be quadratic, then the quadratic term was removed from the model and solved linearly.

The following pre-planned contrasts were also utilized:

Experiment 1- 100\% Dig Lys, No DDGS compared to: 90\% Dig Lys, Low DDGS; 90\% Dig Lys, High DDGS; and 80\% Dig Lys, High DDGS

Experiment 2- $0.31 \%$ nPP, 0\% DDGS compared to: $0.31 \%$ nPP, $8 \%$ DDGS; $0.31 \%$ nPP, 16\% DDGS; and $0.27 \%$ nPP, $16 \%$ DDGS 
These contrasts were chosen because the authors felt that if the original DDGS coefficients for Dig Lys (Experiment 1) and AP (Experiment 2) used in diet formulation were underestimated, and DDGS are included into diets deficient in Dig Lys or AP/nPP, then birds may perform statistically similar to the control diets (100\% Dig Lys or $0.31 \% \mathrm{nPP}$, without DDGS) for each respective experiment.

All data were statistically analyzed using the GLM procedure of Statistical Analysis System [28]. Alpha was designated as 0.05, and letter superscripts were used to denote differences among treatment means.

\section{RESULTS AND DISCUSSION}

\section{Experiment 1: Utilization of Lysine}

Feed Manufacture. Table 7 displays the descriptive feed manufacture data obtained from diets formulated to $100 \%$ Dig Lys at each DDGS inclusion for each dietary phase. All supplemental fat required by diet formulation was added at the mixer prior to pelleting. Fat supplementation increased as DDGS inclusion increased. Therefore, it is difficult to distinguish if feed manufacture variables were affected more by the increased mixer-added fat, or the increased level of DDGS inclusion. However, when comparing each of the variables indicating the quality of pellets produced (percent fines, pellet durability index, modified pellet durability index, and the New Holmen Tester at 30 and 60 s), increasing DDGS inclusion of starter and grower phase diets did not appear to negatively affect pellet quality. Increasing DDGS inclusion in finisher phase diets tended to decrease pellet quality; though this phase utilized the highest DDGS inclusion (20\%) and consequently supplemental mixer-added fat $(2.4 \%)$, in addition to a higher production rate, all of which likely contributing to the decline in pellet quality (Table 7). 
As previously mentioned, diets of a common dietary phase were manufactured in the same day. Production rate was chosen and controlled by the pellet mill operator, by manipulating the rate at which feed empties into the conditioner. Relative electrical energy use of the conditioner was relatively unchanged when comparing diets with similar production rates. However, REEPM tended to decrease as DDGS inclusion increased in diets from a common dietary phase (Table 7). Again, this effect was confounded with increased mixer-added fat that was required when formulating diets to contain increased levels of DDGS and maintain dietary ME.

Bird Performance. Overall (D3-42) live bird performance and D43 carcass characteristics are displayed in Table 8. For D3 average chick weight per pen, there was a significant Dig Lys effect $(P=0.0001)$, though this was expected given that chicks were randomly assigned dietary treatments varying in Dig Lys and DDGS on D1. Increasing Dig Lys to 90\% and 100\% of AGRI STATS levels significantly improved D3-42 LWG $(\mathrm{P}=0.0001)$ and FI $(\mathrm{P}=0.0001$; Table 8). Significance was also established for these variables for the main effect DDGS, demonstrating that Low DDGS inclusions significantly improved D3-42 LWG as compared to No DDGS (P = 0.0375) and including either Low or High DDGS into diets increased D3-42 FI (P = 0.0001). Significant Dig Lys x DDGS interactions were determined for FCR $(\mathrm{P}=0.0001)$, EW $(\mathrm{P}=$ 0.0001), $\mathrm{CW}(\mathrm{P}=0.0001), \mathrm{BBW}(\mathrm{P}=0.0001)$, and $\mathrm{BBY}(\mathrm{P}=0.0021)$. In general, these interactions suggest that across increasing Dig Lys, performance responses improve, but improve the greatest for diets containing Low DDGS, whereas High DDGS diets tend to plateau at higher Dig Lys levels.

Pre-planned contrasts compared the performance of the control diet (100\% Dig Lys, No DDGS) and 90\% Dig Lys diets containing Low and High DDGS, as well as 80\% Dig Lys diet containing High DDGS. These contrasts demonstrated that Low and High levels of DDGS can be 
included into diets formulated to 90\% Dig Lys without affecting FI, FCR, EW or CW (P > 0.05). In addition, High DDGS inclusions into 90\% Dig Lys diets did not affect BBW or BBY (P > 0.05), whereas Low DDGS inclusions into 90\% Dig Lys diets tended to negatively affect BBW ( $\mathrm{P}=$ $0.0635)$ and negatively affected BBY $(\mathrm{P}=0.0299)$. Diets formulated to $80 \%$ Dig Lys containing High levels of DDGS performed significantly worse as compared to the control diet $(\mathrm{P}<0.05)$, with the exception of $\mathrm{D} 3$ average beginning chick weight $(\mathrm{P}=0.1323)$ and $\mathrm{LWG}(\mathrm{P}=0.1417)$. Nevertheless, because differences in LWG $(P=0.0001$; Table 8) were obtained between diets formulated to 90 and 100\% Dig Lys, these pre-planned contrasts suggest that perhaps there is more Dig Lys in the DDGS than was originally accounted for in diet formulation for the DDGS used in this Experiment.

In order to better identify how much Dig Lys was underestimated from the original values used in formulation, regression equations were derived to determine "sparing effects" for each performance metric across Dig Lys levels and solved two ways: Method 1) using the observed metric resulting from each DDGS inclusion at the lowest Dig Lys level in the equation derived from No DDGS inclusion (Table 9); and Method 2) selecting a common performance metric and comparing Dig Lys predictions across DDGS inclusion levels (Table 10). The authors define a "sparing effect" as an additional percentage of a specific nutrient provided by a specific ingredient (in this paper DDGS), as compared to the original Dig Lys used in diet formulation.

All sparing effects verified the original Dig Lys content of the DDGS utilized in this experiment. Sparing effects calculated using Method 1 (Table 9) demonstrated the most consistent sparing effect for a High DDGS inclusion, ranging from $0.018-0.035 \%$. Inclusions of Low DDGS demonstrated a minimal benefit for $\mathrm{CW}$, with a calculated sparing effect of $0.004 \%$; as well as for BBW and BBY, with a calculated sparing effect of $0.012 \%$ (Table 9). Sparing effects 
calculated using Method 2 (Table 10) for this Experiment, established similar sparing effects for Low and High DDGS inclusions for EW (0.0024 and 0.026\%, respectively) and CW (0.017 and 0.018\%, respectively). For FCR, no additional sparing effect was established for a High DDGS inclusion, but a sparing effect for Low DDGS inclusions was determined to be $0.048 \%$ (Table 10). For the BBW and BBY, no additional sparing effect was found for Low DDGS inclusions, while sparing effects of 0.014 and $0.026 \%$ were demonstrated for High DDGS inclusions (Table 10). For LWG, a sparing effect of $0.020 \%$ was established for High DDGS inclusions and the highest sparing effect calculated was found for Low DDGS inclusions, at 0.073\% (Table 10). In summary, the calculated sparing effects for this experiment validate the original Dig Lys value for the DDGS used in this study $(0.7031 \%)$; however, sparing effects also demonstrate that this value may be underestimated, providing a Dig Lys value ranging from 0.7031-0.7731\% (Table 9 and 10).

\section{Experiment 2: Utilization of Phosphorus}

Bird Performance. Table 11 displays the effect of varying AP/nPP and DDGS inclusion on D3-21 live male broiler performance and D21 tibia measurements. As previously mentioned, diets will be referred to according to their analyzed/calculated nPP value and this value will be the estimate for AP. Starting chick weight (D3) did not differ among dietary treatments $(\mathrm{P}>0.05$; Table 11). It is important to note that no significance difference was established for the interaction between AP/nPP and DDGS Level or for the main effect DDGS Level for any of the measured performance variables $(\mathrm{P}>0.05$; Tables 11). These data demonstrate that this particular DDGS product can be included into diets at 8 and $16 \%$ from D3-21, without causing detriment to bird performance. These data do not correspond to Experiment 1; however, Experiment 1 focused on overall (D3-42) effects of DDGS on performance and utilized a floor pen setting, both of which 
differed from Experiment 2. As expected, significance was established for the main effect AP/nPP $(\mathrm{P}<0.05)$. The multiple comparison analysis demonstrated that increasing $\mathrm{AP} / \mathrm{nPP}$ into diets up to $0.31 \%$ improved overall bird performance in a step-wise manner for the following variables: D321 LWG, FI, D21 EW, TA, and percent TA ( $<$ < 0.05; Tables 11). In addition, the multiple comparison analysis demonstrated a step-wise decrease in D3-21 FCR as nPP increased in diets up to $0.28 \%$ ( $<<0.05$; Table 11$)$. These data suggest that the $\mathrm{nPP}$ treatment levels were appropriate to determine regressions to create prediction equations and that the minimum requirement for $\mathrm{P}$ of birds in this Experiment was less than the PC formulation of $0.37 \% \mathrm{nPP}$.

Pre-planned contrasts compared the performance of the control diet $(0.37 \% \mathrm{nPP}, 0 \%$ DDGS) and $0.31 \% \mathrm{nPP}$ diets containing 8 and $16 \%$ DDGS, as well as $0.27 \% \mathrm{nPP}$ diet containing 16\% DDGS. These contrasts demonstrated that 8 and 16\% DDGS can be included into diets containing $0.31 \% \mathrm{nPP}$ without causing detriment to LWG, FI, FCR, EW, TA, or percent TA. In fact, a significant increase was established for the variable LWG $(\mathrm{P}=0.0223$; Table 11) for diets containing $0.31 \% \mathrm{nPP}$ and $8 \%$ DDGS compared to the PC diet. Contrasts comparing diets containing $0.27 \% \mathrm{nPP}$ and $16 \%$ DDGS compared to the PC diet, demonstrated no detriment to most performance variables (Table 11); however, tibia measurements demonstrated a trend $(\mathrm{P}=$ 0.0810; Table 13) for lower percent TA and significantly lower TA $(\mathrm{P}=0.0123$; Table 11). In summary, these pre-planned contrasts suggest that there is likely more AP/nPP in the DDGS tested in this Experiment than was accounted for in the original diet formulation.

Similarly to Experiment 1, regression equations were derived to determine "sparing effects" for each performance metric across nPP levels and solved two ways: Method 1) using the observed metric resulting from each DDGS inclusion at the lowest nPP level in the equation derived from 0\% DDGS inclusion (Table 12); and Method 2) selecting a common performance 
metric and comparing nPP predictions across DDGS inclusion levels (Table 13). Once again, the authors define a "sparing effect" as an additional percentage of a specific nutrient provided by a specific ingredient (in this paper DDGS), as compared to the original AP used in diet formulation.

The calculated sparing effects at least verified the original AP content of the DDGS utilized in this experiment. Sparing effects calculated using Method 1 (Table 12) demonstrated the most consistent sparing effects for a 16\% DDGS inclusion, ranging from $0.012-0.0143 \%$, for all metrics except for TA. Inclusions of 8\% DDGS demonstrated similar benefits for EW and FCR, with calculated sparing effects of 0.013 and $0.015 \%$, respectively; but only a minimal benefit for percent TA and TA, with calculated sparing effects of 0.0046 and $0.0044 \%$, respectively (Table 12). Sparing effects calculated using Method 2 (Table 13) for this experiment once again established the most consistent sparing effects for 16\% DDGS inclusion, with calculated sparing effects ranging from $0.014-0.019 \%$ for EW, FCR and percent TA; and minimal sparing effect established for TA $(0.004 \%)$. A sparing effect of $0.015 \%$ was established for $8 \%$ DDGS inclusion for EW, while no or minimal sparing effects were established for the remaining variables tested (TA, FCR and percent TA), ranging from 0-0.009\% (Table 13). In summary, the calculated sparing effects for this Experiment validate the original AP value for the DDGS used in this study $(0.66 \%)$; however sparing effects also demonstrate that this value may be underestimated, with an $\mathrm{AP} / \mathrm{nPP}$ value ranging from 0.66-0.68\%, using the calculated sparing effects in Table 12 and 13.

\section{Previous Research}

Traditionally DDGS products have been associated with highly variable nutrient profiles [29, 30]; however, due to new technologies and the modernization of DDGS plants in the U.S., this has led to the production of DDGS with consistent nutrient profiles, such as the product tested in these 
studies. For this reason, in addition to the ever increasing costs of other feed ingredients, higher levels of DDGS have been included into U.S. poultry diets than before ( 5\%) [31]. Past research [32] has suggested that diets fed to broilers from D0-14 can include 8\% DDGS and diets fed from D14-28 can contain inclusions of 7.5 to $15 \%$ DDGS without affecting live performance measures. Similarly, research has suggested a 6\% DDGS inclusion into starter phase diets [33], and 12-15\% DDGS inclusions into grower/finisher phase diets [33-35]. Much higher inclusions of up to 20 and 24\% DDGS have been shown to have no negative effect on D1-18 [36] and D1-42 live performance [37], respectively. In addition, inclusions of up to $24 \%$ DDGS demonstrated no effect on breast meat production [37] and only minimal effects on broiler breast meat consumer acceptability [38]. However, it has been found that DDGS inclusions above $12 \%$ can increase broiler thigh meat oxidation over time of storage, but have no effect on breast meat oxidation [38]. In order to properly assess the quality of a feed ingredient for poultry, effects on feed manufacture and subsequent feeding must be considered. Much of the research testing the limitations of DDGS inclusions into poultry diets utilize mash (unconditioned feed) or do not eliminate feed form effects due to varying DDGS inclusions; which is why the current study pelleted all feed in Experiment 1, then ground feed prior to feeding. Research that has investigated the effects of DDGS inclusions on feed manufacture variables is conflicting. Shim and cohorts [37] determined that inclusions of $8 \%$ DDGS can decrease pellet durability in grower diets, while $16 \%$ DDGS decreases the durability of finisher diets. It is important to note that similar to the current study, diets utilized by Shim and others [37] increased in supplemental fat as DDGS inclusions increased; and the authors of the current paper assume that all supplemental fat was added at the mixer, likely contributing to DDGS negative effects on pellet durability. In contrast, Min and others [36] found that increasing DDGS into diets up to 25\% significantly increased 
percentage of fines produced; however, percentage of fines only increased from 1.49 to $10.81 \%$. These diets [36] also included a lignosulfonate pellet binder to help improve pellet quality; which may have confounded observed pelleting results, but could be beneficial in a commercial setting when pelleting diets containing high inclusions of DDGS. Loar and cohorts [32] determined that the inclusion of 15 and 30\% DDGS was detrimental to pellet quality, but also found that these inclusions of DDGS decreased energy required by the pellet mill.

In the current study, Experiment 1 demonstrated that bird performance benefited most from Low levels of DDGS (4\% DDGS from D1-10, 5\% DDGS from D10-22, and 10\% DDGS from D22-42); while Experiment 2 showed no detriment for DDGS inclusions of 8 or $16 \%$ of the diet for D3-21 broilers. As previously mentioned, these experiments differed in methodologies. Descriptive data obtained from the manufacture of diets in Experiment 1 demonstrated that increasing DDGS in diets tended to not affect pellet quality, until diets were manufactured in the finisher phase (containing 10 or 20\% DDGS) with high feed production rates. In addition, increasing DDGS into diets tended to decrease energy consumption of the pellet mill. The practical approach used in this study to determine the utilization of lysine (Experiment 1) and phosphorus (Experiment 2) seems to have been effective and could be used as an alternative method to test the feeding value of other ingredients. 


\section{CONCLUSIONS AND APPLICATIONS}

1. In both Experiments 1 and 2, multiple analyses verified the original Dig Lys $(0.7031 \%)$ and AP $(0.66 \%)$ suggested for this particular DDGS; however, depending on analysis and performance variable, availability may be underestimated by up to 0.07 and 0.02 percentage points, respectively.

2. In Experiment 1, Dig Lys x DDGS interactions demonstrated that performance was best for diets containing High Dig Lys and Low levels of DDGS (4\% Starter, 5\% Grower, 10\% Finisher); and in Experiment 2, increasing DDGS inclusion up to $16 \%$ did not negatively affect chick performance.

3. Increasing Dig Lys (Experiment 1) and AP/nPP (Experiment 2) in diets improved overall bird performance.

\section{REFERENCES}

1. Renewable Fuels Association. Accessed June 30, 2012. http://www.ethanolrfa.org/pages/industry-resources-coproducts.

2. Hoffman, L. and A. Baker. 2010. Market Issues and Prospects for U.S. Distillers' Grains: Supply, Use, and Price Relationships. A report from the economic research service/ USDA.

3. Lumpkins, B. S. and A. B. Batal. 2005. The bioavailability of lysine and phosphorus in distillers dried grains with solubles. Poult. Sci. 84:581-586.

4. Kim, E. J., C. Martinez Amezcua, P. L. Utterback, and C. M. Parsons. 2008. Phosphorus bioavailability, true metabolizable energy, and amino acid digestibilities of high protein corn distillers dried grains and dehydrated corn germ. Poult. Sci. 87:700-705.

5. Pahm, A. A., C. S. Scherer, J. E. Pettigrew, D. H. Baker, C. M. Parsons, and H. S. Stein. 2009. Standardized amino acid digestibility in cecectomized roosters and lysine bioavailability in chicks fed distillers dried grains with solubles. Poult Sci. 88:571-578.

6. Adeola, O. and K. E. Ileleji. 2009. Comparison of two diet types in the determination of metabolizable energy content of corn distillers dried grains with solubles for broiler chickens by the regression method. Poult. Sci. 88:579-585.

7. Kim, E. J., P. L. Utterback, T. J. Applegate, and C. M. Parsons. 2011. Comparisons of amino acid digestibility of feedstuffs determined with the precision-fed cecectomized rooster assay and the standardized ileal amino acid digestibility assay. Poult. Sci. 90:2511-2529. 
8. Stein, H. H., B. Seve, M. F. Fuller, P. J. Moughan, and C. F. M. de Lange. 2007. Invited review: Amino acid bioavailability and digestibility in pig feed ingredients: terminology and application. J. Anim. Sci. 85: 172-180.

9. Dakota Gold BPX 2011. Poet Nutrition, Sioux Falls, SD.

10. AGRI STATS, Inc., Fort Wayne, IN

11. Experiment Station Chemical Laboratories, Agricultural Experiment Station, Univ. Missouri, Columbia, MO.

12. Vertical mixer, Avery Weigh-Tronix, Fairmont, MN.

13. Cobb-Vantress, Siloam Springs, AR. 2008.

14. $4.25 \mathrm{ft}$ length, $1.02 \mathrm{ft}$ diameter short term CPM conditioner ( 3 steam inlet ports), $429 \mathrm{rpm}$ shaft speed; 21 picks; 10 second feed retention time.

15. Master Model Pellet Mill, California Pellet Mills Company, Crawfordsville, IN.

16. Horizontal cooler, Pyramid Processing Equipment LLC, Stilwell, KS.

17. American Society of Agricultural Engineers. 1997. ASAE S269.4: Cubes, pellets, and crumbles-Definitions and methods for determining density, durability, and moisture. ASAE Standards 1997. Am. Soc. Agric. Eng., St. Joseph, MI. Because of the use of a $3 / 16 \times 1.77$ in. die, pellets were sifted in a no. 6 American Society for Testing and Materials (ASTM) screen. A 500-g quantity of sifted pellets was placed in a dust-tight enclosure and tumbled for $10 \mathrm{~min}$ at $50 \mathrm{rpm}$. The enclosure was of the dimensions $12 \times$ 12 in., with a $2 \times 9$ in. plate affixed diagonally along one of the $12 \times 12$ in. sides. The tumbled samples were then sifted again (no. 6 ASTM) and weighed. The PDI was calculated by dividing the weight of pellets after tumbling by the weight of pellets before tumbling, and then multiplying by 100 .

18. New Holman Tester, Tekpro limited, UK.

19. Matterns Hatchery, Beaver Springs, PA.

20.Ziggity Systems Inc., Middlebury, IN. Customized system designed specifically for facilities at West Virginia University.

21. Kuhl Corporation, Flemington, NJ.

22. Hott, J. M., N. P. Buchanan, S. E. Cutlip, and J. S. Moritz. 2008. The effect of moisture addition with a mold inhibitor on pellet quality, feed manufacture, and broiler performance. J. Appl. Poult. Res. 17:262-271.

23. Lilly, K. G. S., C. K. Gehring, K. R. Beaman, P. J. Turk , M. Sperow, and J. S. Moritz. 2011. Examining the relationships between pellet quality, broiler performance, and bird sex. J. Appl. Poult. Res. 20:231-239.

24. NP Analytical Laboratories, St. Louis, MS.

25. Angel, R., N. M. Tamim, T. J. Applegate, A. S. Dhandu, and L. E. Ellestad. 2002. Phytic acid chemistry: influence on phytin-phosphorus availability and phytase efficacy. J. Appl. Poult. Res. 11:471-480.

26. American Association of Cereal Chemists. 1995. AACC Method 44-15A: Moisture AirOven Method. In Approved Methods of the American Association of Analytical Chemists. Vol. II. Am. Assoc. Cereal Chem., St. Paul, MN.

27. Association of Official Analytical Chemists. 2000. Pages 61-62 in Official Methods of Analysis of the Association of Official Analytical Chemists. Vol. 2. 17th ed. Assoc. Off. Anal. Chem., Washington, DC. .

28. SAS Institute. 2009. The SAS System for Windows 2009. Release 8.1. SAS Inst. Inc., Cary, NC. 
29. Batal, A. and N. Dale. 2003. Mineral composition of distillers dried grains with solubles. J. Appl. Poult. Res. 12:400-403.

30. Batal, A. B. and N. M. Dale. 2006. True metabolizable energy and amino acid digestibility of distillers dried grains with solubles. J. Appl. Poult. Res. 15:89-93.

31. Noll, S., C. M. Parsons, and W. Dozier. 2007. Formulating poultry diets with DDGS How far can we go? Pages 91-99 in Proc. $5^{\text {th }}$ Mid-Atlantic Nutr. Conf. Timonium, MD. Univ. Maryland, College Park.

32. Loar II, R. E., J. S. Moritz, J. R. Donaldson, and A. Corzo. 2010. Effects of feeding distillers dried grains with solubles to broilers from 0 to 28 days posthatch on broiler performance, feed manufacture efficiency, and selected intestinal characteristics. Poult. Sci. 89:2242-2250.

33. Lumpkins, B. S., A. B. Batal, and N. M. Dale. 2004. Evaluation of distillers dried grains and solubles as a feed ingredient for broilers. Poult. Sci. 83:1891-1896.

34. Wang, Z., S. Cerrate, C. Coto, Y. Fan, and P. W. Waldroup. 2007a. Utilization of distillers dried grains and solubles (DDGS) in broiler diets using a standardized nutrient matrix. Int. J. Poult. Sci. 6:470-477.

35. Wang, Z., S. Cerrate, C. Coto, Y. Fan, and P. W. Waldroup. 2007b. Use of constant or increasing levels of distillers dried grains and solubles (DDGS) in broiler diets. Int. J. Poult. Sci. 6:501-507.

36. Min, Y. N., A. Hancock, F. Yan, C. Lu, C. Coto, A. Karimi, J. H. Park, F. Z. Liu, and P. W. Waldroup. 2009. Use of combinations of canola meal and distillers dried grains with solubles in broiler starter diets. J. Appl. Poult. Res. 18:725-733.

37. Shim, M. Y., G. M. Pesti, R. I. Bakalli, P. B. Tillman, and R. L. Payne. 2011. Evaluation of corn distillers dried grains with solubles as an alternative ingredient for broilers. Poult. Sci. 90:369-376.

38. Schilling, M. W., V. Battula, R. E. Loar II, V. Jackson, S. Kin, and A. Corzo. 2010. Dietary inclusion level effects on distillers dried grains with solubles on broiler meat quality. Poult Sci. 89:752-760. 
Table 1. Starter period diets formulated to AGRI STATS levels for starter period diets fed from D1-10 in Experiment 1

\begin{tabular}{|c|c|c|c|c|c|c|c|c|c|c|}
\hline \multirow{5}{*}{ Ingredients } & \multicolumn{10}{|c|}{ Starter Period Diet Formulations } \\
\hline & $0 \%$ DDGS & $4 \%$ DDGS & $0 \%$ DDGS & $4 \%$ DDGS & $0 \%$ DDGS & $4 \%$ DDGS & $0 \%$ DDGS & $4 \%$ DDGS & $0 \%$ DDGS & $4 \%$ DDGS \\
\hline & \multicolumn{10}{|c|}{$\%$ of AGRI STATS Digestible Lysine Levels } \\
\hline & \multicolumn{2}{|c|}{$70 \%$} & \multicolumn{2}{|c|}{$80 \%$} & \multicolumn{2}{|c|}{$90 \%$} & \multicolumn{2}{|c|}{$100 \%$} & \multicolumn{2}{|c|}{$110 \%$} \\
\hline & \multicolumn{10}{|c|}{ Ingredient Percent Inclusion } \\
\hline Corn & 70.38 & 67.28 & 66.11 & 63.18 & 65.79 & 62.86 & 65.48 & 62.55 & 60.1 & 56.82 \\
\hline Soybean Meal (48\%) & 21.5 & 20.5 & 25.33 & 24.22 & 25.36 & 24.25 & 25.39 & 24.28 & 30.22 & 29.44 \\
\hline DDGS $^{1}$ & 0 & 4 & 0 & 4 & 0 & 4 & 0 & 4 & 0 & 4 \\
\hline Porcine Meat \& Bone Meal & 5 & 5 & 5 & 5 & 5 & 5 & 5 & 5 & 5 & 5 \\
\hline Animal/Vegetable Blend Fat & 0.5 & 0.67 & 1.04 & 1.17 & 1.14 & 1.27 & 1.25 & 1.38 & 1.91 & 2.08 \\
\hline Limestone & 0.98 & 1.05 & 0.97 & 1.04 & 0.97 & 1.04 & 0.97 & 1.04 & 0.96 & 1.03 \\
\hline Lysine & 0.0009 & 0.002 & 0.03 & 0.04 & 0.18 & 0.19 & 0.34 & 0.35 & 0.35 & 0.35 \\
\hline DL Methionine & 0.4 & 0.38 & 0.37 & 0.35 & 0.37 & 0.35 & 0.37 & 0.35 & 0.33 & 0.31 \\
\hline $\mathrm{Na} \mathrm{Bicarb}$ & 0.06 & 0.03 & 0.07 & 0.05 & 0.14 & 0.12 & 0.22 & 0.19 & 0.22 & 0.19 \\
\hline Dicalcium Phosphorus & 0.31 & 0.19 & 0.28 & 0.17 & 0.28 & 0.17 & 0.29 & 0.17 & 0.25 & 0.14 \\
\hline Vitamin/Mineral Premix & 0.25 & 0.25 & 0.25 & 0.25 & 0.25 & 0.25 & 0.25 & 0.25 & 0.25 & 0.25 \\
\hline Threonine & 0.27 & 0.3 & 0.22 & 0.2 & 0.22 & 0.2 & 0.22 & 0.2 & 0.22 & 0.15 \\
\hline Salt & 0.33 & 0.33 & 0.32 & 0.32 & 0.28 & 0.27 & 0.23 & 0.23 & 0.22 & 0.23 \\
\hline \multirow[t]{2}{*}{ Optiphos $^{2}$} & 0.01 & 0.01 & 0.01 & 0.01 & 0.01 & 0.01 & 0.01 & 0.01 & 0.01 & 0.01 \\
\hline & \multicolumn{10}{|c|}{ Calculated Nutrients (\%) } \\
\hline $\mathrm{ME}(\mathrm{kcal} / \mathrm{kg})$ & 3030.5 & 3030.5 & 3030.5 & 3030.5 & \begin{tabular}{|l|}
3030.5 \\
\end{tabular} & 3030.5 & 3030.5 & 3030.5 & 3030.5 & 3030.5 \\
\hline Crude Protein & 19.61 & 19.92 & 21.04 & 21.28 & 21.15 & 21.38 & 21.26 & 21.49 & 23.06 & 23.41 \\
\hline Digestible (Dig) Lysine & 0.83 & 0.83 & 0.94 & 0.94 & 1.06 & 1.06 & 1.18 & 1.18 & 1.3 & 1.3 \\
\hline Dig Arginine & 1.14 & 1.13 & 1.25 & 1.24 & 1.25 & 1.24 & 1.25 & 1.24 & 1.39 & 1.39 \\
\hline Dig Isoleucine & 0.71 & 0.71 & 0.78 & 0.78 & 0.77 & 0.78 & 0.77 & 0.77 & 0.85 & 0.86 \\
\hline Dig TSAA & 0.89 & 0.89 & 0.89 & 0.88 & 0.88 & 0.88 & 0.89 & 0.88 & 0.89 & 0.89 \\
\hline Dig Valine & 0.83 & 0.84 & 0.89 & 0.9 & 0.89 & 0.9 & 0.89 & 0.9 & 0.97 & 0.98 \\
\hline Calcium & 0.96 & 0.96 & 0.96 & 0.96 & 0.96 & 0.96 & 0.96 & 0.96 & 0.96 & 0.96 \\
\hline \multirow[t]{2}{*}{ Available Phosphorus } & 0.38 & 0.38 & 0.38 & 0.38 & 0.38 & 0.38 & 0.38 & 0.38 & 0.38 & 0.38 \\
\hline & \multicolumn{10}{|c|}{ Analyzed Nutrients $^{3}(\%)$} \\
\hline Crude Protein & 16.58 & 17.33 & 18.65 & 18.53 & 18.47 & 19.17 & 18.79 & 19.59 & 20.15 & 20.83 \\
\hline Lysine & 0.87 & 0.93 & 1.02 & 1.04 & 1.11 & 1.17 & 1.25 & 1.26 & 1.33 & 1.35 \\
\hline TSAA & 0.87 & 0.85 & 0.98 & 0.96 & 0.88 & 0.94 & 0.91 & 0.92 & 0.96 & 0.92 \\
\hline
\end{tabular}

'Distiller's dried grains and solubles (DDGS) source [9] was common and the company's provided nutrient coefficients were utilized in diet formulation; diets were formulated using AGRI STATS data [10]

${ }^{2}$ Optiphos was the commercial phytase utilized in diet formulation; the sparing effect attributed to this enzyme in diet formulation was $0.10 \%$ AP

Diets were analyzed at a commercial laboratory [11]; Crude Protein was determined by Kjeldahl, AOAC Official Method 984.13 (A-D), 2006 and calculated by 6.25 x nitrogen value; Lysine and Total Sulfur Amino Acids (TSAA) were analyzed using AOAC Official Method 982.30E(a,b,c), Chp. 45.3.05, 2006 
Table 2. Grower period diets formulated to AGRI STATS levels for grower diets fed from D11-22 in Experiment 1

\begin{tabular}{|c|c|c|c|c|c|c|c|c|c|c|c|c|c|c|c|}
\hline \multirow{4}{*}{ Ingredients } & \multicolumn{15}{|c|}{ Grower Period Diet Formulations } \\
\hline & $\begin{array}{c}0 \% \\
\text { DDGS }\end{array}$ & $\begin{array}{c}5 \% \\
\text { DDGS }\end{array}$ & $\begin{array}{c}10 \% \\
\text { DDGS }\end{array}$ & $\begin{array}{c}0 \% \\
\text { DDGS }\end{array}$ & $\begin{array}{c}5 \% \\
\text { DDGS }\end{array}$ & $\begin{array}{c}10 \% \\
\text { DDGS }\end{array}$ & $\begin{array}{c}0 \% \\
\text { DDGS }\end{array}$ & $\begin{array}{c}5 \% \\
\text { DDGS }\end{array}$ & $\begin{array}{c}10 \% \\
\text { DDGS }\end{array}$ & $\begin{array}{c}0 \% \\
\text { DDGS }\end{array}$ & $\begin{array}{c}5 \% \\
\text { DDGS }\end{array}$ & $\begin{array}{c}10 \% \\
\text { DDGS }\end{array}$ & $\begin{array}{c}0 \% \\
\text { DDGS }\end{array}$ & $\begin{array}{c}5 \% \\
\text { DDGS }\end{array}$ & $\begin{array}{c}10 \% \\
\text { DDGS }\end{array}$ \\
\hline & \multicolumn{15}{|c|}{$\%$ of AGRI STATS Digestible Lysine Levels } \\
\hline & \multicolumn{3}{|c|}{$70 \%$} & \multicolumn{3}{|c|}{$80 \%$} & \multicolumn{3}{|c|}{$90 \%$} & \multicolumn{3}{|c|}{$100 \%$} & \multicolumn{3}{|c|}{$110 \%$} \\
\hline Corn & 74.65 & 70.28 & 66.05 & 70.31 & 66.81 & 63.37 & 70.03 & 66.53 & 63.1 & 69.76 & 66.26 & 62.82 & 66.77 & 62.53 & 58.27 \\
\hline Soybean Meal $(48 \%)$ & 17.5 & 17 & 16.5 & 21.4 & 20.12 & 18.86 & 21.43 & 20.14 & 18.89 & 21.45 & 20.16 & 18.91 & 24.05 & 23.51 & 23.06 \\
\hline DDGS $^{1}$ & - & 5 & 10 & - & 5 & 10 & - & 5 & 10 & - & 5 & 10 & - & 5 & 10 \\
\hline $\begin{array}{c}\text { Porcine Meat \& Bone } \\
\text { Meal }\end{array}$ & 5 & 4.62 & 3.96 & 5 & 4.53 & 3.89 & 5 & 4.54 & 3.9 & 5 & 4.54 & 3.9 & 5 & 4.45 & 3.79 \\
\hline $\begin{array}{c}\text { Animal/ } \\
\text { Vegetable Blend Fat }\end{array}$ & 0.73 & 0.99 & 1.27 & 1.26 & 1.44 & 1.63 & 1.36 & 1.53 & 1.72 & 1.45 & 1.63 & 1.81 & 1.84 & 2.11 & 2.38 \\
\hline Limestone & 0.87 & 1.01 & 1.17 & 0.86 & 1.01 & 1.18 & 0.86 & 1.01 & 1.17 & 0.86 & 1.01 & 1.17 & 0.86 & 1.01 & 1.18 \\
\hline Lysine & - & - & - & 0.02 & 0.04 & 0.06 & 0.15 & 0.18 & 0.2 & 0.29 & 0.31 & 0.34 & 0.35 & 0.35 & 0.35 \\
\hline DL Methionine & 0.35 & 0.31 & 0.28 & 0.31 & 0.29 & 0.27 & 0.31 & 0.29 & 0.27 & 0.31 & 0.29 & 0.27 & 0.29 & 0.26 & 0.23 \\
\hline Na Bicarb & 0.02 & - & - & 0.03 & 0.01 & - & 0.09 & 0.07 & 0.06 & 0.16 & 0.14 & 0.12 & 0.18 & 0.15 & 0.13 \\
\hline Dicalcium Phosphorus & 0.06 & - & - & 0.04 & - & - & 0.04 & - & - & 0.04 & - & - & 0.02 & - & - \\
\hline Vitamin/Mineral Premix & 0.25 & 0.25 & 0.25 & 0.25 & 0.25 & 0.25 & 0.25 & 0.25 & 0.25 & 0.25 & 0.25 & 0.25 & 0.25 & 0.25 & 0.25 \\
\hline \multirow[t]{2}{*}{ Optiphos $^{2}$} & 0.01 & 0.01 & 0.01 & 0.01 & 0.01 & 0.01 & 0.01 & 0.01 & 0.01 & 0.01 & 0.01 & 0.01 & 0.01 & 0.01 & 0.01 \\
\hline & \multicolumn{15}{|c|}{ Calculated Nutrients $(\%)$} \\
\hline $\mathrm{ME}(\mathrm{kcal} / \mathrm{kg})$ & 3097 & 3097 & 3097 & 3097 & 3097 & 3097 & 3097 & 3097 & 3097 & 3097 & 3097 & 3097 & 3097 & 3097 & 3097 \\
\hline Crude Protein & 17.93 & 18.37 & 18.7 & 19.39 & 19.52 & 19.59 & 19.48 & 19.61 & 19.68 & 19.58 & 19.71 & 19.78 & 20.58 & 20.94 & 21.28 \\
\hline Digestible (Dig) Lysine & 0.74 & 0.74 & 0.74 & 0.84 & 0.84 & 0.84 & 0.95 & 0.94 & 0.94 & 1.05 & 1.05 & 1.05 & 1.16 & 1.16 & 1.16 \\
\hline Dig Arginine & 1.02 & 1.03 & 1.03 & 1.13 & 1.12 & 1.1 & 1.13 & 1.12 & 1.1 & 1.13 & 1.12 & 1.1 & 1.21 & 1.21 & 1.22 \\
\hline Dig Isoleucine & 0.65 & 0.66 & 0.67 & 0.71 & 0.71 & 0.71 & 0.71 & 0.71 & 0.71 & 0.71 & 0.71 & 0.71 & 0.75 & 0.76 & 0.77 \\
\hline Dig TSAA & 0.81 & 0.8 & 0.8 & 0.8 & 0.8 & 0.8 & 0.8 & 0.8 & 0.8 & 0.8 & 0.8 & 0.8 & 0.8 & 0.8 & 0.8 \\
\hline Dig Valine & 0.77 & 0.79 & 0.81 & 0.83 & 0.84 & 0.84 & 0.83 & 0.84 & 0.84 & 0.83 & 0.83 & 0.84 & 0.87 & 0.89 & 0.91 \\
\hline Calcium & 0.86 & 0.86 & 0.86 & 0.86 & 0.86 & 0.86 & 0.86 & 0.86 & 0.86 & 0.86 & 0.86 & 0.86 & 0.86 & 0.86 & 0.86 \\
\hline \multirow[t]{2}{*}{ Available P } & 0.33 & 0.33 & 0.33 & 0.33 & 0.33 & 0.33 & 0.33 & 0.33 & 0.33 & 0.33 & 0.33 & 0.33 & 0.33 & 0.33 & 0.33 \\
\hline & \multicolumn{15}{|c|}{ Analyzed Nutrients ${ }^{3}(\%)$} \\
\hline Crude Protein & 16.11 & 15.09 & 15.93 & 16.99 & 17.08 & 17.40 & 17.47 & 18.10 & 17.44 & 17.87 & 18.18 & 17.56 & 18.88 & 18.96 & 18.67 \\
\hline Lysine & 0.83 & 0.76 & 0.78 & 0.93 & 0.82 & 0.88 & 1.03 & 1.03 & 1.02 & 1.16 & 1.13 & 1.10 & 1.06 & 1.28 & 1.21 \\
\hline TSAA & 0.86 & 0.78 & 0.80 & 0.87 & 0.79 & 0.82 & 0.84 & 0.89 & 0.85 & 0.89 & 0.85 & 0.83 & 0.90 & 0.84 & 0.88 \\
\hline
\end{tabular}

'Distiller's dried grains and solubles (DDGS) source [9] was common and the company's provided nutrient coefficients were utilized in diet formulation; diets were formulated using AGRI STATS data [10]

${ }^{2}$ Optiphos was the commercial phytase utilized in diet formulation; the sparing effect attributed to this enzyme in diet formulation was $0.10 \% \mathrm{AP}$

${ }^{3}$ Diets were analyzed at a commercial laboratory [11]; Crude Protein was determined by Kjeldahl, AOAC Official Method 984.13 (A-D), 2006 and calculated by 6.25 x nitrogen value; Lysine and Total Sulfur

Amino Acids (TSAA) were analyzed using AOAC Official Method 982.30E(a,b,c), Chp. 45.3.05, 2006 
Table 3. Finisher period diets formulated to AGRI STATS levels for finisher period diets fed from D23-42 in Experiment 1

\begin{tabular}{|c|c|c|c|c|c|c|c|c|c|c|c|c|c|c|c|}
\hline \multirow{5}{*}{ Ingredients } & \multicolumn{15}{|c|}{ Finisher Period Diet Formulations } \\
\hline & $\begin{array}{c}0 \% \\
\text { DDGS }\end{array}$ & $\begin{array}{c}10 \% \\
\text { DDGS }\end{array}$ & $\begin{array}{c}20 \% \\
\text { DDGS }\end{array}$ & $\begin{array}{c}0 \% \\
\text { DDGS }\end{array}$ & $\begin{array}{c}10 \% \\
\text { DDGS }\end{array}$ & $\begin{array}{c}20 \% \\
\text { DDGS }\end{array}$ & $\begin{array}{c}0 \% \\
\text { DDGS }\end{array}$ & $\begin{array}{c}10 \% \\
\text { DDGS }\end{array}$ & $\begin{array}{c}20 \% \\
\text { DDGS }\end{array}$ & $\begin{array}{c}0 \% \\
\text { DDGS }\end{array}$ & $\begin{array}{c}10 \% \\
\text { DDGS }\end{array}$ & $\begin{array}{c}20 \% \\
\text { DDGS }\end{array}$ & $\begin{array}{c}0 \% \\
\text { DDGS }\end{array}$ & $\begin{array}{c}10 \% \\
\text { DDGS }\end{array}$ & $\begin{array}{c}20 \% \\
\text { DDGS }\end{array}$ \\
\hline & \multicolumn{15}{|c|}{$\%$ of AGRI STATS Digestible Lysine Levels } \\
\hline & \multicolumn{3}{|c|}{$70 \%$} & \multicolumn{3}{|c|}{$80 \%$} & \multicolumn{3}{|c|}{$90 \%$} & \multicolumn{3}{|c|}{$100 \%$} & \multirow{2}{*}{\multicolumn{3}{|c|}{$110 \%$}} \\
\hline & \multicolumn{12}{|c|}{ Ingredient Percent Inclusion } & & & \\
\hline Corn & 79.26 & 70.81 & 63.08 & 75.56 & 68.66 & 60.91 & 75.33 & 68.45 & 60.7 & 75.09 & 68.22 & 60.48 & 74.6 & 66.07 & 57.5 \\
\hline Soybean Meal $(48 \%)$ & 13 & 12.2 & 10.5 & 16.58 & 14.08 & 12.39 & 16.6 & 14.1 & 12.41 & 16.62 & 14.12 & 12.43 & 16.89 & 15.99 & 15.09 \\
\hline DDGS $^{1}$ & - & 10 & 20 & - & 10 & 20 & - & 10 & 20 & - & 10 & 20 & - & 10 & 20 \\
\hline $\begin{array}{c}\text { Porcine Meat \& Bone } \\
\text { Meal }\end{array}$ & 4.93 & 3.38 & 2.07 & 4.6 & 3.32 & 2.02 & 4.61 & 3.33 & 2.03 & 4.61 & 3.33 & 2.03 & 4.61 & 3.28 & 1.95 \\
\hline $\begin{array}{c}\text { Fat Animal/ } \\
\text { Vegetable Blend }\end{array}$ & 0.97 & 1.52 & 1.99 & 1.43 & 1.81 & 2.29 & 1.51 & 1.88 & 2.35 & 1.59 & 1.96 & 2.43 & 1.7 & 2.25 & 2.82 \\
\hline Limestone & 0.79 & 1.19 & 1.52 & 0.85 & 1.19 & 1.52 & 0.85 & 1.19 & 1.52 & 0.85 & 1.19 & 1.52 & 0.85 & 1.19 & 1.52 \\
\hline Lysine & - & - & 0.02 & 0.008 & 0.06 & 0.08 & 0.12 & 0.17 & 0.2 & 0.24 & 0.29 & 0.31 & 0.35 & 0.35 & 0.35 \\
\hline DL Methionine & 0.26 & 0.21 & 0.16 & 0.23 & 0.19 & 0.15 & 0.24 & 0.19 & 0.15 & 0.24 & 0.19 & 0.15 & 0.23 & 0.18 & 0.14 \\
\hline Na Bicarb & - & - & - & - & - & - & 0.04 & 0.01 & - & 0.1 & 0.06 & 0.02 & 0.15 & 0.09 & 0.04 \\
\hline Vitamin/Mineral Premix & 0.25 & 0.25 & 0.25 & 0.25 & 0.25 & 0.25 & 0.25 & 0.25 & 0.25 & 0.25 & 0.25 & 0.25 & 0.25 & 0.25 & 0.25 \\
\hline Threonine & 0.2 & 0.13 & 0.1 & 0.14 & 0.11 & 0.07 & 0.14 & 0.11 & 0.08 & 0.14 & 0.11 & 0.08 & 0.14 & 0.09 & 0.05 \\
\hline Salt & 0.32 & 0.31 & 0.3 & 0.33 & 0.31 & 0.3 & 0.3 & 0.31 & 0.3 & 0.26 & 0.27 & 0.28 & 0.23 & 0.25 & 0.27 \\
\hline \multirow[t]{2}{*}{ Optiphos $^{2}$} & 0.01 & 0.01 & 0.01 & 0.01 & 0.01 & 0.01 & 0.01 & 0.01 & 0.01 & 0.01 & 0.01 & 0.01 & 0.01 & 0.01 & 0.01 \\
\hline & \multicolumn{15}{|c|}{ Calculated Nutrients (\%) } \\
\hline $\mathrm{ME}(\mathrm{kcal} / \mathrm{kg})$ & 3162.74 & 3162.74 & 3162.74 & 3162.74 & 3162.74 & 3162.74 & 3162.74 & 3162.74 & 3162.74 & 3162.74 & 3162.74 & 3162.74 & 3162.74 & 3162.74 & 3162.74 \\
\hline Crude Protein & 16 & 16.6 & 17.01 & 17.18 & 17.31 & 17.74 & 17.26 & 17.4 & 17.82 & 17.34 & 17.48 & 17.9 & 17.5 & 18.19 & 18.89 \\
\hline Digestible Lysine & 0.63 & 0.63 & 0.62 & 0.71 & 0.71 & 0.72 & 0.8 & 0.8 & 0.8 & 0.89 & 0.89 & 0.89 & 0.98 & 0.98 & 0.98 \\
\hline Digestible Arginine & 0.88 & 0.89 & 0.88 & 0.98 & 0.95 & 0.94 & 0.98 & 0.95 & 0.93 & 0.98 & 0.95 & 0.93 & 0.99 & 1 & 1.01 \\
\hline Digestible Isoleucine & 0.57 & 0.59 & 0.6 & 0.63 & 0.62 & 0.63 & 0.63 & 0.62 & 0.63 & 0.63 & 0.62 & 0.63 & 0.63 & 0.65 & 0.67 \\
\hline Digestible TSAA & 0.68 & 0.69 & 0.69 & 0.69 & 0.69 & 0.7 & 0.69 & 0.69 & 0.7 & 0.69 & 0.69 & 0.7 & 0.69 & 0.69 & 0.7 \\
\hline Digestible Valine & 0.69 & 0.73 & 0.76 & 0.74 & 0.76 & 0.78 & 0.74 & 0.76 & 0.78 & 0.74 & 0.76 & 0.78 & 0.75 & 0.79 & 0.82 \\
\hline Calcium & 0.8 & 0.8 & 0.8 & 0.8 & 0.8 & 0.8 & 0.8 & 0.8 & 0.8 & 0.8 & 0.8 & 0.8 & 0.8 & 0.8 & 0.8 \\
\hline \multirow[t]{2}{*}{ Available P } & 0.31 & 0.3 & 0.3 & 0.3 & 0.3 & 0.3 & 0.3 & 0.3 & 0.3 & 0.3 & 0.3 & 0.3 & 0.3 & 0.3 & 0.3 \\
\hline & \multicolumn{15}{|c|}{ Analyzed Nutrients $^{3}(\%)$} \\
\hline $\begin{array}{l}\text { Crude Protein } \\
\end{array}$ & 14.17 & 14.64 & 15.82 & 15.32 & 15.45 & 16.85 & 15.21 & 16.02 & 17.09 & 15.80 & 16.78 & 16.95 & 15.71 & 17.46 & 18.23 \\
\hline Lysine & 0.71 & 0.70 & 0.73 & 0.77 & 0.80 & 0.85 & 0.86 & 0.84 & 0.88 & 1.00 & 1.00 & 0.98 & 1.05 & 1.10 & 1.05 \\
\hline TSAA & 0.77 & 0.75 & 0.73 & 0.76 & 0.73 & 0.76 & 0.75 & 0.73 & 0.74 & 0.79 & 0.75 & 0.74 & 0.76 & 0.77 & 0.77 \\
\hline
\end{tabular}

${ }^{1}$ Distiller's dried grains and solubles (DDGS) source [9] was common and the company's provided nutrient coefficients were utilized in diet formulation; diets were formulated using AGRI STATS data [10]

Optiphos was the commercial phytase utilized in diet formulation; the sparing effect attributed to this enzyme in diet formulation was $0.10 \% \mathrm{AP}$

${ }^{3}$ Diets were analyzed at a commercial laboratory [11]; Crude Protein was determined by Kjeldahl, AOAC Official Method 984.13 (A-D), 2006 and calculated by 6.25 x nitrogen value; Lysine and Total Sulfur

Amino Acids (TSAA) were analyzed using AOAC Official Method 982.30E(a,b,c), Chp. 45.3.05, 2006 
Table 4. Outline of dietary treatments manufactured and fed in Experiment 1 from D3-42 1

\begin{tabular}{|c|c|c|c|c|c|}
\hline Diet & $\begin{array}{c}(\%) \\
\text { AGRI STATS } \\
\text { Digestible Lysine }^{2}\end{array}$ & $\begin{array}{l}\text { Starter Period, } \\
\text { D1-10 DDGS } \\
\text { inclusion }(\%)\end{array}$ & $\begin{array}{l}\text { Grower Period, } \\
\text { D11-22 DDGS } \\
\text { inclusion }(\%)\end{array}$ & $\begin{array}{c}\text { Finisher Period, } \\
\text { D23-42 DDGS } \\
\text { inclusion }(\%)\end{array}$ & $\begin{array}{c}\text { Overall DDGS } \\
\text { inclusion Level }^{4}\end{array}$ \\
\hline 1 & \multirow{3}{*}{70} & 0 & 0 & 0 & No \\
\hline 2 & & \multirow{2}{*}{4} & 5 & 10 & Low \\
\hline 3 & & & 10 & 20 & High \\
\hline 4 & \multirow{3}{*}{80} & 0 & 0 & 0 & No \\
\hline 5 & & \multirow{2}{*}{4} & 5 & 10 & Low \\
\hline 6 & & & 10 & 20 & High \\
\hline 7 & \multirow{3}{*}{90} & 0 & 0 & 0 & No \\
\hline 8 & & \multirow{2}{*}{4} & 5 & 10 & Low \\
\hline 9 & & & 10 & 20 & High \\
\hline 10 & \multirow{3}{*}{100} & 0 & 0 & 0 & No \\
\hline 11 & & \multirow{2}{*}{4} & 5 & 10 & Low \\
\hline 12 & & & 10 & 20 & High \\
\hline 13 & \multirow{3}{*}{110} & 0 & 0 & 0 & No \\
\hline 14 & & \multirow{2}{*}{4} & 5 & 10 & Low \\
\hline 15 & & & 10 & 20 & High \\
\hline
\end{tabular}

${ }^{1}$ A $5 \times 3$ factorial analysis was utilized with variations in diet formulations for digestible lysine (Dig Lys) $(70,80,90,100$, or $110 \%$ of AGRI STATS data [10]) and DDGS Level (No, Low, or High).

${ }^{2}$ Digestible amino acid to Dig Lys ratios considered in diet formulation included: methionine, TSAA, threonine, tryptophan, arginine, isoleucine and valine.

${ }^{3}$ Distiller's dried grains and solubles (DDGS) source was common among diets [9] and the company's provided nutrient coefficients were utilized in diet formulation

${ }^{4}$ DDGS inclusion levels containing No DDGS received 0\% DDGS throughout grow-out; Low DDGS received diets containing 4\% DDGS (d1-10), 5\% DDGS (D10-22), and 10\% DDGS (D22-42); High DDGS received diets containing 4\% DDGS (D1-10), 10\% DDGS (D10-22), and 20\% DDGS (D22-42) 
Table 5. Diets varying in available phosphorus (AP) and distiller's dried grains and solubles (DDGS) fed in Experiment 2 from D3-21

\begin{tabular}{|c|c|c|c|c|c|c|}
\hline \multirow{4}{*}{ Ingredients } & $0 \%$ DDGS & $\begin{array}{c}8 \% \\
\text { DDGS }\end{array}$ & $\begin{array}{c}16 \% \\
\text { DDGS }\end{array}$ & $0 \%$ DDGS & $\begin{array}{c}8 \% \\
\text { DDGS }\end{array}$ & $\begin{array}{c}16 \% \\
\text { DDGS }\end{array}$ \\
\hline & \multicolumn{6}{|c|}{ Varying Levels of Available Phosphorus (\%) } \\
\hline & \multicolumn{3}{|c|}{0.45 (Positive Control) } & \multicolumn{3}{|c|}{0.21 (Negative Control) } \\
\hline & \multicolumn{6}{|c|}{ Ingredient Percent Inclusion } \\
\hline Corn & 65.21 & 59.33 & 53.22 & 65.43 & 58.95 & 52.48 \\
\hline Soybean Meal (48\%) & 25.41 & 23.22 & 21.24 & 27.61 & 26.56 & 25.5 \\
\hline DDGS $^{1}$ & - & 8 & 16 & - & 8 & 16 \\
\hline Porcine Meat \& Bone Meal & 5 & 5 & 5 & 2.13 & 1.08 & 0.03 \\
\hline Fat- Animal/Vegetable Blend & 1.34 & 1.6 & 1.88 & 1.3 & 1.71 & 2.11 \\
\hline Limestone & 0.76 & 0.89 & 1.03 & 1.85 & 2.12 & 2.38 \\
\hline Lysine & 0.34 & 0.36 & 0.37 & 0.34 & 0.35 & 0.36 \\
\hline DL Methionine & 0.37 & 0.33 & 0.29 & 0.37 & 0.32 & 0.28 \\
\hline $\mathrm{Na}$ Bicarb & 0.22 & 0.17 & 0.12 & 0.24 & 0.2 & 0.16 \\
\hline Dicalcium Phosphorus & 0.66 & 0.43 & 0.2 & - & - & - \\
\hline Vitamin/Mineral Premix & 0.25 & 0.25 & 0.25 & 0.25 & 0.25 & 0.25 \\
\hline Threonine & 0.22 & 0.19 & 0.16 & 0.22 & 0.18 & 0.15 \\
\hline \multirow[t]{2}{*}{ Salt } & 0.23 & 0.23 & 0.23 & 0.26 & 0.28 & 0.29 \\
\hline & \multicolumn{6}{|c|}{ Calculated Nutrients $^{2}(\%)$} \\
\hline $\mathrm{ME}(\mathrm{kcal} / \mathrm{kg})$ & 3030.5 & 3030.5 & 3030.5 & 3030.5 & 3030.5 & 3030.5 \\
\hline Crude Protein & 21.25 & 21.73 & 22.28 & 20.87 & 21.3 & 21.73 \\
\hline Digestible Lysine & 1.18 & 1.18 & 1.18 & 1.18 & 1.18 & 1.18 \\
\hline Digestible Arginine & 1.25 & 1.24 & 1.24 & 1.24 & 1.24 & 0.24 \\
\hline Digestible Isoleucine & 0.77 & 0.77 & 0.78 & 0.79 & 0.8 & 0.81 \\
\hline Digestible Methionine & 0.63 & 0.61 & 0.59 & 0.63 & 0.6 & 0.58 \\
\hline Digestible TSAA & 0.88 & 0.89 & 0.89 & 0.89 & 0.89 & 0.89 \\
\hline Digestible Threonine & 0.77 & 0.77 & 0.77 & 0.77 & 0.77 & 0.77 \\
\hline Digestible Tryptophan & 0.21 & 0.21 & 0.21 & 0.22 & 0.23 & 0.23 \\
\hline Digestible Valine & 0.89 & 0.91 & 0.93 & 0.89 & 0.92 & 0.94 \\
\hline Calcium & 0.96 & 0.96 & 0.96 & 0.96 & 0.96 & 0.96 \\
\hline Available Phosphorus & 0.45 & 0.45 & 0.45 & 0.21 & 0.21 & 0.21 \\
\hline Sodium & 0.2 & 0.2 & 0.2 & 0.2 & 0.2 & 0.2 \\
\hline Chlorine & 0.28 & 0.28 & 0.28 & 0.28 & 0.28 & 0.28 \\
\hline
\end{tabular}

${ }^{1}$ Distiller's dried grains and solubles (DDGS) source was common among diets [9] and the company's provided nutrient coefficients were utilized in diet formulation

${ }^{2}$ Diets were formulated using AGRI STATS data [10] for digestible amino acid to Dig Lys ratios considered in diet formulation included: methionine,

TSAA, threonine, tryptophan, arginine, isoleucine and valine. 
Table 6. Analyzed ${ }^{1}$ diets fed in Experiment 2 from D3-21

\begin{tabular}{|c|c|c|c|c|c|c|c|}
\hline $\begin{array}{c}\text { DDGS }^{2} \\
\text { Inclusion } \\
(\%)\end{array}$ & $\begin{array}{c}\text { Formulated } \\
\text { Available } \mathrm{P}^{3} \\
(\%)\end{array}$ & $\begin{array}{l}\text { Dietary Treatment } \\
\text { Ratios (NC:PC) }\end{array}$ & $\begin{array}{c}\text { Total } \mathrm{P}^{5} \\
(\%)\end{array}$ & $\begin{array}{c}\text { Phytic } \\
\text { Acid }^{6} \\
(\%)\end{array}$ & $\begin{array}{l}\text { Calculated } \\
\mathrm{nPP}^{7}\end{array}$ & $\begin{array}{l}\mathrm{Ash}^{8} \\
(\%)\end{array}$ & $\begin{array}{l}\mathrm{Ca}^{9} \\
(\%)\end{array}$ \\
\hline \multirow{5}{*}{0} & 0.21 & 100:0 & 0.41 & 0.83 & 0.18 & 5.1 & 1.1 \\
\hline & 0.27 & $75: 25$ & 0.46 & 0.84 & 0.22 & 4.6 & 0.99 \\
\hline & 0.33 & $50: 50$ & 0.51 & 0.84 & 0.27 & 5.1 & 0.88 \\
\hline & 0.39 & $75: 25$ & 0.53 & 0.85 & 0.29 & 4.8 & 0.88 \\
\hline & 0.45 & $0: 100$ & 0.60 & 0.78 & 0.38 & 4.6 & 0.87 \\
\hline \multirow{5}{*}{8} & 0.21 & 100:0 & 0.41 & 0.85 & 0.17 & 4.9 & 0.95 \\
\hline & 0.27 & $75: 25$ & 0.45 & 0.81 & 0.22 & 4.8 & 0.92 \\
\hline & 0.33 & $50: 50$ & 0.52 & 0.83 & 0.29 & 4.6 & 0.93 \\
\hline & 0.39 & $75: 25$ & 0.54 & 0.78 & 0.32 & 4.7 & 0.85 \\
\hline & 0.45 & $0: 100$ & 0.59 & 0.82 & 0.36 & 4.6 & 0.89 \\
\hline \multirow{5}{*}{16} & 0.21 & 100:0 & 0.41 & 0.86 & 0.17 & 5.5 & 0.97 \\
\hline & 0.27 & $75: 25$ & 0.46 & 0.84 & 0.22 & 4.9 & 0.94 \\
\hline & 0.33 & $50: 50$ & 0.51 & 0.80 & 0.28 & 4.9 & 0.94 \\
\hline & 0.39 & $75: 25$ & 0.56 & 0.86 & 0.32 & 5.3 & 0.88 \\
\hline & 0.45 & $0: 100$ & 0.60 & 0.78 & 0.38 & 5.0 & 0.83 \\
\hline
\end{tabular}

${ }^{\mathrm{I}}$ All diets were analyzed at a commercial laboratory [24]

${ }^{2}$ Diets varied in inclusions of distiller's dried grains with solubles (DDGS) at either 0,8 , or $16 \%$

${ }^{3}$ Formulated Available $\mathrm{P}$ (Phosphorus) represents the goal Available P content of each diet fed

${ }^{4}$ Negative Control (NC) and Positive Control (PC) diets with either 0, 8, or 16\% DDGS were mixed. To create an additional three diets varying in AP for each level of DDGS inclusion, NC:PC ratios were mixed (25:75; 50:50; 75:25) ${ }^{5}$ Total P (Phosphorus) was determined by first ashing the sample in a muffle furnace to remove organic material. The ash residue is dissolved in dilute acid. The sample solution is analyzed using a Technicon Auto-Analyzer system, where the solution is treated with molybdic-sulfuric acid reagent, forming phosphomolybdate. Stannous chloridehydrazine sulfate is added to reduce the phosphomolybdate, with a resultant blue color. The concentration of phosphorus $(\mathrm{P})$ is then determined by comparing the absorbance of the sample solution to the absorbance of standard solutions using colorimetric spectroscopy [24]

${ }^{6}$ Phytic acid is extracted with dilute hydrochloric acid solution, and separated from inorganic phosphates on an anion exchange column. Phytate is eluted with a sodium chloride solution. The eluate is digested with sulfuric/nitric acid, freeing phosphorus, which is reacted with ammonium molybdate and sulfonic acid solutions, forming a blue color complex which is measured spectrophotometrically. Phosphorus concentration is quantitated from a set of standards of known concentration that are taken through the color reaction. Values are converted to phytic acid based on molecular weight equivalence [24]

${ }^{7}$ Non phytate phosphorus (nPP) values were calculated using the following equation: Analyzed Total P - (Analyzed Phytic Acid x 0.282); this equation is used because approximately $28.2 \%$ of the phytic acid is phosphorus [25]

${ }^{8}$ Ash was determined using AOAC Official Method 942.05 [24]

${ }^{9} \mathrm{Calcium}$ is abbreviated $\mathrm{Ca}$ and was determined by first ashing the sample in a muffle furnace to remove organic material. Next, ash residue is dissolved in dilute acid and then an excess of lanthanum buffer is added to minimize chemical interferences and ionization. The concentration of calcium $(\mathrm{Ca})$ is determined by comparing the absorbance of the sample solution to the absorbance of standard solutions using atomic absorption spectroscopy [24] 
Table 7. Descriptive feed manufacturing variables for Experiment 1 diets formulated to $100 \%$ AGRI STATS digestible lysine (Dig Lys) ${ }^{1}$

\begin{tabular}{|c|c|c|c|c|c|c|c|c|c|c|}
\hline $\begin{array}{c}\text { Diet } \\
\text { Formulated } \\
\text { to } 100 \% \\
\text { Dig Lys }\end{array}$ & $\begin{array}{c}\text { DDGS }^{5} \\
\text { Inclusion } \\
(\%)\end{array}$ & $\begin{array}{l}\text { Mixer- } \\
\text { Added } \\
\text { Fat }^{6} \\
(\%)\end{array}$ & $\begin{array}{c}\text { Fines }^{7} \\
(\%)\end{array}$ & $\begin{array}{c}\text { Pellet } \\
\text { Durability } \\
\text { Index }^{8} \\
(\%)\end{array}$ & $\begin{array}{l}\text { Modified } \\
\text { Pellet } \\
\text { Durability } \\
\text { Index }^{9} \\
(\%)\end{array}$ & $\begin{array}{c}\text { New } \\
\text { Holman } \\
\text { Tester } \\
30 \mathrm{~s}^{10}(\%)\end{array}$ & $\begin{array}{c}\text { New } \\
\text { Holman } \\
\text { Tester } \\
60 \mathrm{~s}^{11}(\%)\end{array}$ & $\begin{array}{l}\text { Total } \\
\text { Production } \\
\text { Rate }^{12} \\
\text { (tonne/hr) }\end{array}$ & $\begin{array}{c}\text { Relative } \\
\text { Electrical } \\
\text { Energy } \\
\text { Usage of } \\
\text { Conditioner } \\
\text { (kwh/tonne) }\end{array}$ & $\begin{array}{l}\text { Relative } \\
\text { Electrical } \\
\text { Energy } \\
\text { Usage of } \\
\text { Pellet Mill } \\
\text { (kwh/ } \\
\text { tonne) }\end{array}$ \\
\hline \multirow{2}{*}{ Starter $^{2}$} & 0 & 1.25 & 12.2 & 86.67 & 80.84 & 79.2 & 50.8 & 0.712 & 0.170 & 6.36 \\
\hline & 4 & 1.38 & 15.09 & 85.22 & 80.29 & 74.6 & 43.7 & 0.824 & 0.042 & 5.35 \\
\hline & & & & & & & & & & \\
\hline \multirow{3}{*}{ Grower $^{3}$} & 0 & 1.45 & 11.39 & 78.42 & 68.51 & 61.3 & 24.1 & 0.819 & 0.059 & 5.56 \\
\hline & 5 & 1.63 & 6.78 & 78.82 & 69.94 & 67.7 & 31.8 & 0.816 & 0.067 & 5.58 \\
\hline & 10 & 1.81 & 14.58 & 81.16 & 72.92 & 70.2 & 37.9 & 0.789 & 0.043 & 4.93 \\
\hline & & & & & & & & & & \\
\hline \multirow{3}{*}{ Finisher ${ }^{4}$} & 0 & 1.59 & 6.72 & 71.11 & 62.58 & 52.6 & 20.6 & 1.22 & 0.116 & 4.94 \\
\hline & 10 & 1.96 & 11.21 & 64.33 & 52.72 & 43.6 & 13.8 & 1.20 & 0.144 & 4.87 \\
\hline & 20 & 2.43 & 10.02 & 65.8 & 52.76 & 50.7 & 15.3 & 1.18 & 0.117 & 4.12 \\
\hline
\end{tabular}

${ }^{1}$ Descriptive feed manufacture data is provided for only diets formulated to 100\% digestible lysine for each of the dietary phases (Starter, Grower and Finisher); For all phases, diets were pelleted in order of increasing Dig Lys for a common DDGS (distiller's dried grains and solubles) inclusion, increasing from 0\% DDGS.

${ }^{2}$ Day of manufacture was 7/5/2011 and the ambient temperature recorded at the feed mill in Morgantown, $\mathrm{WV}$ on the day of feed manufacture was $28.9^{\circ} \mathrm{C}$ with 0 inches of precipitation.

${ }^{3}$ Day of manufacture was 7/16/2011 and the ambient temperature recorded at the feed mill in Morgantown, WV on the day of feed manufacture was $29.4^{\circ} \mathrm{C}$ with 0 inches of precipitation.

${ }^{4}$ Day of manufacture was $7 / 25 / 2011$ and the ambient temperature recorded at the feed mill in Morgantown, WV on the day of feed manufacture was $27.8^{\circ} \mathrm{F}$ with 0.18 inches of precipitation.

${ }^{5}$ Represents the inclusion of distiller's dried grains and solubles (DDGS) [9] inclusion level required by the treatment.

${ }^{6}$ Mixer-added fat $(\%)$ represents the amount of fat added at the mixer; all supplemental fat required by diet formulation was added at the mixer.

${ }^{7}$ Percent fines is defined as the percentage of feed manufactured collected at the cooler.

${ }^{8}$ Pellet durability index was determined by placing $500 \mathrm{~g}$ of sifted pellets into a Pfost tumbler. Samples were tumbled for $10 \mathrm{~min}$ at $50 \mathrm{rpm}$. The sample was then sifted again and weighed. Pellet durability index was calculated as the percentage of sifted pellets retained after tumbling.

Modified pellet durability index was determined in a similar manner to pellet durability index with the exception of adding 5, 13-mm hex nuts to the pretumbled sample to obtain added pellet agitation.

${ }^{10}$ Lignotester uses a sample of $100 \mathrm{~g}$ of pellets and subjected to air flow within a perforated chamber for $30 \mathrm{~s}$

${ }^{11}$ Lignotester uses a sample of $100 \mathrm{~g}$ of pellets and subjected to air flow within a perforated chamber for $60 \mathrm{~s}$

${ }^{12}$ Total production rate varied depending upon dietary phase due to pellet mill operator and weather conditions 
Table 8. The effect of varying Digestible Lysine (Dig Lys) and distiller's dried grains and solubles (DDGS) inclusion on D3-42 male broiler performance

\begin{tabular}{|c|c|c|c|c|c|c|c|c|c|}
\hline \multicolumn{2}{|c|}{ Treatment ${ }^{1}$} & \multirow{2}{*}{$\begin{array}{c}\text { D3 Avg Beg } \\
\begin{array}{c}\text { Chick Wt }{ }^{2} \\
\text { (kg/chick) }\end{array} \\
0.0583^{\mathrm{e}}\end{array}$} & \multirow{2}{*}{$\begin{array}{c}\text { D3-42 } \\
\text { LWG } \\
\text { (kg/chick) }\end{array}$} & \multirow{2}{*}{$\begin{array}{c}\begin{array}{c}\text { D3-42 } \\
\text { Pen FI } \\
\text { (kg/pen) }\end{array} \\
48.84^{\mathrm{h}} \\
\end{array}$} & \multirow{2}{*}{$\begin{array}{c}\begin{array}{c}\mathrm{D} 3-42 \\
\mathrm{FCR}^{3} \\
(\mathrm{~kg} / \mathrm{kg})\end{array} \\
2.85^{\mathrm{b}} \\
\end{array}$} & \multirow{2}{*}{$\begin{array}{c}\text { D42 Avg } \\
\text { EW }^{4} \\
\text { (kg/bird) }\end{array}$} & \multirow{2}{*}{$\begin{array}{c}\text { D43 Avg } \\
\text { Hot CW } \\
(\mathrm{kg})\end{array}$} & \multirow{2}{*}{$\begin{array}{l}\begin{array}{l}\text { D43 Avg Hot } \\
\text { BBW }^{6}(\mathrm{~kg})\end{array} \\
0.077^{\mathrm{i}}\end{array}$} & \multirow{2}{*}{$\begin{array}{c}\text { D43 Avg } \\
\begin{array}{c}\text { BB Yield } \\
(\%)\end{array} \\
13.91^{\mathrm{h}}\end{array}$} \\
\hline \multirow{3}{*}{$\begin{array}{l}70 \% \\
\text { Dig Lys }\end{array}$} & No DDGS & & & & & & & & \\
\hline & Low DDGS & $0.0603^{\mathrm{d}}$ & $0.744^{\mathrm{f}}$ & $53.03^{\text {gh }}$ & $3.44^{\mathrm{a}}$ & $0.804^{\mathrm{j}}$ & $0.513^{\mathrm{i}}$ & $0.073^{\mathrm{i}}$ & $14.12^{\mathrm{h}}$ \\
\hline & High DDGS & $0.0604^{\mathrm{cd}}$ & $0.943^{\text {def }}$ & $53.94^{\text {gh }}$ & $2.78^{\mathrm{bc}}$ & $1.00^{\mathrm{i}}$ & $0.628^{\text {hi }}$ & $0.090^{i}$ & $14.29^{\mathrm{gh}}$ \\
\hline \multirow{3}{*}{$\begin{array}{l}80 \% \\
\text { Dig Lys }\end{array}$} & No DDGS & $0.0616^{\text {abcd }}$ & $1.08^{\text {cdef }}$ & $52.03^{\text {gh }}$ & $2.49^{\mathrm{d}}$ & $1.15^{\mathrm{h}}$ & $0.743^{\text {gh }}$ & $0.124^{\text {gh }}$ & $16.64^{\mathrm{ef}}$ \\
\hline & Low DDGS & $0.0621^{\text {abcd }}$ & $1.15^{\text {cdef }}$ & $57.11^{\mathrm{fg}}$ & $2.43^{\mathrm{d}}$ & $1.20^{\mathrm{gh}}$ & $0.744^{\text {gh }}$ & $0.121^{\text {gh }}$ & $16.09^{\mathrm{fg}}$ \\
\hline & High DDGS & $0.0612^{\mathrm{bcd}}$ & $1.17^{\text {cdef }}$ & $60.61^{\text {ef }}$ & $2.54^{\mathrm{d}}$ & $1.24^{\mathrm{g}}$ & $0.832^{\mathrm{g}}$ & $0.140^{g}$ & $16.76^{\mathrm{ef}}$ \\
\hline \multirow{3}{*}{$\begin{array}{c}90 \% \\
\text { Dig Lys }\end{array}$} & No DDGS & $0.0627^{\mathrm{ab}}$ & $1.53^{\text {bcde }}$ & $65.24^{\mathrm{de}}$ & $1.99^{\mathrm{ef}}$ & $1.59^{\mathrm{f}}$ & $1.09^{\mathrm{ef}}$ & $0.210^{\mathrm{ef}}$ & $19.32^{\text {cd }}$ \\
\hline & Low DDGS & $0.0623^{\mathrm{abc}}$ & $2.70^{\mathrm{a}}$ & $69.90^{\text {cd }}$ & $1.70^{\text {gh }}$ & $1.73^{\mathrm{de}}$ & $1.24^{\text {cd }}$ & $0.241^{\mathrm{de}}$ & $19.28^{\text {cd }}$ \\
\hline & High DDGS & $0.0624^{\mathrm{ab}}$ & $1.68^{\mathrm{bcd}}$ & $70.09^{\text {bcd }}$ & $1.94 \mathrm{e}^{\mathrm{fg}}$ & $1.73^{\mathrm{de}}$ & $1.20^{\mathrm{de}}$ & $0.250^{\text {cd }}$ & $20.75^{\mathrm{bc}}$ \\
\hline \multirow{3}{*}{$\begin{array}{l}100 \% \\
\text { Dig Lys }\end{array}$} & No DDGS & $0.0626^{\mathrm{ab}}$ & $1.73^{\mathrm{bc}}$ & $70.56^{\text {bcd }}$ & $1.84^{\text {efgh }}$ & $1.80^{\mathrm{d}}$ & $1.28^{\mathrm{cd}}$ & $0.276^{\mathrm{cd}}$ & $21.43^{\mathrm{b}}$ \\
\hline & Low DDGS & $0.0634^{\mathrm{a}}$ & $2.10^{\mathrm{ab}}$ & $78.09^{\mathrm{a}}$ & $1.72^{\mathrm{fgh}}$ & $2.06^{\mathrm{b}}$ & $1.48^{\mathrm{b}}$ & $0.333^{\mathrm{b}}$ & $22.47^{\mathrm{ab}}$ \\
\hline & High DDGS & $0.0622^{\text {abcd }}$ & $1.92^{\mathrm{b}}$ & $74.95^{\text {abc }}$ & $1.85^{\text {efgh }}$ & $1.96^{\mathrm{c}}$ & $1.38^{\mathrm{c}}$ & $0.285^{\mathrm{c}}$ & $21.20^{\mathrm{bc}}$ \\
\hline \multirow{3}{*}{$\begin{array}{l}110 \% \\
\text { Dig Lys }\end{array}$} & No DDGS & $0.0629^{\mathrm{ab}}$ & $1.61^{\mathrm{bcd}}$ & $68.54^{\mathrm{d}}$ & $2.03^{\mathrm{e}}$ & $1.66^{\mathrm{ef}}$ & $1.08^{\mathrm{f}}$ & $0.198^{\mathrm{f}}$ & $18.26^{\mathrm{de}}$ \\
\hline & Low DDGS & $0.0614^{\mathrm{bcd}}$ & $2.26^{\mathrm{ab}}$ & $77.65^{\mathrm{a}}$ & $1.60^{\mathrm{h}}$ & $2.24^{\mathrm{a}}$ & $1.60^{\mathrm{a}}$ & $0.377^{\mathrm{a}}$ & $23.59^{\mathrm{a}}$ \\
\hline & High DDGS & $0.0621^{\text {abcd }}$ & $2.18^{\mathrm{ab}}$ & $75.52^{\mathrm{ab}}$ & $1.72^{\text {fgh }}$ & $2.18^{\mathrm{a}}$ & $1.50^{\mathrm{ab}}$ & $0.324^{\mathrm{b}}$ & $21.55^{\mathrm{b}}$ \\
\hline \multicolumn{10}{|c|}{ Probabilities and error } \\
\hline & ANOVA P-value & 0.0001 & 0.0001 & 0.0001 & 0.0001 & 0.0001 & 0.0001 & 0.0001 & 0.0001 \\
\hline & Fisher's LSD ${ }^{8}$ & 0.0018 & 0.7414 & 5.553 & 0.276 & 0.0889 & 0.1187 & 0.0375 & 1.9388 \\
\hline & SEM $^{9}$ & 0.0007 & 0.2631 & 1.970 & 0.0979 & 0.0315 & 0.0421 & 0.0133 & 0.6879 \\
\hline \multicolumn{10}{|c|}{ Marginal Means } \\
\hline $70 \%$ Dig & Lys $\left(0.73 \%\right.$ Average Dig Lys $\left.{ }^{10}\right)$ & $0.0597^{\mathrm{c}}$ & $0.839^{\mathrm{b}}$ & $51.93^{\mathrm{d}}$ & $3.02^{\mathrm{a}}$ & $0.898^{\mathrm{e}}$ & $0.565^{\mathrm{d}}$ & $0.080^{\mathrm{d}}$ & $14.11^{\mathrm{d}}$ \\
\hline $80 \%$ Dig & Lys (0.83\% Average Dig Lys) & $0.0616^{\mathrm{b}}$ & $1.13^{\mathrm{b}}$ & $56.58^{\mathrm{c}}$ & $2.49^{\mathrm{b}}$ & $1.20^{\mathrm{d}}$ & $0.773^{\mathrm{c}}$ & $0.128^{\mathrm{c}}$ & $16.50^{\mathrm{c}}$ \\
\hline $90 \%$ Dig & Lys (0.93\% Average Dig Lys) & $0.0624^{\mathrm{ab}}$ & $1.97^{\mathrm{a}}$ & $68.41^{\mathrm{b}}$ & $1.88^{\mathrm{c}}$ & $1.68^{\mathrm{c}}$ & $1.78^{\mathrm{b}}$ & $0.234^{\mathrm{b}}$ & $19.78^{b}$ \\
\hline $100 \% \mathrm{Di}$ & Lys (1.04\% Average Dig Lys) & $0.0627^{\mathrm{a}}$ & $1.92^{\mathrm{a}}$ & $74.53^{\mathrm{a}}$ & $1.80^{\mathrm{c}}$ & $1.94^{\mathrm{b}}$ & $1.37^{\mathrm{a}}$ & $0.298^{\mathrm{a}}$ & $21.70^{\mathrm{a}}$ \\
\hline $110 \% \mathrm{Di}$ & Lys (1.15\% Average Dig Lys) & $0.0621^{\mathrm{ab}}$ & $2.02^{\mathrm{a}}$ & $73.91^{\mathrm{a}}$ & $1.79^{\mathrm{c}}$ & $2.03^{\mathrm{a}}$ & $1.39^{\mathrm{a}}$ & $0.300^{\mathrm{a}}$ & $21.13^{\mathrm{a}}$ \\
\hline & No DDGS & 0.0616 & $1.36^{\mathrm{b}}$ & $61.04^{\mathrm{b}}$ & 2.24 & $1.42^{\mathrm{b}}$ & $0.948^{\mathrm{b}}$ & $0.177^{\mathrm{b}}$ & $17.91^{\mathrm{b}}$ \\
\hline & Low DDGS & 0.0619 & $1.79^{\mathrm{a}}$ & $67.16^{\mathrm{a}}$ & 2.18 & $1.61^{\mathrm{a}}$ & $1.12^{\mathrm{a}}$ & $0.229^{\mathrm{a}}$ & $19.11^{\mathrm{a}}$ \\
\hline & High DDGS & 0.0617 & $1.58^{\mathrm{ab}}$ & $67.02^{\mathrm{a}}$ & 2.17 & $1.62^{\mathrm{a}}$ & $1.10^{\mathrm{a}}$ & $0.218^{\mathrm{a}}$ & $18.91^{\mathrm{a}}$ \\
\hline \multicolumn{10}{|c|}{ Main effect and interaction probabilities } \\
\hline & Dig Lys Level & 0.0001 & 0.0001 & 0.0001 & 0.0001 & 0.0001 & 0.0001 & 0.0001 & 0.0001 \\
\hline & DDGS Level & 0.7718 & 0.0375 & 0.0001 & 0.4568 & 0.0001 & 0.0001 & 0.0001 & 0.0162 \\
\hline Dig & Lys Level x DDGS Level & 0.1940 & 0.2925 & 0.7600 & 0.0001 & 0.0001 & 0.0001 & 0.0001 & 0.0021 \\
\hline \multicolumn{10}{|c|}{ Contrasts (P-values) using average digestible lysine consumed over grow-out period } \\
\hline $\begin{array}{r}0.93 \\
1\end{array}$ & $\begin{array}{l}\text { 6 Dig Lys / Low DDGS vs } \\
\text { 94 Dig Lys / No DDGS }\end{array}$ & 0.7254 & 0.0105 & 0.8147 & 0.3202 & 0.1660 & 0.5082 & 0.0635 & 0.0299 \\
\hline $\begin{array}{r}0.93 \\
1.0\end{array}$ & $\begin{array}{l}6 \text { Dig Lys / High DDGS vs } \\
4 \% \text { Dig Lys / No DDGS }\end{array}$ & 0.8376 & 0.9001 & 0.8668 & 0.4422 & 0.1265 & 0.1813 & 0.1676 & 0.4816 \\
\hline $\begin{array}{r}0.83 \\
1.04 \\
\end{array}$ & $\begin{array}{l}6 \text { Dig Lys / High DDGS vs } \\
\text { \% Dig Lysine / No DDGS }\end{array}$ & 0.1323 & 0.1417 & 0.0006 & 0.0001 & 0.0001 & 0.0001 & 0.0001 & 0.0001 \\
\hline \multicolumn{10}{|c|}{ 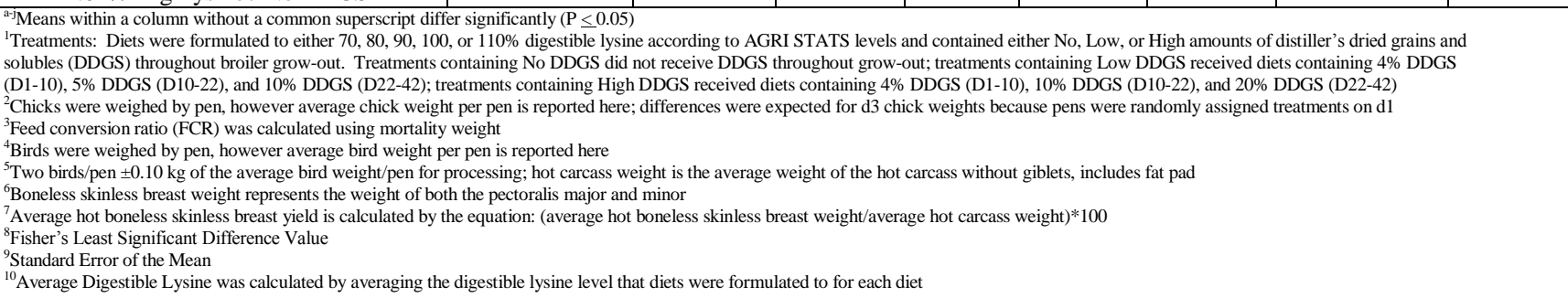 } \\
\hline
\end{tabular}


Table 9. Distiller's dried grains and solubles (DDGS) sparing effects for Average Digestible Lysine (Dig Lys) from standard curve quadratic regression (Method 1)

\begin{tabular}{|c|c|c|c|c|c|c|c|c|c|c|c|c|}
\hline & \multicolumn{2}{|c|}{$\begin{array}{l}\text { D } 42 \text { Avg. Bird } \\
\text { Weight }\end{array}$} & \multicolumn{2}{|c|}{ D 3-42 FCR } & \multicolumn{2}{|c|}{$\begin{array}{l}\text { D 3-42 Avg. Live } \\
\text { Weight Gain }\end{array}$} & \multicolumn{2}{|c|}{$\begin{array}{l}\text { D } 43 \text { Avg. Hot } \\
\text { Carcass Weight }\end{array}$} & \multicolumn{2}{|c|}{$\begin{array}{c}\text { D } 43 \text { Avg. Hot } \\
\text { Boneless Skinless } \\
\text { Breast Weight }\end{array}$} & \multicolumn{2}{|c|}{$\begin{array}{c}\text { D } 43 \text { Avg. Hot } \\
\text { Boneless Skinless } \\
\text { Breast Yield (\%) }\end{array}$} \\
\hline $\begin{array}{c}\text { DDGS } \\
\text { Inclusion } \\
\text { (0.73\% } \\
\text { Avg. Dig } \\
\text { Lys) })^{1}\end{array}$ & $\begin{array}{l}\text { Derived } \\
\text { Calc. Dig } \\
\text { Lys }^{2}\end{array}$ & $\begin{array}{c}\text { Avg. } \\
\text { Dig Lys } \\
\text { Sparing } \\
\text { Effect }\end{array}$ & $\begin{array}{l}\text { Derived } \\
\text { Calc. } \\
\text { Dig } \\
\text { Lys }^{3}\end{array}$ & $\begin{array}{l}\text { Avg. } \\
\text { Dig Lys } \\
\text { Sparing } \\
\text { Effect }\end{array}$ & $\begin{array}{l}\text { Derived } \\
\text { Calc. } \\
\text { Dig } \\
\text { Lys }\end{array}$ & $\begin{array}{c}\text { Avg. } \\
\text { Dig Lys } \\
\text { Sparing } \\
\text { Effect }\end{array}$ & $\begin{array}{l}\text { Derived } \\
\text { Calc. } \\
\text { Dig Lys }\end{array}$ & $\begin{array}{l}\text { Avg. } \\
\text { Dig Lys } \\
\text { Sparing } \\
\text { Effect }\end{array}$ & $\begin{array}{l}\text { Derived } \\
\text { Calc. } \\
\text { Dig Lys }\end{array}$ & $\begin{array}{c}\text { Avg. } \\
\text { Dig Lys } \\
\text { Sparing } \\
\text { Effect }\end{array}$ & $\begin{array}{l}\text { Derived } \\
\text { Calc. } \\
\text { Dig Lys }^{7}\end{array}$ & $\begin{array}{c}\text { Avg. } \\
\text { Dig Lys } \\
\text { Sparing } \\
\text { Effect }\end{array}$ \\
\hline $\begin{array}{c}\text { Low } \\
\text { DDGS }\end{array}$ & 0.725 & $\mathbf{0}$ & 0.653 & $\mathbf{0}$ & 0.724 & $\mathbf{0}$ & 0.734 & 0.004 & 0.742 & 0.012 & 0.742 & 0.012 \\
\hline $\begin{array}{l}\text { High } \\
\text { DDGS }\end{array}$ & 0.765 & 0.035 & 0.749 & 0.019 & 0.765 & 0.035 & 0.763 & 0.033 & 0.758 & 0.028 & 0.748 & 0.018 \\
\hline
\end{tabular}

${ }^{1}$ Diets were formulated to either 70, 80, 90, 100, or 110\% digestible lysine according to AGRI STATS data [10], Avg Dig Lys was calculated by averaging the digestible lysine levels that diets were formulated to throughout grow-out; diets also contained either No, Low, or High amounts of distiller's dried grains and solubles (DDGS) throughout broiler grow-out. Treatments containing No DDGS did not receive DDGS throughout grow-out; treatments containing Low DDGS received diets containing 4\% DDGS (D1-10), 5\% DDGS (D10-22), and 10\% DDGS (D22-42); treatments containing High DDGS received diets containing 4\% DDGS (D1-10), 10\% DDGS (D10-22), and 20\% DDGS (D22-42); the Avg Dig Lys of 0.73\% was subtracted from each derived calc. to determine sparing effects

${ }^{2}$ Calculated Dig Lys values were derived from the quadratic regression of D42 Avg. Bird Wt for diets containing either Low or High DDGS using the equation:

Calc. Dig Lys $=-7.197 x^{2}+15.603 x-6.724-D 42$ Avg. Bird Wt, $R^{2}=0.9206$

${ }^{3}$ Calculated Dig Lys values were derived from the quadratic regression of D3-42 FCR for diets containing either Low or High DDGS using the equation:

Calc. Dig Lys $=9.917 \mathrm{x}^{2}-20.791 \mathrm{x}+12.79-\mathrm{D} 3-42$ FCR, $\mathrm{R}^{2}=0.7755$

${ }^{4}$ Calculated Dig Lys values were derived from the quadratic regression of D 3-42 Avg. LWG for diets containing either Low or High DDGS using the equation:

Calc. Dig Lys $=-6.9428 \mathrm{x}^{2}+15.1425 \mathrm{x}-6.58-\mathrm{D} 3-42$ Avg. LWG, $\mathrm{R}^{2}=0.9133$

${ }^{5}$ Calculated Dig Lys values were derived from the quadratic regression of D43 Avg. Hot Carcass Wt for diets containing either Low or High DDGS using the equation: Calc. Dig Lys $=-6.497 \mathrm{x}^{2}+13.715 \mathrm{x}-6.054-\mathrm{D} 43$ Avg. Hot Carcass Wt, $\mathrm{R}^{2}=0.8205$

${ }^{6}$ Calculated Dig Lys values were derived from the quadratic regression of D 43 Avg. Hot Breast Wt for diets containing either Low or High DDGS using the equation:

Calc. Dig Lys $=-1.872 x^{2}-3.8906 x-1.783-D 43$ Avg. Hot Breast Wt, $R^{2}=0.7441$

${ }^{7}$ Calculated Dig Lys values were derived from the quadratic regression of D 43 Avg. Hot Breast Yield for diets containing either Low or High DDGS using the equation:

Calc. Dig Lys $=-83.945 x^{2}+170.524 x-66.3035-D 43$ Avg. Hot Breast Yield, $R^{2}=0.6711$ 
Table 10. Distiller's dried grains and solubles (DDGS) sparing effects for Digestible Lysine (Dig Lys) ${ }^{1}$ using each DDGS Level's regression analysis (Method 2)

\begin{tabular}{|c|c|c|c|c|c|c|c|c|c|c|c|c|}
\hline \multirow{2}{*}{$\begin{array}{l}\text { DDGS } \\
\text { Level }^{2}\end{array}$} & \multicolumn{2}{|c|}{$\begin{array}{c}\text { D } 42 \text { Avg. Bird } \\
\text { Weight }\end{array}$} & \multicolumn{2}{|c|}{ D 3-42 FCR } & \multicolumn{2}{|c|}{$\begin{array}{l}\text { D 3-42 Avg. Live } \\
\text { Weight Gain }\end{array}$} & \multicolumn{2}{|c|}{$\begin{array}{l}\text { D } 43 \text { Avg. Hot } \\
\text { Carcass Weight }\end{array}$} & \multicolumn{2}{|c|}{$\begin{array}{c}\text { D } 43 \text { Avg. Hot } \\
\text { Boneless Skinless } \\
\text { Breast Weight }\end{array}$} & \multicolumn{2}{|c|}{$\begin{array}{c}\text { D } 43 \text { Avg. Hot } \\
\text { Boneless Skinless } \\
\text { Breast Yield }(\%)\end{array}$} \\
\hline & $\begin{array}{l}\text { Derived } \\
\text { Calc. Dig } \\
\text { Lys }^{3}\end{array}$ & $\begin{array}{c}\text { Avg. } \\
\text { Dig Lys } \\
\text { Sparing } \\
\text { Effect }\end{array}$ & $\begin{array}{c}\text { Derived } \\
\text { Calc. } \\
\text { Dig } \\
\text { Lys }\end{array}$ & $\begin{array}{c}\text { Avg. } \\
\text { Dig Lys } \\
\text { Sparing } \\
\text { Effect }\end{array}$ & $\begin{array}{c}\text { Derived } \\
\text { Calc. } \\
\text { Dig } \\
\text { Lys }^{5}\end{array}$ & $\begin{array}{c}\text { Avg. } \\
\text { Dig Lys } \\
\text { Sparing } \\
\text { Effect }\end{array}$ & $\begin{array}{l}\text { Derived } \\
\text { Calc. } \\
\text { Dig Lys }^{6}\end{array}$ & $\begin{array}{c}\text { Avg. } \\
\text { Dig Lys } \\
\text { Sparing } \\
\text { Effect }\end{array}$ & $\begin{array}{l}\text { Derived } \\
\text { Calc. } \\
\text { Dig Lys }^{7}\end{array}$ & $\begin{array}{c}\text { Avg. } \\
\text { Dig Lys } \\
\text { Sparing } \\
\text { Effect }\end{array}$ & $\begin{array}{l}\text { Derived } \\
\text { Calc. } \\
\text { Dig Lys }\end{array}$ & $\begin{array}{c}\text { Avg. } \\
\text { Dig Lys } \\
\text { Sparing } \\
\text { Effect }\end{array}$ \\
\hline $\begin{array}{c}\text { No } \\
\text { DDGS }\end{array}$ & 0.904 & - & 0.945 & - & 0.930 & 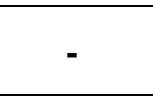 & 0.887 & - & 0.895 & - & 0.956 & - \\
\hline $\begin{array}{c}\text { Low } \\
\text { DDGS }\end{array}$ & 0.880 & 0.024 & 0.897 & 0.048 & 0.857 & 0.073 & 0.870 & 0.017 & 0.899 & 0 & 0.973 & $\mathbf{0}$ \\
\hline $\begin{array}{c}\text { High } \\
\text { DDGS }\end{array}$ & 0.878 & 0.026 & 0.954 & $\mathbf{0}$ & 0.910 & 0.020 & 0.869 & 0.018 & 0.881 & 0.014 & 0.930 & 0.026 \\
\hline
\end{tabular}

${ }^{1}$ Diets were formulated to either 70, 80, 90, 100, or 110\% digestible lysine according to AGRI STATS data [10], Avg Dig Lys was calculated by averaging the digestible lysine levels that diets were formulated to throughout grow-out

${ }^{2}$ DDGS levels were No, Low, or High amounts of distiller's dried grains and solubles (DDGS) throughout broiler grow-out. Treatments containing No DDGS did not receive DDGS throughout grow-out; treatments containing Low DDGS received diets containing 4\% DDGS (D1-10), 5\% DDGS (D10-22), and 10\% DDGS (D22-42); treatments containing High DDGS received diets containing 4\% DDGS (D110), 10\% DDGS (D10-22), and 20\% DDGS (D22-42); toy ' $y$ ' values were substituted into each regression equation to determine the calculated Avg Dig Lys obtained for each DDGS level; Derived values obtained from No DDGS were subtracted from each derived value for Low and High DDGS to determine sparing effects

${ }^{3}$ Calculated Dig Lys values were derived from regression of D42 Avg. Bird Wt $(\mathrm{y}=1.5 \mathrm{~kg})$ :

No DDGS equation: $y=-7.197 x^{2}+15.603 x-6.724-1.5, R^{2}=0.9206$; Low DDGS equation: $y=-4.89 x^{2}+12.743 x-5.928, R^{2}=0.9713 ;$ High DDGS equation: $y=-2.484 x^{2}+7.596 x-3.255, R^{2}=0.9612$ ${ }^{4}$ Calculated Dig Lys values were derived from the quadratic regression of D3-42 FCR $(y=2.0)$ : No DDGS equation: $y=9.917 x^{2}-20.791 x+12.79, R^{2}=0.7755 ;$ Low DDGS equation: $y=17.045 x^{2}-36.7 x$ $+20.73, \mathrm{R}^{2}=0.8043$; High DDGS equation: $\mathrm{y}=5.378 \mathrm{x}^{2}-12.7715 \mathrm{x}+9.29, \mathrm{R}^{2}=0.8183$

${ }^{5}$ Calculated Dig Lys values were derived from the quadratic regression of D 3-42 Avg. LWG $(y=1.5 \mathrm{~kg})$ : No DDGS equation: $y=-6.9428 \mathrm{x}^{2}+15.1425 \mathrm{x}-6.58, \mathrm{R}^{2}=0.9133 ;$ Low DDGS equation: $\mathrm{y}=$ $3.723 \mathrm{x}-1.69, \mathrm{R}^{2}=0.1956$; High DDGS equation: $\mathrm{y}=3.058 \mathrm{x}-1.283, \mathrm{R}^{2}=0.9528$

${ }^{6}$ Calculated Dig Lys values were derived from regression of D43 Hot Carcass Wt $(\mathrm{y}=1.0 \mathrm{~kg})$

No DDGS equation: $y=-6.4967 x^{2}+13.715 x-6.054, R^{2}=0.8205$; Low DDGS equation: $y=-3.75 x^{2}+9.814 x-4.701, R^{2}=0.9247 ;$ High DDGS equation: $y=-2.5387 x^{2}+6.904-3.0826, R^{2}=0.9104$ ${ }^{7}$ Calculated Dig Lys values were derived from the quadratic regression of D43 Hot Boneless Skinless Breast Wt $(y=0.20 \mathrm{~kg})$ : No DDGS equation: $y=-1.872 \mathrm{x}^{2}-3.891 \mathrm{x}-1.983$, $\mathrm{R}^{2}=0.7441 ;$ Low DDGS equation: $y=0.7799 x-0.501, R^{2}=0.9090$; High DDGS equation: $y=-0.756 x^{2}-2.003 x-0.9775, R^{2}=0.8801$

${ }^{8}$ Calculated Dig Lys values were derived from the quadratic regression of D43 Hot Boneless Skinless Breast Yield $(y=20 \%)$ : No DDGS equation: $y=-83.945 x^{2}+170.524 x-66.304, R^{2}=0.6711 ;$ Low DDGS equation: $y=24.059 x-3.408, R^{2}=0.7802$; High DDGS equation: $y=-54.193 x^{2}+119.825 x-44.572, R^{2}=0.8148$ 
Table 11. The effect of varying Available Phosphorus (AP) and distiller's dried grains and solubles (DDGS) inclusion on D3-21 male broiler chick performance

\begin{tabular}{|c|c|c|c|c|c|c|c|c|}
\hline \multicolumn{2}{|c|}{ Treatment $^{1}$} & $\begin{array}{c}\text { D3 Beg } \\
\text { Chick Wt }^{2} \\
\text { (kg/chick) }\end{array}$ & $\begin{array}{c}\text { D3-21 } \\
\text { LWG } \\
\text { (kg/chick) }\end{array}$ & $\begin{array}{c}\text { D3-21 } \\
\text { Pen FI } \\
\text { (kg/pen) }\end{array}$ & $\begin{array}{c}\text { D3-21 } \\
\text { FCR }^{3} \\
(\mathrm{~kg} / \mathrm{kg})\end{array}$ & $\begin{array}{l}\text { D21 EW } \\
\text { (kg/chick) }\end{array}$ & $\begin{array}{c}\text { D21\% } \\
\text { TA/chick }^{5}\end{array}$ & $\begin{array}{c}\text { D21 Avg } \\
\text { TA (mg/ } \\
\text { chick) }\end{array}$ \\
\hline \multirow{3}{*}{$\begin{array}{c}0.21 \% \text { AP } \\
(0.17 \% \mathrm{nPP})\end{array}$} & $0 \%$ DDGS & 0.055 & $0.249^{\mathrm{g}}$ & $2.38^{\text {hi }}$ & $2.00^{\mathrm{a}}$ & $0.302^{\mathrm{g}}$ & $20.41^{\mathrm{h}}$ & $235.12^{\mathrm{e}}$ \\
\hline & $8 \%$ DDGS & 0.055 & $0.284^{\mathrm{g}}$ & $2.29^{i}$ & $1.88^{\mathrm{ab}}$ & $0.331^{\mathrm{g}}$ & $21.51^{\mathrm{h}}$ & $271.34^{\mathrm{e}}$ \\
\hline & $16 \%$ DDGS & 0.055 & $0.277^{\mathrm{g}}$ & $2.49^{\mathrm{h}}$ & $1.89^{\mathrm{ab}}$ & $0.330^{\mathrm{g}}$ & $22.49^{\text {gh }}$ & $278.08^{\mathrm{e}}$ \\
\hline \multirow{3}{*}{$\begin{array}{c}0.27 \% \text { AP } \\
(0.22 \% \mathrm{nPP})\end{array}$} & $0 \%$ DDGS & 0.055 & $0.359^{\mathrm{ef}}$ & $2.90^{\mathrm{g}}$ & $1.75^{\mathrm{bc}}$ & $0.405^{\mathrm{f}}$ & $24.28^{\mathrm{fg}}$ & $361.40^{\mathrm{d}}$ \\
\hline & $8 \%$ DDGS & 0.056 & $0.345^{\mathrm{f}}$ & $2.93^{\mathrm{fg}}$ & $1.77^{\mathrm{bc}}$ & $0.401^{\mathrm{f}}$ & $25.03^{\text {efg }}$ & $357.59^{d}$ \\
\hline & $16 \%$ DDGS & 0.055 & $0.367^{\text {def }}$ & $3.05^{\mathrm{efg}}$ & $1.73^{\mathrm{bc}}$ & $0.423^{\mathrm{ef}}$ & $26.49^{\mathrm{def}}$ & $392.60^{\mathrm{d}}$ \\
\hline \multirow{3}{*}{$\begin{array}{c}0.33 \% \text { AP } \\
(0.28 \% \text { nPP })\end{array}$} & $0 \%$ DDGS & 0.055 & $0.386^{\text {cde }}$ & $3.09^{\text {defg }}$ & $1.67^{\mathrm{c}}$ & $0.435^{\text {edf }}$ & $27.56^{\text {cde }}$ & $441.64^{\mathrm{c}}$ \\
\hline & $8 \%$ DDGS & 0.055 & $0.440^{\mathrm{a}}$ & $3.09^{\mathrm{def}}$ & $1.65^{\mathrm{c}}$ & $0.476^{\mathrm{abc}}$ & $28.31^{\mathrm{bcd}}$ & $481.33^{b c}$ \\
\hline & $16 \%$ DDGS & 0.056 & $0.390^{\text {bcde }}$ & $3.17^{\text {bcde }}$ & $1.63^{\mathrm{c}}$ & $0.446^{\text {cde }}$ & $27.57^{\text {cde }}$ & $458.85^{\mathrm{c}}$ \\
\hline \multirow{3}{*}{$\begin{array}{c}0.39 \% \text { AP } \\
(0.31 \% \mathrm{nPP})\end{array}$} & $0 \%$ DDGS & 0.055 & $0.406^{\mathrm{abcd}}$ & $3.36^{\mathrm{a}}$ & $1.66^{\mathrm{c}}$ & $0.461^{\mathrm{abcd}}$ & $31.79^{\mathrm{a}}$ & $538.30^{\mathrm{a}}$ \\
\hline & $8 \%$ DDGS & 0.055 & $0.442^{\mathrm{a}}$ & $3.14^{\text {cde }}$ & $1.65^{\mathrm{c}}$ & $0.484^{\mathrm{a}}$ & $30.69^{\mathrm{ab}}$ & $548.21^{\mathrm{a}}$ \\
\hline & $16 \%$ DDGS & 0.056 & $0.427^{\mathrm{a}}$ & $3.35^{\mathrm{ab}}$ & $1.65^{\mathrm{c}}$ & $0.482^{\mathrm{a}}$ & $29.60^{\mathrm{abc}}$ & $544.40^{\mathrm{a}}$ \\
\hline \multirow{3}{*}{$\begin{array}{c}0.45 \% \text { AP } \\
(0.37 \% \mathrm{nPP})\end{array}$} & $0 \%$ DDGS & 0.055 & $0.399^{\text {bcde }}$ & $3.23^{\mathrm{abcd}}$ & $1.64^{\mathrm{c}}$ & $0.454^{\text {abcde }}$ & $30.38^{\mathrm{ab}}$ & $526.24^{\mathrm{ab}}$ \\
\hline & $8 \%$ DDGS & 0.055 & $0.408^{\mathrm{abc}}$ & $3.38^{\mathrm{a}}$ & $1.67^{\mathrm{c}}$ & $0.463^{\text {abcd }}$ & $31.47^{\mathrm{a}}$ & $554.49^{\mathrm{a}}$ \\
\hline & $16 \%$ DDGS & 0.055 & $0.391^{\text {bcde }}$ & $3.32^{\mathrm{abc}}$ & $1.70^{\mathrm{c}}$ & $0.446^{\text {bcde }}$ & $29.86^{\mathrm{abc}}$ & $522.95^{\mathrm{ab}}$ \\
\hline \multicolumn{9}{|c|}{ Probabilities and error } \\
\hline \multicolumn{2}{|c|}{ ANOVA P-value } & 0.7244 & 0.0001 & 0.0001 & 0.0001 & 0.0001 & 0.0001 & 0.0001 \\
\hline \multicolumn{2}{|c|}{ Fisher's LSD ${ }^{6}$} & -- & 0.0397 & 0.1865 & 0.1616 & 0.0363 & 2.6105 & 48.783 \\
\hline \multicolumn{2}{|c|}{ SEM $^{7}$} & 0.0003 & 0.0142 & 0.0664 & 0.0576 & 0.0129 & 0.9298 & 17.376 \\
\hline \multicolumn{9}{|c|}{ Marginal Means } \\
\hline \multicolumn{2}{|c|}{$0.21 \% \mathrm{AP}\left(0.17 \% \mathrm{nPP}^{8}\right)$} & 0.055 & $0.270^{\mathrm{d}}$ & $2.39^{\mathrm{d}}$ & $1.92^{\mathrm{a}}$ & $0.321^{\mathrm{d}}$ & $21.47^{\mathrm{d}}$ & $261.51^{\mathrm{d}}$ \\
\hline \multicolumn{2}{|c|}{$0.27 \% \mathrm{AP}(0.22 \% \mathrm{nPP})$} & 0.055 & $0.357^{\mathrm{c}}$ & $2.96^{\mathrm{c}}$ & $1.75^{\mathrm{b}}$ & $0.410^{\mathrm{c}}$ & $25.27^{\mathrm{c}}$ & $370.53^{\mathrm{c}}$ \\
\hline \multicolumn{2}{|c|}{$0.33 \% \mathrm{AP}(0.28 \% \mathrm{nPP})$} & 0.055 & $0.405^{\mathrm{b}}$ & $3.21^{\mathrm{b}}$ & $1.65^{\mathrm{c}}$ & $0.452^{\mathrm{b}}$ & $27.81^{\mathrm{b}}$ & $460.61^{b}$ \\
\hline \multicolumn{2}{|c|}{$0.39 \%$ AP $(0.31 \%$ nPP $)$} & 0.055 & $0.425^{\mathrm{a}}$ & $3.28^{\mathrm{a}}$ & $1.65^{\mathrm{c}}$ & $0.476^{\mathrm{a}}$ & $30.69^{\mathrm{a}}$ & $543.64^{\mathrm{a}}$ \\
\hline \multicolumn{2}{|c|}{$0.45 \% \mathrm{AP}(0.37 \% \mathrm{nPP})$} & 0.055 & $0.399^{\mathrm{b}}$ & $3.31^{\mathrm{a}}$ & $1.67^{\mathrm{c}}$ & $0.454^{\mathrm{ab}}$ & $30.57^{\mathrm{a}}$ & $534.56^{\mathrm{a}}$ \\
\hline \multicolumn{2}{|c|}{$0 \%$ DDGS } & 0.055 & 0.360 & 3.00 & 1.74 & 0.411 & 26.88 & 420.54 \\
\hline \multicolumn{2}{|c|}{$8 \%$ DDGS } & 0.055 & 0.384 & 2.97 & 1.72 & 0.431 & 27.42 & 442.59 \\
\hline \multicolumn{2}{|c|}{$16 \%$ DDGS } & 0.055 & 0.370 & 3.08 & 1.72 & 0.425 & 27.20 & 439.38 \\
\hline \multicolumn{9}{|c|}{ Main effect and interaction probabilities } \\
\hline \multicolumn{2}{|c|}{ AP/nPP Level } & 0.3305 & 0.0001 & 0.0001 & 0.0001 & 0.0001 & 0.0001 & 0.0001 \\
\hline \multicolumn{2}{|c|}{ DDGS Level } & 0.8244 & 0.0669 & 0.0623 & 0.7683 & 0.1010 & 0.6014 & 0.2187 \\
\hline \multicolumn{2}{|c|}{ AP/nPP Level x DDGS Level } & 0.3555 & 0.3788 & 0.1893 & 0.8200 & 0.6633 & 0.1394 & 0.7656 \\
\hline \multicolumn{9}{|c|}{ Contrasts (P-values) using calculated nPP values } \\
\hline \multicolumn{2}{|c|}{$\begin{array}{c}0.31 \% \mathrm{nPP} / 8 \% \text { DDGS vs } \\
0.37 \% \mathrm{nPP} / 0 \% \text { DDGS }\end{array}$} & - & 0.0223 & 0.1540 & 0.9463 & 0.0898 & 0.5547 & 0.2953 \\
\hline \multicolumn{2}{|c|}{$\begin{array}{c}0.31 \% \mathrm{nPP} / 16 \% \text { DDGS vs } \\
0.37 \% \mathrm{nPP} / 0 \% \text { DDGS }\end{array}$} & - & 0.1614 & 0.3074 & 0.8963 & 0.1274 & 0.5580 & 0.4603 \\
\hline $\begin{array}{r}0.27 \% \mathrm{nPP} / \\
0.37 \% \mathrm{nPI}\end{array}$ & $\begin{array}{l}\% \text { DDGS vs } \\
0 \% \text { DDGS }\end{array}$ & - & 0.8126 & 0.2477 & 0.8770 & 0.7273 & 0.0810 & 0.0123 \\
\hline
\end{tabular}

${ }^{a-1}$ Means within a column without a common superscript differ significantly $(\mathrm{P}<0.05)$

${ }^{1}$ Treatments: Diets were formulated to either $0.21,0.27,0.33,0.39$, or $0.45 \%$ Available Phosphorus (AP) and contained either 0,8 , or $16 \%$ distiller's dried grains and solubles (DDGS); in parentheses are the average nPP calculated/analyzed values using the following equation: Analyzed Total P - (Analyzed Phytic Acid * 0.282 ); this equation is used because approximately $28.2 \%$ of the phytic acid is phosphorus [25]; the analyzed/calculated nPP value is considered to be the estimate for $\mathrm{AP}$

${ }^{2}$ Chicks were weighed by pen, however average chick weight per pen is reported here

${ }^{3}$ Feed conversion was calculated using mortality weight

${ }^{4}$ Birds were weighed by pen, however average bird weight per pen is reported here

${ }^{5}$ Left tibias were excised on $\mathrm{d} 21$, dried at $100^{\circ} \mathrm{C}$ for 12 hours and ashed at $600^{\circ} \mathrm{C}$ for $16 \mathrm{~h}$

${ }^{6}$ Fisher's Least Significant Difference Value

${ }^{7}$ Standard Error of the Mean

${ }^{8}$ In parentheses following the \%AP that diets were formulated to, is the average calculated nPP value for diets formulated to the same AP, but different levels of DDGS 
Table 12. Distiller's dried grains and solubles (DDGS) sparing effects for Available Phosphorus (AP) from standard curve quadratic regression (Method 1)

\begin{tabular}{|c|c|c|c|c|c|c|c|c|}
\hline \multirow{2}{*}{$\begin{array}{l}\text { DDGS Inclusion } \\
(0.18 \% \mathrm{nPP})^{1}\end{array}$} & \multicolumn{2}{|c|}{ D 21 Ending Chick Wt } & \multicolumn{2}{|c|}{ D3-21 FCR } & \multicolumn{2}{|c|}{ Tibia Ash/Chick (\%) } & \multicolumn{2}{|c|}{ Tibia Ash (mg/chick) } \\
\hline & $\begin{array}{c}\text { Derived } \\
\text { Calc. } \text { AP }^{2}\end{array}$ & $\begin{array}{c}\text { AP Sparing } \\
\text { Effect }\end{array}$ & $\begin{array}{c}\text { Derived } \\
\text { Calc. } \text { AP }^{3}\end{array}$ & $\begin{array}{c}\text { AP Sparing } \\
\text { Effect }\end{array}$ & $\begin{array}{c}\text { Derived } \\
\text { Calc. } \text { AP }^{4}\end{array}$ & $\begin{array}{c}\text { AP Sparing } \\
\text { Effect }\end{array}$ & $\begin{array}{c}\text { Derived } \\
\text { Calc. AP }\end{array}$ & $\begin{array}{c}\text { AP Sparing } \\
\text { Effect }\end{array}$ \\
\hline $8 \%$ DDGS & 0.193 & 0.013 & 0.1945 & 0.015 & 0.1846 & 0.0046 & 0.1844 & 0.0044 \\
\hline $16 \%$ DDGS & 0.193 & 0.013 & 0.1919 & 0.012 & 0.1943 & 0.0143 & 0.1868 & 0.0068 \\
\hline
\end{tabular}

${ }^{1}$ The calculated non-phytate phosphorus (nPP) value for the diet formulated to contain $0.21 \%$ AP and $0 \%$ distiller's dried grains and solubles (DDGS) was $0.18 \%$. $\mathrm{nPP}$ values were calculated using the following equation: Analyzed Total $\mathrm{P}$ - (Analyzed Phytic Acid * 0.282) [25]; this equation is used because approximately $28.2 \%$ of the phytic acid is phosphorus; this nPP is subtracted from each derived calc. AP to determine the sparing effect; the analyzed/calculated nPP value is considered to be the estimate for AP

${ }^{2}$ Calculated AP values were derived from the quadratic regression of D21 Average chick weight for $0.21 \%$ AP containing either 8 or $16 \%$ DDGS using the equation: Calc. AP $=-6.25 \mathrm{x}^{2}+4.013 \mathrm{x}-0.21059-\mathrm{D} 21 \mathrm{Avg}$. Ending Chick Wt, $\mathrm{R}^{2}=0.8934$

${ }^{3}$ Calculated AP values were derived from the quadratic regression of D3-21 FCR for $0.21 \%$ AP containing either 8 or $16 \%$ DDGS using the equation: Calc. $\mathrm{AP}=13.92 \mathrm{x}^{2}-9.19 \mathrm{x}+1.261-\mathrm{D} 3-21 \mathrm{FCR}, \mathrm{R}^{2}=0.5847$

${ }^{4}$ Calculated AP values were derived from the quadratic regression of $\%$ Tibia Ash/Chick for $0.21 \%$ AP containing either 8 or $16 \%$ DDGS using the equation: Calc. $\mathrm{AP}=290.944 \mathrm{x}^{2}+211.89 \mathrm{x}-7.692-\%$ Tibia Ash/Chick, $\mathrm{R}^{2}=0.6256$

${ }^{5}$ Calculated AP values were derived from the quadratic regression of Tibia Ash mg/Chick for $0.21 \%$ AP containing either 8 or $16 \%$ DDGS using the equation: Calc. AP $=-7672.01 \mathrm{x}^{2}+5668.1626 \mathrm{x}-512.895-$ Tibia Ash mg/Chick, $\mathrm{R}^{2}=0.8740$ 
Table 13. Distiller's dried grains and solubles (DDGS) sparing effects for Available Phosphorus (AP) using each DDGS Level's regression analysis (Method 2)

\begin{tabular}{|c|c|c|c|c|c|c|c|c|}
\hline \multirow{2}{*}{$\begin{array}{c}\text { DDGS } \\
\text { Inclusion }\end{array}$} & \multicolumn{2}{|c|}{ D 21 Ending Chick Wt } & \multicolumn{2}{|c|}{ D3-21 FCR } & \multicolumn{2}{c|}{ Tibia Ash/Chick (\%) } & \multicolumn{2}{c|}{ Tibia Ash (mg/chick) } \\
\cline { 2 - 8 } & $\begin{array}{c}\text { Derived Calc. } \\
\text { AP }(\%)^{2}\end{array}$ & $\begin{array}{c}\text { \% AP } \\
\text { Sparing } \\
\text { Effect }\end{array}$ & $\begin{array}{c}\text { Derived Calc. } \\
\text { AP }(\%)^{3}\end{array}$ & $\begin{array}{c}\text { \% AP } \\
\text { Sparing } \\
\text { Effect }\end{array}$ & $\begin{array}{c}\text { Derived Calc. } \\
\text { AP }(\%)^{4}\end{array}$ & $\begin{array}{c}\text { \% AP } \\
\text { Sparing } \\
\text { Effect }\end{array}$ & $\begin{array}{c}\text { Derived Calc. } \\
\text { AP }(\%)\end{array}$ & $\begin{array}{c}\text { \% AP } \\
\text { Sparing } \\
\text { Effect }\end{array}$ \\
\hline 0\% DDGS & 0.228 & - & 0.256 & - & 0.222 & - & 0.303 & - \\
\hline 8\% DDGS & 0.213 & $\mathbf{0 . 0 1 5}$ & 0.253 & $\mathbf{0 . 0 0 3}$ & 0.225 & $\mathbf{0}$ & 0.294 & $\mathbf{0 . 0 0 9}$ \\
\hline $16 \%$ DDGS & 0.213 & $\mathbf{0 . 0 1 5}$ & 0.237 & $\mathbf{0 . 0 1 9}$ & 0.208 & $\mathbf{0 . 0 1 4}$ & 0.299 & $\mathbf{0 . 0 0 4}$ \\
\hline
\end{tabular}

${ }^{\mathrm{I}}$ Diets were formulated to either $0.21,0.27,0.33,0.39$, or $0.45 \%$ Available Phosphorus (AP) and contained either 0,8 , or $16 \%$ distiller's dried grains and solubles (DDGS); the analyzed/calculated nPP value is considered to be the estimate for AP; A regression analysis was conducted for each DDGS level; toy ' $y$ ' values were inserted into each equation to obtain a derived calculated AP for each variable; Derived values from 8 and 16\% DDGS diets were subtracted from the derived value from $0 \%$ DDGS diets to determine the sparing effect

${ }^{2}$ Calculated AP values were derived from regression of D21 Average chick weight $(\mathrm{y}=0.400 \mathrm{~kg})$ using the equations:

$0 \%$ DDGS: $y=-6.25 x^{2}+4.013 x-0.2106, R^{2}=0.8934 ; 8 \%$ DDGS: $y=-6.49 x^{2}+4.209 x-0.2024, R^{2}=0.7155 ; 16 \%$ DDGS: $y=-6.568 x^{2}+4.13 x-0.1813, R^{2}=$ 0.6864

${ }^{3}$ Calculated AP values were derived from regression of D3-21 FCR $(\mathrm{y}=1.70)$ using the equations:

$0 \%$ DDGS: $y=13.92 x^{2}-9.19 x+3.14, R^{2}=0.5847 ; 8 \%$ DDGS: $y=10.128 x^{2}-6.651 x+2.734, R^{2}=0.4333 ; 16 \%$ DDGS: $y=14.913 x^{2}-9.024 x+3.0, R^{2}=$ 0.2698

${ }^{4}$ Calculated AP values were derived from regression of $\%$ Tibia Ash/Chick $(\mathrm{y}=25 \%)$ using the equations:

0\% DDGS: $y=290.944 x^{2}+211.89 x-7.29, R^{2}=0.6256 ; 8 \%$ DDGS: $y=52.24 x+13.239, R^{2}=0.7350,16 \%$ DDGS: $y=34.262 x+17.865, R^{2}=0.5417$

${ }^{5}$ Calculated AP values were derived from regression of Tibia Ash $\mathrm{mg} / \mathrm{Chick}(\mathrm{y}=500 \mathrm{mg})$ using the equations:

0\% DDGS: $y=-7672.01 x^{2}+5668.1626 x-512.895, R^{2}=0.8740 ; 8 \%$ DDGS: $y=-5476.90 x^{2}+4479.92 x-343.92, R^{2}=0.8242,16 \%$ DDGS: $y=-6731.66 x^{2}+$ $4921.74 x-369.71, R^{2}=0.8261$ 
APPENDIX: Inorganic feed phosphate effects on feed quality and manufacturing efficiency (ACCEPTED FOR PEER-REVIEW PUBLICATION)

K. G. S. Wamsley ${ }^{*}$, C. K. Gehring ${ }^{*}$, A. Corzo ${ }^{\dagger}$, E. A. Fontana ${ }^{\ddagger}$, and J. S. Moritz ${ }^{* 1}$

*Division of Animal and Nutritional Sciences, West Virginia University, Morgantown 26506

†Department of Poultry Science, Mississippi State University, Mississippi State 39762

${ }^{+}$Mosaic Feed Ingredients, The Mosaic Co., Tampa 33569

Primary Audience: Feed Mill Managers, Nutritionists, Researchers

${ }^{1}$ Corresponding Author: Joe.Moritz@mail.wvu.edu 


\section{SUMMARY}

Inorganic feed phosphates are often incorporated into commercial feed formulations to meet nutritional requirements and enhance feed manufacture; however, peer-reviewed publications supporting the enhancement of manufacture are limited. Two experiments were conducted to determine the effects of inorganic feed phosphates on feed quality and manufacturing efficiency. Feed was manufactured utilizing a latin square design at West Virginia University's pilot feed mill. In Experiment 1, corn-soybean meal based diets without meat and bone meal were formulated to include monocalcium phosphate (MCaP) from two different manufacture plants (MCaPA and $\mathrm{MCaPB}$ ), dicalcium phosphate (DCaP) or tricalcium phosphate (TCaP). In Experiment 2, cornsoybean meal based diets without meat and bone meal were formulated to include monocalcium phosphate of a coarse particle size (MCaPC), MCaP, DCaP, or TCaP. Feed production rate was constant among treatments within each experiment due to the experimental design. The inclusion of TCaP decreased energy consumption of the pellet mill in both experiments. Inorganic feed phosphate source affected pellet durability; however, overall feed quality differences were minimal and would likely not affect bird performance upon feeding.

keywords: feed manufacture, pellet quality, inorganic feed phosphates 


\section{DESCRIPTION OF THE PROBLEM}

Most commercial poultry diets are deficient in non-phytate phosphorus and must be supplemented with inorganic feed phosphate in order to meet requirements. Inorganic feed phosphates can be expensive and vary in nutrient content, particle size, and density, depending upon source of ingredients and manufacturing technique employed [1]. In addition, commercial poultry diets are usually pelleted and consideration should be given to the impact that ingredients such as inorganic feed phosphates have on pelleting parameters [2-4]. In particular, abrasive properties of inorganic feed phosphates may scour the pellet die and affect feed production rate and/or energy use of the pellet mill [5]. More specifically, inorganic feed phosphate particles have been proposed to maintain a clean die by dislodging residual feed that would adhere to the inner die surface. Few publications have addressed the impact of inorganic feed phosphates on feed quality and manufacture. The objective of both Experiments 1 and 2 was to evaluate the effect of four different sources of modern inorganic feed phosphates in corn-soybean meal based broiler diets on feed quality and manufacturing efficiency.

\section{MATERIALS AND METHODS}

\section{Diet Preparations}

Experiment 1. Four commercially available inorganic feed phosphate sources were utilized in this experiment: 1) Monocalcium Phosphate obtained from Manufacture Plant A (MCaPA); 2) Monocalcium Phosphate obtained from Manufacture Plant B (MCaPB); 3) Dicalcium Phosphate (DCaP); 4) Tricalcium Phosphate (TCaP). Respective ingredient calcium, phosphorus, sodium, bulk density, and particle size are listed in Table 1. The Monocalcium Phosphates (MCaPA and $\mathrm{MCaPB}$ ) and $\mathrm{DCaP}$ used in this experiment were created by combining 
wet process defluorinated phosphoric acid with calcium carbonate [6]. The TCaP utilized in this experiment was produced by thermochemically conditioning phosphate rock to reduce fluorine and improve the physical nature of the product [6]. Diets were formulated in accordance with Cobb 500 broiler starter phase recommendations and without the use of meat and bone meal so that the level of inorganic feed phosphorus would be maximized in order to better access effects on feed quality and manufacture efficiency (Table 2) [7]. Two $636 \mathrm{~kg}$ batches were created for each of the four inorganic feed phosphate sources. Mixing was accomplished with a ten min dry mix, followed by a ten min wet mix (i.e. after soybean oil addition) in a single screw vertical mixer [8]. Each $636 \mathrm{~kg}$ batch was divided into four $159 \mathrm{~kg}$ allotments and each aliquot from the main batch was re-mixed with its corresponding aliquot for seven min. These $318 \mathrm{~kg}$ aliquots represented the experimental unit to be steam conditioned and pelleted.

Experiment 2. Four commercially available inorganic feed phosphate sources were utilized in this experiment: 1) a monocalcium phosphate of a similar particle size as Experiment 1(MCaP); 2) a monocalcium phosphate of a more coarse particle size (MCaPC); 3) DCaP; 4) TCaP (Table 1). The same diet formulations were utilized for this experiment as those used for Experiment 1 (Table 2). The batching procedure was similar to Experiment 1 with the exception of larger batch and replicate sizes. Two $930 \mathrm{~kg}$ batches were created for each of the four feed phosphate sources. Mixing was accomplished with a ten min dry mix, followed by a ten min wet mix (i.e. after soybean oil addition) in a vertical screw mixer [8]. Each $930 \mathrm{~kg}$ batch was divided into four $227 \mathrm{~kg}$ allotments and each aliquot from the main batch was re-mixed with its corresponding aliquot for seven min. Combined allotments represented the $454 \mathrm{~kg}$ experimental unit to be steam conditioned and pelleted. 


\section{Feed Manufacture: Experiments 1 and 2}

All diets were batched and manufactured at West Virginia University’s pilot feed mill. Mash diets were conditioned using a short-term conditioner $(0.31 \times 1.30 \mathrm{~m}, 10 \mathrm{~s}$ retention time $)$ [9] with a constant temperature of $82.2^{\circ} \mathrm{C}$ and an incoming steam pressure of $262 \mathrm{kPa}$, , then pellets were extruded using a 40-horsepower California pellet mill [10] with a $4.76 \times 38.1 \mathrm{~mm}$ pellet die. The rate of feed entering the conditioner for Experiments 1 and 2 was adjusted to achieve an approximate production rate of 0.9 and 1.37 tonne/hr, respectively. These production rates represented usage of the pellet mill at the manufacturer's suggested rate and beyond. Feed production rate was constant among treatments within each experiment. After pelleting, each diet was cooled for 1.25 min on a horizontal belt cooler [11] using forced ambient air.

Each day prior to pelleting, $90.7 \mathrm{~kg}$ of feed was used to warm up the pellet die. Therefore, the time necessary to raise mash temperature to $82.2^{\circ} \mathrm{C}$ was standardized to two min. Feed quality and manufacture variables measured included: production rate, conditioner relative electrical energy usage (CREE), pellet mill relative electrical energy usage (PMREE), pellet durability index (PDI) [12], modified pellet durability index (MPDI) [12], and total fines production [13]. A representative pelleted sample was obtained from each replicate and sent to a commercial laboratory for total phosphorus and calcium analysis. All samples analyzed were within expected calcium and total phosphorus ranges (data presented as analyzed means across studies and replications, Table 2). Similar feed quality and manufacturing efficiency variables were recorded in both experiments; however, in Experiment 2 fines percentages obtained after mixing pellets were also calculated in an attempt to estimate fines generated with feed handling. Fines generated after handling were estimated by placing $91 \mathrm{~kg}$ of pelleted feed in the vertical mixer [8] for a two min period and measuring the percentage of fines from a $23 \mathrm{~kg}$ sample of the mixed pellets. 


\section{Inorganic Feed Phosphate Images}

A Zeiss Axio Imager, model M1 [14] was used to capture a 5x magnification image of MCaP, DCaP, and TCaP (Figure 1). The authors' intentions were to demonstrate variations in angularity of these inorganic feed phosphates.

\section{Statistical Analysis: Experiments 1 and 2}

Diets were manufactured using a latin square experimental design. Day of manufacture and run order were used as blocking criterion. Analysis of variance was determined and treatment means were further compared using Fisher's least significant difference test. All statistics were conducted using the GLM procedure of Statistical Analysis System [15]. Alpha was designated as 0.05 , and letter superscripts were used to denote differences among treatment means.

\section{RESULTS AND DISCUSSION}

\section{Experiment 1}

Inorganic feed phosphate source did not affect production rate due to the experimental design $(\mathrm{P}>0.05$; Table 3$)$. In addition, $\mathrm{CREE}$ was not affected $(\mathrm{P}>0.05$; Table 3$)$. The inclusion of TCaP into diets resulted in the lowest PMREE, while MCaPB and DCaP had the highest PMREE, and MCaPA was intermediate $(\mathrm{P}<0.05$; Table 3). The inclusion of $\mathrm{MCaPB}$ or $\mathrm{DCaP}$ into diets resulted in higher PDI than the inclusion of MCaPA or TCaP $(\mathrm{P}<0.05$; Table 3$)$. However, these differences were numerically small i.e. 89 vs. $91 \%$, a difference of only 3 percentage points. Modified pellet durability index followed similar trends. Total fines differed among treatments by a maximum of only 1.6 percentage points. Recent data using Cobb 500 
broilers has shown that larger variations in pellet quality are necessary to elicit bird performance effects [16]. In fact, that study [16] demonstrated that a 10 percentage point increase of intact pellets corresponds to a 0.4 point improved feed conversion ratio, 10 gram increase in carcass weight, and a 4 gram increase in breast weight with Cobb 500 broilers. We speculate that the small variations in feed quality in the current study would likely not elicit bird performance differences upon feeding.

\section{Experiment 2}

Production rate was again not significantly affected by inorganic feed phosphate source due to experimental design $(\mathrm{P}>0.05$; Table 4$)$. In addition, $\mathrm{CREE}$ was not affected $(\mathrm{P}>0.05$; Table 4). The inclusion of TCaP into diets resulted in the lowest PMREE, while MCaP and MCaPC had the highest PMREE, and DCaP was intermediate $(\mathrm{P}<0.05$; Table 4). Pellet durability, defined as PDI and MPDI, was significantly decreased when diet formulations contained MCaPC compared to formulations containing any other inorganic feed phosphate source $(\mathrm{P}<0.05)$. Similar to Experiment 1, these differences were significant, but small in magnitude (Table 4). No significant differences were obtained for either total fines produced or fines generated after handling. We again speculate that these small feed quality differences would likely not impact bird performance upon feeding, as indicated by past research [16].

\section{Discussion: Experiments 1 and 2}

The primary differences between the two experiments included the use of MCaPC and an increased production rate in Experiment 2 compared to Experiment 1. Past research has reported that inclusions of TCaP increase production rate [2]; although in the current study, production rate 
was not influenced by inorganic feed phosphate inclusion due to study design. However, TCaP consistently reduced PMREE by over 9 and $11 \%$ compared to the mean of the other treatments pooled in Experiments 1 and 2, respectively. Therefore, we speculate that if electrical energy input to the pellet mill was held constant, then TCaP would have likely increased production rate. The influence of TCaP source on energy consumption and production rate has been anecdotally described as having a "scouring effect" on the pellet die. More specifically, TCaP particles have been proposed to maintain a clean die by dislodging residual feed that would adhere to the inner die surface, thus enhancing throughput and/or electrical energy usage. Die scouring by TCaP may be explained by density, particle size, and shape. The most dense inorganic feed phosphate used in this study was TCaP, followed by DCaP and then MCaP (Table 1). The TCaP used in this study was the smallest particle size of all tested inorganic feed phosphates (Table 1). Perhaps the high density, small diameter particles provided greater inertia within the die, thus enhancing die scouring. In addition, the shape of $\mathrm{TCaP}$ differs from $\mathrm{MCaP}$ and $\mathrm{DCaP}$ (Figure 1). The variation in the shape coincides with production methodologies. The angularity of TCaP relative to MCaP and DCaP may also lend itself to enhanced die scouring due its abrasive nature (Figure 1).

Interestingly, feed quality was similar between the experiments despite experimental differences in production rate. Typically, an increase in production rate decreases feed retention time within the pellet die and decreases pellet quality. However, these experiments were conducted during different times of the year and using different lots of ingredients; therefore, ingredient nutrient content may have affected pellet binding. In addition, ambient temperature dictates the amount of steam addition necessary to meet a goal conditioning temperature, which consequently affects pellet quality [17]. 
Conditioner relative electrical energy usage followed production rate in each experiment. The conditioner was set at a constant rate, thus a decrease in feed augered into the conditioner (method that was implemented to adjust production rate), as in Experiment 1, required the conditioner to run for an increased amount of time per feed volume and utilize more energy relative to increased feed auger rate and consequent conditioner energy use in Experiment 2. The pellet mill was also set at a constant rate. However, higher feed volume exposure in Experiment 2 likely increased energy usage to a similar degree as when the pellet mill worked for an extended amount of time per feed volume as in Experiment 1.

Future research should focus on lower inclusions of inorganic feed phosphates incorporated in more practical diet formulations that contain phytase, animal byproducts, and distiller's dried grains and solubles. In addition, sand should be assessed for die scouring properties. A variable not measured in this study that is also of great interest for future research is inorganic feed phosphate and sand effects on pellet die longevity. The results observed in the current study indicate that the use of high inclusions of inorganic feed phosphate (1.66-1.94\%) can impact manufacturing efficiency, thus potentially impacting electrical cost and/or production capacity.

\section{CONCLUSIONS AND APPLICATIONS}

1. The use of TCaP at high inclusions in corn-soybean based diets decreased PMREE by over 9 and $11 \%$ when compared to the mean of $\mathrm{MCaP}$ and $\mathrm{DCaP}$ pooled treatments in Experiments 1 and 2, respectively, likely via a die "scouring effect" associated with TCaP density, particle size, and angularity. 
2. Due to experimental design, production rate was not affected by inorganic feed phosphate source; however, we propose that if electrical energy input to the pellet mill was held constant, then $\mathrm{TCaP}$ would likely increase production rate relative to $\mathrm{MCaP}$ and $\mathrm{DCaP}$.

3. Differences in feed quality due to inorganic feed phosphate source were observed in both experiments; however, treatments differed by less than 3 percentage points, i.e. $89-91 \%$ PDI, and would likely not elicit bird performance differences upon feeding.

\section{REFERENCES}

1. Lima, F. R., C. X. Mendonca, Jr., J. C. Alvarez, G. Ratti, S. L. R. Lenharo, H. Kahn, and J.M.F. Garzillo, 1995. Chemical and physical evaluations of commercial dicalcium phosphates as sources of biologically available phosphorus for broiler chicks. Poult. Sci. 74:1659-1670.

2. Behnke, K. C. 1981. Pellet mill performance as affected by mineral source. Feedstuffs. 53:34-36.

3. Verner, W. A. 1988. Phosphates in pelleting: best cost vs. least cost. Feed Manage. 39:56-58.

4. Lowe, R. and S. Zwart. 2007. Does the choice of feed phosphate affect pelleting behavior? Feed Compound. 27:20-23.

5. Behnke, K. C. 2009. Pelleting with today's ingredients challenges. Acervo Congreso Ponencia XIV Congreso Bienal. http://amena.mx/wpcontent/uploads/2010/11/13KBehnke.pdf

6. Mosaic Co. Riverview, Florida.

7. Cobb 500 max yield guide (Cobb-Vantress Inc., Siloam Springs, AR), starter.

8. Vertical mixer, Avery Weigh-Tronix, Fairmont, MN

9. $4.25 \mathrm{ft}$ length, $1.02 \mathrm{ft}$ diameter short term CPM conditioner ( 3 steam inlet ports), $429 \mathrm{rpm}$ shaft speed; 21 picks; 10 second feed retention time.

10. Master Model Pellet Mill, California Pellet Mill Company (CPM), Crawfordsville, IN.

11. Horizontal cooler, Pyramid Processing Equipment LLC, Stilwell, KS.

12. American Society of Agricultural Engineers. 1997. ASAE S269.4, Cubes, pellets, and crumbles-Definitions and methods for determining density, durability, and moisture. Standards 1997. Am. Soc. Agric. Eng., St. Joseph, MI. Due to the use of a 3/16 in. x 1.77 in. die, pellets were sifted in a No. 6 American Society for Testing and Materials (ASTM) screen. Five hundred grams of sifted pellets were placed in a dust-tight enclosure and tumbled for $10 \mathrm{~min}$ at $50 \mathrm{rpm}$. The enclosure was of the dimensions $12 \times 12$ in., with a $2 \times$ 9 in. plate affixed diagonally along one of the $12 \times 12$ in. sides. The tumbled samples were then sifted again (No. 6 ASTM) and weighed. The pellet durability index was calculated by dividing the weight of pellets after tumbling by the weight of pellets before tumbling, then multiplying by 100 . The modified pellet durability index was determined in a similar 
manner with the exception of adding 5, 13-mm hex nuts to the pretumbled sample to obtain added pellet agitation.

13. Total fines production was calculated by sifting approximately $45 \mathrm{~kg}$ of feed from each treatment replicate.

14. Carl Zeiss MicroImaging GmbH. Göttingen, Germany.

15. SAS Institute. 2009. The SAS System for Windows 2009. Release 9.2. SAS Inst. Inc., Cary, NC.

16. Lilly, K. G. S., C. K. Gehring, K. R. Beaman, P. J. Turk, M. Sperow, J. S. Moritz. 2011. Examining the relationship between pellet quality, broiler performance and bird sex. J. Appl. Poult. Res. $20: 231-239$.

17. Riemer, L. L., and W. A. Beggs, 1993. Making Better Pellets: Harnessing Steam Quality. FEED Management. 44: 1. Watt Publishing Company, Mt. Morris, Ill.

18. Ro-Tap particle size analyzer model RX-29 type $110 \mathrm{~V} 60 \mathrm{H} 2$, WS Tyler, Mentor, OH. One hundred grams of ground corn for each diet was placed in a dust-tight enclosed series of stacked (No. 4, 6, . .) American Society for Testing and Materials (ASTM) screens affixed to the Ro-Tap particle size analyzer and shaken for $10 \mathrm{~min}$. The screens were then separated and weighed. Particle size was calculated by subtracting the weight of the screen from the final weight of screen and sample after shaking. The mean geometric particle size and log normal geometric standard deviation were calculated as described by McEllhiney [19].

19. McEllhiney, R. R. 1994. Determining and expressing particle size. Pages 545-547 in Feed Manufacture Technology IV. American Feed Industry Association, Inc., Arlington, VA. 
Table 1. Specifications of inorganic feed phosphate products ${ }^{1}$ utilized in Experiments 1 and 2

\begin{tabular}{|c|c|c|c|c|c|}
\hline Analysis $^{2}$ & $\mathrm{MCaPA}^{3}$ & $\mathrm{MCaPB}^{4}$ & $\mathrm{MCaPC}^{5}$ & $\mathrm{DCaP}^{6}$ & $\mathrm{TCaP}^{7}$ \\
\hline Phosphorus (\%) & 21 & 21 & 21 & 18.5 & 18 \\
\hline Calcium (\%) & 16 & 16 & 16 & 20 & 28 \\
\hline Sodium (\%) & - & - & - & - & 4.7 \\
\hline \multicolumn{6}{|l|}{} \\
\hline Bulk Density (kg/m $\left.{ }^{3}\right)$ & 894 & 913 & 929 & 975 & 1314 \\
\hline \multicolumn{7}{|l|}{} \\
\hline Average Particle Size $(\mu \mathrm{m})^{8}$ & 345 & 345 & 1527 & 373 & 180 \\
\hline
\end{tabular}

${ }^{1}$ Inorganic feed phosphate products were manufactured by Mosaic Co. [6]

${ }^{2}$ All analyses were conducted by Mosaic Co. [6]

${ }^{3}$ Monocalcium Phosphate produced by Manufacturing Plant A, also described as MCaP in Experiment 2

${ }^{4}$ Monocalcium Phosphate produced by Manufacturing Plant B

${ }^{5}$ Monocalcium Phosphate of a coarse particle size produced by Manufacturing Plant B

${ }^{6}$ Dicalcium Phosphate produced by Manufacturing Plant A

${ }^{7}$ Tricalcium Phosphate produced by Manufacturing Plant A

${ }^{8}$ Partcle size was determined with a Ro-Tap particle size analyzer [18] 
Table 2. Diet formulations and nutrient parameters ${ }^{1}$ for Experiments 1 and 2

\begin{tabular}{|c|c|c|c|}
\hline Ingredients & $\begin{array}{l}\mathrm{MCaP}^{2} \text { diet } \\
(\% \text { inclusion })\end{array}$ & $\begin{array}{l}\mathrm{DCaP}^{3} \text { diet } \\
(\% \text { inclusion })\end{array}$ & $\begin{array}{l}\mathrm{TCaP}^{4} \text { diet } \\
\text { (\% inclusion) }\end{array}$ \\
\hline Corn & 57.89 & 58.00 & 59.08 \\
\hline Soybean meal $(48 \%)^{5}$ & 36.06 & 36.04 & 35.84 \\
\hline Soybean oil & 1.89 & 1.86 & 1.57 \\
\hline Feed phosphate $^{6}$ & 1.66 & 1.89 & 1.94 \\
\hline Limestone & 1.37 & 1.09 & 0.66 \\
\hline Salt & 0.47 & 0.47 & 0.24 \\
\hline Vitamin mineral premix $^{7}$ & 0.25 & 0.25 & 0.25 \\
\hline $\mathrm{DL}$ - methionine & 0.23 & 0.23 & 0.23 \\
\hline Coban $60^{8}$ & 0.08 & 0.08 & 0.08 \\
\hline BMD $60^{9}$ & 0.05 & 0.05 & 0.05 \\
\hline Lysine & 0.04 & 0.04 & 0.05 \\
\hline Threonine & 0.003 & 0.003 & 0.004 \\
\hline \multicolumn{4}{|c|}{ Calculated nutrients } \\
\hline $\mathrm{ME}(\mathrm{kcal} / \mathrm{kg})$ & 3022 & 3022 & 3022 \\
\hline Lysine (\%) & 1.33 & 1.33 & 1.33 \\
\hline Methionine (\%) & 0.61 & 0.61 & 0.61 \\
\hline Threonine $(\%)$ & 0.85 & 0.85 & 0.85 \\
\hline Tryptophan (\%) & 0.30 & 0.30 & 0.30 \\
\hline Calcium (\%) & 0.91 & 0.91 & 0.91 \\
\hline Available P (\%) & 0.45 & 0.45 & 0.45 \\
\hline Sodium (\%) & 0.20 & 0.20 & 0.20 \\
\hline \multicolumn{4}{|c|}{ Analyzed nutrients $^{10}$} \\
\hline Calcium $(\%)$ & 0.84 & 0.84 & 0.90 \\
\hline Total Phosphorus (\%) & 0.72 & 0.71 & 0.70 \\
\hline
\end{tabular}

${ }^{1}$ Diets formulated to Cobb 500 broiler max yield specifications (starter phase)

${ }^{2}$ Monocalcium Phosphate containing $16 \%$ Ca, $21 \%$ P; bulk density $894 \mathrm{~kg} / \mathrm{m}^{3}$

${ }^{3}$ Dicalcium Phosphate containing $20 \% \mathrm{Ca}, 18.5 \% \mathrm{P}$; bulk density $975 \mathrm{~kg} / \mathrm{m}^{3}$

${ }^{4}$ Tricalcium Phosphate containing $28 \% \mathrm{Ca}, 18 \% \mathrm{P}, 4.7 \% \mathrm{Na}$; bulk density $1314 \mathrm{~kg} / \mathrm{m}^{3}$

${ }^{5}$ Crude Protein content of soybean meal is $48 \%$

${ }^{6}$ Feed Phosphate inclusion based on treatment and Phosphorus content was assumed $100 \%$ available

${ }^{7}$ Supplied per kilogram of diet: manganese, $0.02 \%$; zinc, $0.02 \%$; iron, $0.01 \%$; copper, $0.0025 \%$; iodine, $0.0003 \%$; selenium, $0.00003 \%$; folic acid, $0.69 \mathrm{mg}$; choline, $386 \mathrm{mg}$; riboflavin, $6.61 \mathrm{mg}$; biotin, $0.03 \mathrm{mg}$; vitamin $\mathrm{B}_{6}, 1.38 \mathrm{mg}$; niacin, $27.56 \mathrm{mg}$; pantothenic acid, $6.61 \mathrm{mg}$; thiamine, $2.20 \mathrm{mg}$; manadione, $0.83 \mathrm{mg}$; vitamin $\mathrm{B}_{12}, 0.01 \mathrm{mg}$; vitamin E, $16.53 \mathrm{IU}$; vitamin $\mathrm{D}_{3}$, 2,133 ICU; vitamin A, 7,716 IU.

${ }^{8}$ Active drug ingredient Monensin Sodium $60 \mathrm{~g} / \mathrm{lb}$ (90 g/ton inclusion), Elanco Animal Health, Indianapolis, IN. As an aid in the prevention of coccidiosis caused by Eimeria necarix, Eimeria tenella, Eimeria acervulina, Eimeria brunette, Eimeria mivati, and Eimeria maxima.

${ }^{9}$ Bacitracin Methylene Disalicylate $60 \mathrm{~g} / \mathrm{lb}$ (60 g/ton inclusion), Alpharma, Fort Lee, NJ. For increased rate of weight gain and improved feed efficiency.

${ }^{10}$ These values were pooled across replicate treatments and experiments. 
Table 3. Feed manufacture variables associated with standard pelleting of Cobb 500 broiler starter phase diets containing different sources of inorganic feed phosphate (Experiment 1)

\begin{tabular}{|c|c|c|c|c|c|c|}
\hline $\begin{array}{l}\text { Inorganic feed } \\
\text { phosphate } \\
\text { source }\end{array}$ & $\begin{array}{l}\text { Production } \\
\text { Rate } \\
\text { (tonne/hr) }\end{array}$ & $\begin{array}{c}\text { Relative } \\
\text { Conditioner } \\
\text { Electrical Energy } \\
\text { Usage (CREE) } \\
\text { (kwh/tonne) }\end{array}$ & $\begin{array}{c}\text { Relative Pellet } \\
\text { Mill Electrical } \\
\text { Energy Usage } \\
\text { (PMREE) } \\
\text { (kwh/tonne) }\end{array}$ & $\begin{array}{c}\text { Pellet } \\
\text { Durability } \\
\text { Index }^{1}(\mathrm{PDI}) \\
(\%)\end{array}$ & $\begin{array}{l}\text { Modified } \\
\text { Pellet } \\
\text { Durability } \\
\text { Index }^{2} \\
\text { (MPDI) } \\
(\%)\end{array}$ & $\begin{array}{c}\text { Total Fines } \\
\text { Production } \\
\text { (\%) }\end{array}$ \\
\hline $\mathrm{MCaPA}^{4}$ & 0.8390 & 0.2044 & $5.276^{\mathrm{b}}$ & $89.22^{\mathrm{b}}$ & $85.22^{\mathrm{c}}$ & $11.51^{\mathrm{a}}$ \\
\hline $\mathrm{MCaPB}^{5}$ & 0.8265 & 0.2136 & $5.457^{\mathrm{a}}$ & $90.96^{\mathrm{a}}$ & $87.14^{\mathrm{ab}}$ & $10.19^{\mathrm{b}}$ \\
\hline $\mathrm{DCaP}^{6}$ & 0.8210 & 0.2104 & $5.530^{\mathrm{a}}$ & $91.16^{\mathrm{a}}$ & $87.76^{\mathrm{a}}$ & $10.15^{b}$ \\
\hline $\mathrm{TCaP}^{7}$ & 0.8240 & 0.2218 & $5.014^{\mathrm{c}}$ & $89.89^{b}$ & $86.17^{\mathrm{bc}}$ & $9.88^{\mathrm{b}}$ \\
\hline $\mathrm{LSD}^{8}$ & -- & -- & 0.0758 & 0.8549 & 1.3847 & 0.519 \\
\hline \multicolumn{7}{|c|}{ Probabilities } \\
\hline ANOVA P-value & 0.1161 & 0.7297 & 0.0001 & 0.0042 & 0.0173 & 0.0010 \\
\hline SEM $^{9}$ & 0.0045 & 0.0108 & 0.0219 & 0.2470 & 0.4001 & 0.1500 \\
\hline
\end{tabular}

${ }^{\mathrm{a}-\mathrm{c}}$ Means within a column without a common superscript differ significantly $(\mathrm{P} \leq 0.05)$

${ }^{1}$ Pellet durability index was determined by placing 500 grams of sifted pellets into a Pfost tumbler. Samples were tumbled for 10 min at $50 \mathrm{rpm}$. The sample was then sifted again and weighed. Pellet durability index was calculated as the percent of sifted pellets retained after tumbling.

${ }^{2}$ Modified pellet durability index was measured similar to the previous description, with the exception of the addition of five 13 -mm hexagonal nuts to the $500 \mathrm{~g}$ sample prior to tumbling.

${ }^{3}$ Total fines production was calculated by sifting approximately $45 \mathrm{~kg}$ of feed from each treatment replicate.

${ }^{4} \mathrm{MCaPA}=$ Monocalcium Phosphate manufactured at Plant A; $16 \% \mathrm{Ca}, 21 \% \mathrm{P} ;$ bulk density $894 \mathrm{~kg} / \mathrm{m}^{3} \mathrm{MCaPB}=$ Monocalcium Phosphate manufactured at Plant B; $16 \%$ Ca, $21 \%$ P;

bulk density $894 \mathrm{~kg} / \mathrm{m}^{3}$

${ }^{6} \mathrm{DCaP}=$ Dicalcium Phosphate produced at Location A; $20 \% \mathrm{Ca}, 18.5 \% \mathrm{P}$; bulk density $975 \mathrm{~kg} / \mathrm{m}^{3}$

${ }^{7} \mathrm{TCaP}=$ Tricalcium Phosphate produced in Location A; $28 \% \mathrm{Ca}, 18 \% \mathrm{P}, 4.7 \% \mathrm{Na}$; bulk density $1314 \mathrm{~kg} / \mathrm{m}^{3}$

${ }^{8}$ Fisher's Least Significant Difference multiple comparison test

${ }^{9}$ Standard Error of the Mean 
Table 4. Feed manufacture variables associated with standard pelleting of Cobb 500 broiler starter phase diets containing different sources of inorganic feed phosphate (Experiment 2)

\begin{tabular}{|c|c|c|c|c|c|c|c|}
\hline $\begin{array}{l}\text { Inorganic feed } \\
\text { phosphate } \\
\text { source }\end{array}$ & $\begin{array}{l}\text { Production } \\
\text { Rate } \\
\text { (tonne/hr) }\end{array}$ & $\begin{array}{l}\text { Relative Conditioner } \\
\text { Electrical Energy } \\
\text { Usage (CREE) } \\
\text { (kwh/tonne) }\end{array}$ & $\begin{array}{c}\text { Relative Pellet } \\
\text { Mill Electrical } \\
\text { Energy Usage } \\
\text { (PMREE) } \\
\text { (kwh/tonne) }\end{array}$ & $\begin{array}{c}\text { Pellet } \\
\text { Durability } \\
\text { Index }^{1} \\
(\mathrm{PDI}) \\
(\%)\end{array}$ & $\begin{array}{l}\text { Modified Pellet } \\
\text { Durability } \\
\text { Index }^{2}(\text { MPDI) } \\
(\%)\end{array}$ & $\begin{array}{l}\text { Total Fines } \\
\text { Production } \\
\text { (\%) }\end{array}$ & $\begin{array}{c}\text { Mixed Fines } \\
(\%)\end{array}$ \\
\hline $\mathrm{MCaP}^{5}$ & 1.326 & 0.117 & $5.559^{\mathrm{a}}$ & $90.99^{\mathrm{a}}$ & $86.92^{\mathrm{a}}$ & 10.00 & 18.39 \\
\hline $\mathrm{MCaPC}^{6}$ & 1.308 & 0.117 & $5.517^{\mathrm{a}}$ & $88.78^{\mathrm{b}}$ & $82.38^{\mathrm{b}}$ & 11.27 & 21.82 \\
\hline $\mathrm{DCaP}^{7}$ & 1.330 & 0.118 & $5.273^{\mathrm{b}}$ & $90.24^{\mathrm{a}}$ & $85.81^{\mathrm{a}}$ & 12.21 & 19.54 \\
\hline $\mathrm{TCaP}^{8}$ & 1.317 & 0.101 & $4.814^{\mathrm{c}}$ & $90.83^{\mathrm{a}}$ & $86.61^{\mathrm{a}}$ & 11.10 & 18.78 \\
\hline Fisher's LSD $^{9}$ & -- & -- & 0.106 & 0.893 & 1.342 & -- & -- \\
\hline \multicolumn{8}{|c|}{ Probabilities } \\
\hline ANOVA P-value & 0.4418 & 0.2032 & 0.0001 & 0.0033 & 0.0006 & 0.3052 & 0.3413 \\
\hline $\mathrm{SEM}^{10}$ & 0.0099 & 0.0056 & 0.0307 & 0.2579 & 0.3879 & 0.7394 & 1.316 \\
\hline
\end{tabular}

${ }^{\mathrm{a}-\mathrm{c}}$ Means within a column without a common superscript differ significantly $(\mathrm{P} \leq 0.05)$

${ }^{1}$ Pellet durability index was determined by placing $500 \mathrm{~g}$ of sifted pellets into a Pfost tumbler. Samples were tumbled for 10 min at $50 \mathrm{rpm}$. The sample was then sifted again and weighed. Pellet durability index was calculated as the percent of sifted pellets retained after tumbling.

${ }^{2}$ Modified pellet durability index was measured similar to the previous description, with the exception of the addition of five 13-mm hexagonal nuts to the 500g sample prior to tumbling.

${ }^{3}$ Total fines production was calculated by sifting approximately $45 \mathrm{~kg}$ of feed from each treatment replicate.

${ }^{4}$ Mixed fines were determined by placing $91 \mathrm{~kg}$ of pelleted feed in the vertical mixer for a two min period and measuring the percentage of fines from a $23 \mathrm{~kg}$ sample of the mixed feed.

${ }^{5} \mathrm{MCaP}=$ Monocalcium Phosphate manufactured at Plant A; $16 \% \mathrm{Ca}, 21 \% \mathrm{P}$; bulk density $894 \mathrm{~kg} / \mathrm{m}^{3}$

${ }^{6} \mathrm{MCaPC}=$ Monocalcium Phosphate of a coarse particle size, manufactured at Plant B; $16 \% \mathrm{Ca}, 21 \% \mathrm{P}$; bulk density $894 \mathrm{~kg} / \mathrm{m}^{3}$

${ }^{7} \mathrm{DCaP}=$ Dicalcium Phosphate produced at Location A; $20 \% \mathrm{Ca}, 18.5 \% \mathrm{P}$; bulk density $975 \mathrm{~kg} / \mathrm{m}^{3}$

${ }^{8} \mathrm{TCaP}=$ Tricalcium Phosphate produced in Location A; $28 \% \mathrm{Ca}, 18 \% \mathrm{P}, 4.7 \% \mathrm{Na}$; bulk density $1314 \mathrm{~kg} / \mathrm{m}^{3}$

${ }^{9}$ Fisher's Least Significant Difference multiple comparison test

${ }^{10}$ Standard Error of the Mean 


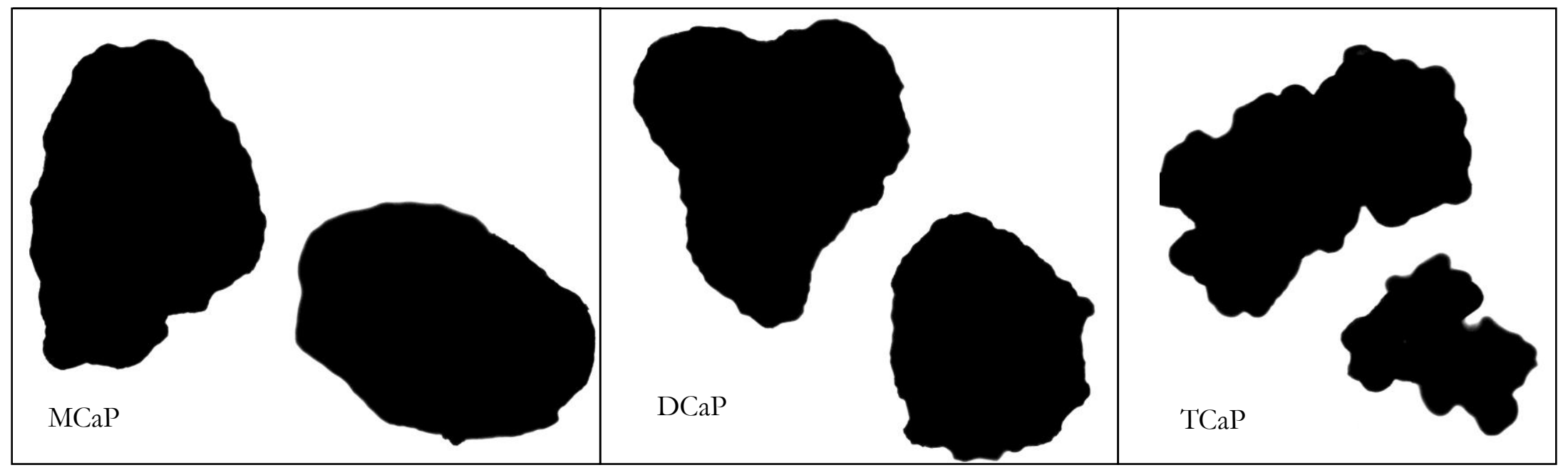

Figure 1. 5x magnification [14] of (from left to right) Monocalcium Phosphate (MCaP), Dicalcium Phosphate (DCaP) and Tricalcium Phosphate $(\mathrm{TCaP})$ 


\section{CURRICULUM VITAE}

\section{ACADEMIC TRAINING}

Current Degree: Doctor of Philosophy with a Certificate in University Teaching, Animal and Food Science

Expected Graduation Date: August 29, 2012

Dissertation: Strategies to maximize feed quality and poultry performance

WEST VIRGINIA UNIVERSITY

Master of Science, Animal and Food Science; December 2010

Thesis: Maximizing broiler performance through feed

WEST VIRGINIA UNIVERSITY

Bachelor of Science, Animal and Nutritional Sciences; May 2009

WEST VIRGINIA UNIVERSITY

\section{ACADEMIC HONORS/AWARDS}

\section{Awards and Honors:}

- Member of Golden Key International Honour Society (01/2011-Currently)

- Committee Member to hire new Assistant Biochemistry Professor; WVU Division of Animal and Nutritional Sciences (12/2011-Currently)

- Student Representative Member for WVU Davis College of Agriculture, Natural Resources, and

Design New Dean Search Committee (8/24/2010-1/31/2011)

- Assistant Coach for WVU Poultry Judging Team

○ Team placed $3^{\text {rd }}$ at $201045^{\text {th }}$ Annual National Collegiate Poultry Judging Contest hosted by the University of Arkansas

○ Team placed $3^{\text {rd }}$ at 2011 U.S. Poultry \& Egg Association National Poultry Judging Contest in Baton Rouge, LA

○ Team placed $2^{\text {nd }}$ at $201146^{\text {th }}$ Annual National Collegiate Poultry Judging Contest hosted by the University of Arkansas

- Undergraduate Student Research Paper Certificate of Excellence, "The effects of fiber, moisture and protein on pellet manufacture variables". Presented at the annual meeting of the Poultry Science Association. (7/22/2008)

\section{Scholarships Received:}

- Received Competitive Divisional Funding for Graduate School (2009-Current)

- Davis/Michael Veterinary Scholarship (2005-2006)

- Scholarship from WVU Rowing (2005-2006)

- WVU HERF Scholarship (2005-2006)

- Lawrence \& Larna Cavendish Scholarship (2005-2006)

- Shady Spring Citizenship Scholarship (2005-2006)

- West Virginia Promise Scholarship (2005-2009) 


\section{PUBLICATIONS}

\section{Peer-Reviewed Manuscripts}

K.G.S. Wamsley and J.S. Moritz. Resolving poor pellet quality and maintaining amino acid digestibility in commercial turkey feed manufacture. J. Appl. Poult. Res. (Submitted)

K.G.S. Wamsley, R. E. Loar II, K. Karges, and J.S. Moritz. The use of practical diets and regression analyses to determine utilization of lysine and phosphorus in corn distillers dried grains and solubles using Cobb 500 male broilers. J. Appl. Poult. Res. (Submitted)

K.G.S. Wamsley, C.K. Gehring, A.C. Corzo and J.S. Moritz. Inorganic feed phosphate effects on feed quality and manufacture. J. Appl. Poult. Res. (In Print)

K.R. Beaman, K.G.S. Lilly, C.K. Gehring, P.J. Turk, and J.S. Moritz. Determining efficacy of an exogenous enzyme cocktail post pelleting using broiler performance and metabolism. J. Appl. Poult. Res (Accepted).

S. A. Loop, K.G.S. Lilly, L. K. Shires, C. K. Gehring, K. R. Beaman, M. E. Persia, and J. S. Moritz In vitro testing of phytase retained activity post-pelleting may not adequately predict efficacy. J. Appl. Poult. Res. (JAPR-11-00384; In Print)

L.K. Shires, K.G.S. Lilly, S.A. Loop, C.K. Gehring, K.R. Beaman and J.S. Moritz. 2012. Justifying phytogenic feed additive matrix values in conjunction with exogenous feed enzymes. J. Appl. Poult. Res. 21:39-47.

K.G.S. Lilly, C.K. Gehring, K.R. Beaman, and J.S. Moritz. 2011. Examining the relationship between pellet quality, broiler performance and bird sex. J. Appl. Poult. Res. 20: 231-239.

K.G.S. Lilly, K.R. Beaman, B.N. West, L.K. Shires, S.A. Loop, P.J. Turk, G.K. Bissonnette, and J.S. Moritz. 2011. Strategies to reduce preslaughter Salmonella in organic broilers. J. Appl. Poult. Res._20:313321.

C. K. Gehring, K.G.S. Lilly, L.K. Worley, K. R. Beaman, S. A. Loop, and J. S. Moritz. 2011. Increasing mixer-added fat improves exogenous enzyme efficacy and broiler performance. J Appl. Poult. Res. 20: 75-89.

N.P. Buchanan, K.G.S. Lilly, C.K. Gehring, and J.S. Moritz. 2010. The effects of altering diet formulation and manufacturing technique on pellet quality. J. Appl. Poult. Res. 19:112-120.

N.P. Buchanan, K.G.S. Lilly, and J.S. Moritz. 2010. The effects of diet formulation, manufacturing technique, and antibiotic inclusion on broiler performance and intestinal morphology. J. Appl. Poult. Res. 19: 121-131.

Rack, A.L., K.G.S. Lilly, K.R. Beaman, C.K. Gehring and J.S. Moritz. 2009. The effect of genotype , choicefeeding and season on organically-reared broilers fed diets devoid of synthetic methionine. J. Appl. Poult. Res. 18: 54-65.

\section{Popular Press}

WATT Poultry USA (August 2011). Kelley G.S. Lilly and Joe S. Moritz, "Feeding broilers High Quality Pellets Shows Positive Economic Return" Pages 26-29.

\section{Conference Proceedings}

Moritz, J.S. and K.G.S. Lilly. 2010 Production strategies and feeding opportunities for pellets of high quality. Mid-Atlantic Nutrition Conference. March 24-25 ${ }^{\text {th }}$. Baltimore, MD.

Moritz, J.S. and K.G.S. Lilly. 2010 Production strategies and feeding opportunities for pellets of high quality. California Animal Nutrition Conference May $26^{\text {th }}-27$ th. Fresno State, California State University.

Gehring, C.K., K.G.S. Lilly, and J.S. Moritz. 2009. Maximizing the performance of broilers fed pelleted diets. Multi-State Poultry Feeding and Nutrition Conference. May 19-21 ${ }^{\text {st }}$, Indianapolis, IN. 


\section{Conference Abstracts}

K.G.S. Wamsley, R.E. Loar II, K. Karges, and J.S. Moritz. 2012. Establishing the bioavailability of phosphorus in corn DDGS for D3-21 Cobb 500 male broilers. Poult Sci (Accepted abstract for paper presentation PSA 2012).

K.G.S. Wamsley, R.E. Loar II, K. Karges, and J.S. Moritz. 2012. Establishing the bioavailability of lysine in corn DDGS for D3-42 Cobb 500 male broilers. Poult Sci (Accepted abstract for paper presentation PSA 2012).

M.E. Lemons, K.G.S. Wamsley, A.E. Lamp, A.M. Evans, K.J. Shipe, and J.S. Moritz. 2012. Lignosulfonate pellet binder and fat increase broiler feed retention time. Poult Sci (Accepted abstract for paper presentation PSA 2012)

K. J. Shipe, A. M. Evans, K.G.S. Wamsley, and J. S. Moritz. 2012. Effects of feed manufacture techniques that vary feed exposure to pellet die heat and pressure on TAAD, furfural, and HMF. Poult Sci (Accepted abstract for paper presentation PSA 2012).

A.E. Lamp, M.E. Lemons, K.G.S. Wamsley, A.M. Evans, K.J. Shipe, and J.S Moritz. 2012. The effect of pasture access, breed, and diet on laying hen health, performance, and EPA and DHA content of eggs. Poult Sci (Accepted abstract for paper presentation PSA 2012).

K.G.S. Lilly, L.K. Shires, B.N. Swiger, A.M. Evans, K.J. Shipe, and J.S. Moritz. 2011. Manufacturing techniques to improve pellet quality of commercial turkey diet formulations and six week male poult performance. $18^{\text {th }}$ European Symposium on Poultry Nutrition. (Accepted Abstract \& Full Text Submission). Presentation in Cesme- Izmir, Turkey. November 2011.

K.G.S. Lilly, L.K. Shires, B.N. West and J.S. Moritz. 2011. Resolving pellet quality issues with the manufacture of commercial turkey diet formulations. International Southern Poultry Science Forum. Atlanta, GA. SSPS 2011 Meeting Abstracts No 74.

K.G.S. Lilly, L.K. Shires, B.N. Swiger, A.M. Evans, K.J. Shipe, and J.S. Moritz. 2011. Resolving pellet quality issues and improving turkey poult performance with the manufacture of commercial turkey diet formulations. Poult. Sci. 90:388.

A.E. Lamp, L.K. Shires, K.G.S. Lilly, B.N. Swiger, K. Matak, and J.S. Moritz. 2011. The effect of marine and flaxseed oil inclusion in diets for pastured laying flocks on EPA, DHA, and consumer acceptability of eggs. $18^{\text {th }}$ European Symposium on Poultry Nutrition. (Accepted Abstract \& Full Text Submission). Poster Presentation in Cesme- Izmir, Turkey. November 2011.

K.J. Shipe, A.M. Evans, K.G.S Lilly, L.K. Shires, B.N. Swiger, and J.S.Moritz. 2011. Effects of feed manufacture techniques that vary feed exposure to pellet die heat and pressure on pellet quality and subsequent broiler lysine utilization. Poult. Sci. 90:389.

L.K. Shires, B.N. West, K.G.S. Lilly, and J.S. Moritz. 2011. The effects of early feed amino acid and late feed non-phytate phosphorus levels on large tom performance, yield, and litter composition. Poult. Sci. 90:321.

L.K. Shires, K.G.S. Lilly, B.N. Swiger, and J.S. Moritz. 2011. The effect of marine and flaxseed oil inclusion in diets for pastured laying flocks on EPA, DHA, and consumer acceptability of eggs. Poult. Sci. 90:338.

L. K. Shires, S.A. Loop, K.G.S Lilly, K. R. Beaman, B.N. West and J. S. Moritz. 2011. Practical assessment of a novel phosphorus source (poultry litter ash) on feed manufacture and feeding broilers. International Southern Poultry Science Forum. Atlanta, GA. Poult Sci. SSPS 2011 Meeting Abstracts No 28.

K.G.S. Lilly, K.R. Beaman, B.N. West, L.K. Shires, S.A. Loop, P.J. Turk, G.K. Bissonnette, and J.S. Moritz. 2010. Strategies to reduce preharvest Salmonella in organic broilers. Mid-Atlantic Nutrition Conference. March 24-25 ${ }^{\text {th }}$. Baltimore, MD. (Accepted Abstr.)

K.G.S. Lilly, K.R. Beaman, B.N. West, L.K. Shires, S.A. Loop, P.J. Turk, G.K. Bissonnette, and J.S. Moritz. 2010. Strategies to reduce preharvest Salmonella in organic broilers. Poult. Sci. 89:346. 
B.N. West, K.G.S. Lilly, K.R. Beaman, L K. Shires, S.A. Loop, and J.S. Moritz. 2010. The effects of strain and dietary phosphorus level on large tom turkey performance. Poult. Sci. 89: W267.

K.R. Beaman, K.G.S. Lilly, C.K. Gehring, L.K. Shires, S.A. Loop and J.S. Moritz. 2010. Determining efficacy of a thermally processed exogenous enzyme cocktail for broilers. Poult. Sci. 89: 331.

B.N. West, K.G.S. Lilly, K.R. Beaman, L K. Shires, S.A. Loop, and J.S. Moritz. 2010. The effects of strain and dietary phosphorus level on large tom turkey performance. Mid-Atlantic Nutrition Conference. March 24-25 ${ }^{\text {th }}$. Baltimore, MD.. (Accepted Abstr.)

K.R. Beaman, K.G.S. Lilly, C.K. Gehring, L.K. Shires, S.A. Loop and J.S. Moritz. 2010. Determining efficacy of a thermally processed exogenous enzyme cocktail for broilers. Mid-Atlantic Nutrition Conference. March 24-25 ${ }^{\text {th }}$. Baltimore, MD.. (Accepted Abstr.)

K.G.S. Lilly, C.K. Gehring, K.R. Beaman, and J.S. Moritz. 2009. Examining the relationship between pellet quality, broiler performance and bird sex. Poult. Sci. 88:143.

C. K. Gehring, K.G.S. Lilly, L.K. Worley, K. R. Beaman, S. A. Loop, and J. S. Moritz. 2009. Increasing mixer-added fat improves exogenous enzyme efficacy and broiler performance. Poult. Sci. 88:142

K.G.S. Lilly, N.P. Buchanan, S.E. Cutlip, and J.S. Moritz. 2008. The effects of fiber, moisture and protein on pellet manufacture variables. Poult. Sci. 87:168.

Buchanan, N.P., K.G.S. Lilly, C.K. Gehring and J.S. Moritz. 2008. The effect of diet formulation and manufacturing technique on pellet processing variables and quality. Poult. Sci. 87:166.

Buchanan, N.P., K.G.S. Lilly, A. L. Rack, K. R. Beaman, and J. S. Moritz. 2008. The effect of diet formulation, manufacturing technique, and antibiotic inclusion on broiler growth and development. Poult. Sci. 87:167.

Rack, A.L., K.G.S. Lilly, K.R. Beaman, C.K. Gehring and J.S. Moritz. 2008. The effect of genotype, choicefeeding and season on organically-reared broilers fed diets devoid of synthetic methionine. Poult. Sci. 87:26.

\section{Manuscripts in Preparation}

K.G.S. Wamsley and J.S. Moritz. Assessment of diet formulation strategies that improve crumble quality and poult performance. J. Appl. Poult. Res.

K.G.S. Wamsley and J.S. Moritz. D1-42 Yeast Product inclusion and D42-118 feed form effects on large tom performance using feed produced at a commercial mill. J. Appl. Poult. Res.

K.G.S. Wamsley, A.M. Evans, and J.S. Moritz. The effect of normal and high phytase inclusion on D1-42 poult performance, gut inflammation and phosphorus content of litter. J. Appl. Poult. Res.

\section{RESEARCH AND TEACHING EXPERIENCE}

\section{GRADUATE (PhD)}

Graduate Teaching Assistant (PhD)

- Teaching Assistant for Poultry Judging Course (ANPR 338, 339)

- Teaching Assistant for Poultry Production (ANPR 367)

- Guest Lecturer in Pork Production Class

Graduate Research Assistant (PhD)

January-December 2011

- Contract Studies with JBS United, Enzivia, Phytex, Verenium, Poet Nutrition, Virginia Poultry Grower's Coop, Lignotech, BRI, and Adisseo

- Assist with planning for WV Poultry Week, state fair activities (2/16/2011)

- Conducted research with Virginia Poultry Grower's Coop which incorporated pellet binder inclusion, varying mixer added fat and amino acid density to improve turkey performance for the Coop (Feb-June 2011) 
- Led two contract studies with Poet Nutrition Inc. utilizing various inclusions of dried distillers grains and soluble to establish the utilization of lysine and phosphorus using a broiler model (Summer 2011)

- Conducted research with Virginia Poultry Grower's Coop which varied early phytase and late DDGS inclusions to assess their effect on turkey tom performance (July 2011-Nov 2011)

- Conducted research with Virginia Poultry Grower's Coop examining Yeast Product inclusion on brooder phase performance and feed form effects from D42-126 for large turkey toms (Feb-June 2012)

\section{Workshop Speaking Engagements (PhD)}

- Assist with Veterinary Technician classes to help the students learn about poultry and teach them to efficiently draw blood from poultry

- Small Farm Conference, Assisted with talk on backyard poultry production (2/19/2011)

- Grazing Conference, Assisted with talk on backyard poultry production (3/4/2011)

- Coordinated activities and displays (birds and poster) for Monongalia County and WV State Fair (Summer 2011)

- Preston County Kid's Safety Day (6/4/2011)

- Mercer County Extension Talk, Assisted with talk on backyard poultry production (6/21/2011)

- Assisted with WV poultry week activities (7/26-7/27/2011,7/23-25/2012)

- Assisted with Poultry Workshop at WVU Organic Field Day (8/4/2011, 8/9/2012)

- Doddridge County Extension Workshop, Assist with talk on backyard poultry production $(2 / 20 / 2012)$

- Roane and Jackson Counties Extension Workshop, Assist with talk on backyard poultry production $(2 / 21 / 2012)$

- Wood County Extension Workshop, Assist with talk on backyard poultry production (2/23/2012)

- Small Farm Conference, Assist with workshop and talks on backyard poultry production (3/13/3/2012)

- Guest Lecturer for Agriculture in the Classroom (for WV Educators) (6/15/2012)

\section{Competitive Grant Experience (PhD)}

- Two Accepted Pre-Proposal Grants for US Poultry \& Egg Association entitled: "Identifying ingredient and feed additive segregation in the commercial broiler industry and its effect on bird health and performance" and "Predicting optimal pellet quality and nutrient availability for maximizing broiler health and performance" (5/31/2011). Full Proposals were submitted 7/21/2011, but not funded.

- Two Accepted Pre-Proposal Grants for US Poultry \& Egg Association entitled: "The effect of manufacturing technique and bactericidal liquid inclusion to reduce Salmonella and improve the hygienic quality of feed and health in broiler chickens" and "Predicting optimal pellet quality and nutrient availability for maximizing broiler health and performance" (12/15/2011). Full Proposals were submitted 2/10/2012, but not funded.

\section{National Meeting Paper Presentations (PhD)}

- 2012 Poultry Science Association (Athens, GA) (Graduate Student)

"Establishing the bioavailability of phosphorus in corn DDGS for D3-21 Cobb 500 male broilers"

- 2012 Poultry Science Association (Athens, GA) (Graduate Student)

"Establishing the bioavailability of lysine in corn DDGS for D3-21 Cobb 500 male broilers"

- 2011 Poultry Science Association (St. Louis, MI) (Graduate Student)

"Resolving pellet quality issues and improving turkey poult performance with the manufacture of commercial turkey diet formulations." 


\section{International Meeting Paper Presentations (PhD)}

- $18^{\text {th }}$ European Symposium on Poultry Nutrition. (Cesme- Izmir, Turkey; November 2011)

"Manufacturing techniques to improve pellet quality of commercial turkey diet formulations and six week male poult performance"

- 2011 International Poultry Scientific Forum (Atlanta, Georgia) (Graduate Student)

"Resolving pellet quality issues with the manufacture of commercial turkey diet formulations."

\section{Professional Development}

-International Poultry Scientific Forum, Atlanta, GA (2011, 2012)

-International Poultry Expo, Atlanta, GA (2008- present)

-Poultry Science Association Annual Meeting (2007- present)

-Feed Mill Education Conference, Sponsored by US Poultry \& Egg Association in Nashville, TN (3/2324/2011)

- Campus Interviews for University Faculty Positions, hosted by WVU Graduate Student Services $(1 / 17 / 2012)$

\section{GRADUATE (M.S)}

\section{Graduate Teaching Assistant (M.S.)}

Fall 2009-December 2010

- Teaching Assistant for Poultry Production Class and Corresponding Lab (Role includes lecturing occasionally in class and organizing and lecturing for lab at the WVU Animal Science Farm) (Fall '09)

- Teaching Assistant for Poultry Judging Course (ANPR 338, 339)

\section{Graduate Research Assistant (M.S.)}

Summer 2009-December 2010

- Competitive Divisional Funded

- Led study funded by a USDA/NIFSI grant "An Integrated Systems Approach to Reduce Salmonella in Organic and All Natural Poultry" (Managing two Grow-outs of 300 birds at the WVU Organic Farm and processing samples for qualitative analysis of Salmonella spp.)

- Mentor for Student Undergraduate Research Experience (6/09-8/09)

- Consulting for Virginia Poultry Growers Cooperative (VPGC) $(12 / 15 / 09)$

- Poster Presentation for Open House Celebrating Collaborative Research with WVU and VPGC $(1 / 5 / 09)$

- Contract Pelleting Studies with Mosaic Inc., DSM, Delacon, Syngenta, H.J. Baker, and Phytex

- Attended and Presented Poster at Mid Atlantic Nutrition Conference (3/24-25/2010)

\section{Workshop Speaking Engagements (M.S.)}

- Guest Lecturer for Agriculture in the Classroom (for WV Educators) $(6 / 19 / 09 ; 6 / 18 / 10)$

- Annual Speaker at Organic Field Day (2007-present; held each summer at WVU)

- Invited Speaker for VA Cattleman's Association (8/6/09)

- Poster presentation for WV State Fair (8/17/09)

- Lead organizer for Career Development Event (9/23/09)

- Guest Lecturer for Intro to Animal Science Course (11/10)

- Poultry Judge for County Fairs (Allegheny County, MD; 7/18/2010) (Berkeley County Youth Fair, WV; 8/3/2010)

- Assisted with WV Poultry Week and WV Poultry Week 4H Judging Contest (7/27-30/2010)

- Assisted with the organization and running of the Poultry Building at the WV State Fair (8/128/22/10)

- Preston County Kids Day Fair Poultry Presentation (10/10) 
- Assist with Veterinary Technician classes to help the students learn about poultry and teach them to efficiently draw blood from poultry

National Meeting Paper Presentations (M.S.)

- 2009 Poultry Science Association (Raleigh, NC) (Graduate Student)

"Examining the relationship between pellet quality, broiler performance and bird sex."

- 2010 Joint Animal Science Meeting (Denver, CO) (Graduate Student)

"Strategies to prevent preharvest Salmonella in organic broilers."

Professional Development

-Mid-Atlantic Nutrition Conference, Baltimore, MD (2010)

-International Poultry Expo, Atlanta, GA (2010)

-Poultry Science Association Annual Meeting (2010)

\section{UNDERGRADUATE}

\section{Student Undergraduate Research Experience}

Summer 2007/08

- Organic Broiler Research (Summer '07)

- Preliminary Modeling Pellet Quality Study (Summer '07)

- Modeling Pellet Quality, Broiler Performance and Bird Sex (Summer '08)

\section{Undergraduate Research Assistant}

Fall 2007-2009

- Head Coordinator of Three Separate Modeling Pellet Quality Studies

(Manufacturing Feed and Managing 1,200-1,600 Birds per Study)

- Contract Pelleting Studies with Mosaic Inc. and Phytex

- Contract Study with Alltech

- Assisted with Study Pertaining to Diet Formulation and Pellet Quality Effects on Broilers

\section{Undergraduate Teaching Assistant}

- Teaching Assistant for Poultry Judging Course

- Regular Guest Lecturer on Poultry Judging for Intro to Animal Science Class

- Guest Lecturer at Greene County (PA) Organic Poultry Field Day (4/9/08)

\section{National Meeting Paper Presentations}

-2008 Poultry Science Association (Niagara Falls, Canada) (Undergraduate Student)

"The effects of fiber, moisture and protein on pellet manufacture variables."

\section{Professional Development}

- Organic Alliance Meeting, Baltimore, MD (2008)

-International Poultry Expo, Atlanta, GA (2008-2009)

-Poultry Science Association Annual Meeting (2007-2009) 